\title{
Analysis and development of augmented reality applications for the dissemination of cultural heritage
}

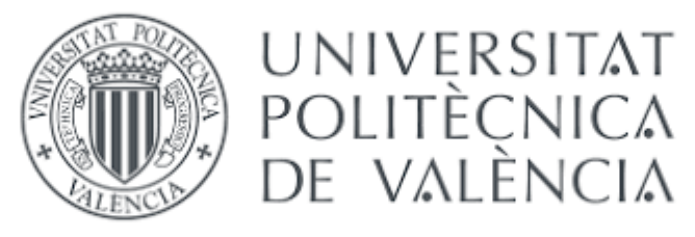

Silvia Blanco Pons

Advisor: José Luis Lerma García

Photogrammetry and Laser Scanner Research Group (GiFLE)

Department of Cartographic Engineering Geodesy and Photogrammetry

Universitat Politècnica de València

Valencia, September 2021 


\section{Agradecimientos}

Me gustaría expresar mi agradecimiento a todos aquellos que de una manera u otra han formado parte de este trabajo.

En primer lugar, quiero dar las gracias al Prof. José Luis Lerma, director de la presente tesis, quien me introdujo en el mundo de la investigación y me ha guiado en el desarrollo de la misma. Es un gran profesional con una enorme experiencia como investigador que me ha ayudado en el planteamiento de cada una de las publicaciones.

También quisiera agradecer el apoyo de mis compañeros del grupo de investigación GiFLE en la Universitat Politècnica de València, por los buenos ratos que pasé con ellos. Quisiera hacer una mención especial a mi compañera y amiga Berta Carrión, quien ha estado implicada en todo el desarrollo de mi tesis, aportando valiosas ideas y por sus contribuciones durante todo el proceso. Por su gran profesionalidad y por ser un gran apoyo, muchas gracias amiga.

Al Prof. Valentín Villaverde, catedrático de la Universitat de València en el Departamento de Prehistoria, Arqueología e Historia Antigua, por su contribución sobre el Arte Levantino.

De mi estancia en Canadá en el centro de investigación CIMS (Carleton Immersive Media Studio) agradecer en primer lugar a Stephen Fai, director del centro, por darme la oportunidad de formar parte de su equipo durante cuatro meses. A Joshua Chartrand y a Michelle Duong, por su contribución en la parte de la tesis allí desarrollada, ambos son muy trabajadores e hicieron un gran esfuerzo por presentar la publicación. En CIMS desarrollan proyectos muy interesantes relacionados con la divulgación del patrimonio de Canadá y fue un placer trabajar con ellos.

Por último, agradecer todo el apoyo de mi familia durante toda la etapa universitaria y durante estos últimos años de investigación; para ellos, mi educación siempre fue lo primero.

Muchas gracias a todos. 


\section{Abstract}

Rock art is part of our cultural heritage, it is one of the first artistic expressions of human beings and provides knowledge about past times. Rock paintings are found in shelters that are not always easy to access and are exposed to climatic agents that degrade this art over the years. Due to their great cultural interest and their fragility, it is important to find documentation and dissemination techniques that do not damage either the paintings or their environment. It is essential to maintain and conserve these artistic manifestations, but at the same time, they must be brought to the public in a safe way. Nowadays, most archaeological sites provide guides who explain in situ the rock paintings and their interpretation, although it is often difficult to identify the figures represented due to their deteriorated state. Nowadays there are tools that can facilitate access to rock art and improve the interpretation of the paintings, simply by using mobile devices that practically everyone carries in their pocket.

Over the last decade, the evolution of the smartphone has been astonishing. In recent years, mobile phones have gone from being a simple communication tool to an intelligent device that integrates several high-resolution cameras, GPS, a wide variety of sensors such as the accelerometer, gyroscope or infrared as well as internet connection among many other things. This has been a revolution in application development and has made augmented reality (AR) a reality. The first AR device was created in 1957 with the Sensorama machine, but it was not until half a century later that technology-enabled this visualisation technique to be launched.

AR consists of superimposing virtual elements on the real environment, so that the user perceives these elements as if they were part of the reality they are looking at. AR applications on smartphones allow virtual content to be visualised through the device's camera. AR is a very powerful tool for dissemination as it allows any type of information to be added to reality, from a simple informative text to an interactive 3D model. It can be used as a guide in a museum, it can show the recreation of a destroyed monument, or, as in the case study presented here, it can help in the interpretation of cave paintings.

This thesis is based on the idea that AR can greatly enhance the interpretation of rock art without affecting or damaging the paintings. It can be used to attract a wider audience, to introduce the history of the rock art paintings and at the same time provide the visitor with a much more enriching experience.

Throughout the thesis, the technique of AR visualisation using mobile devices has been studied in-depth. The different programming libraries have been analysed by means of case studies in real environments as well as the factors that can affect the paintings recognition. An AR application applied to a real case of rock art paintings has been developed and subsequently evaluated by a group of people. Finally, the effect of sunlight and its changes throughout the day on image recognition in outdoor environments has been studied.

This work provides a starting point for the AR applications development applied to the dissemination of cultural heritage, especially focused on rock art, an environment that suffers from additional difficulties due to its location, the difficulty of characteristic points recognition and changes in sunlight, problems that have been tried to solve throughout the study. 
The main outcomes have been very favourable, using freely available programming libraries, and it has been possible to develop a set of AR applications in different places. The evaluations have been very positive, with users who have tested the applications confirming that the interpretation of the paintings is easier for them and they can better understand the purpose of the paintings.

The major drawback is the lack of knowledge about this technique and the loss of realism in some cases due to occlusion, i.e. the virtual objects are not positioned behind the real objects. The good news is that this technology is evolving very fast and during the development of the thesis there have been great advances, among them, the development of new programming libraries developed by Google and Apple, which provide the necessary tools to create very powerful and immersive applications, where the user will feel part of the virtual environments created. 


\section{Resumen}

El arte rupestre forma parte de nuestro patrimonio cultural, es una de las primeras expresiones artísticas del ser humano y aporta conocimiento sobre épocas pasadas. Las pinturas rupestres se hallan en abrigos no siempre de fácil acceso expuesto a agentes climáticos que a lo largo de los años degradan este arte. Debido a su gran interés cultural y a su fragilidad, es importante encontrar técnicas de documentación y difusión que no dañen ni la pintura ni su

entorno. Es fundamental mantener y conservar estas manifestaciones artísticas, pero al mismo tiempo se deben acercar al público de una forma segura. Actualmente, la mayoría de yacimientos arqueológicos proporcionan guías que explican in situ las pinturas rupestres y su interpretación, aunque suele ser difícil identificar las figuras representadas debido a su deteriorado estado. Hoy es día existen herramientas que pueden facilitar el acceso al arte rupestre y mejorar la interpretación de las pinturas, simplemente utilizando dispositivos móviles que prácticamente todo el mundo lleva en su bolsillo.

En la última década, la evolución de los dispositivos móviles ha sido asombrosa. En los últimos años, los móviles han pasado de ser una simple herramienta de comunicación a un dispositivo inteligente que integra varias cámaras de alta resolución, GPS, una gran variedad de sensores como el acelerómetro, giróscopo o infrarrojo además de conexión a internet entre otras muchas cosas. Esto ha supuesto una revolución en el desarrollo de aplicaciones y ha logrado que la realidad aumentada (RA) se vuelva una realidad. El primer dispositivo de RA se creó en 1957 con la máquina Sensorama pero no ha sido hasta medio siglo después cuando la tecnología ha permitido el despegue de esta técnica de visualización.

La RA consiste en la superposición de elementos virtuales sobre el entorno real, de manera que el usuario percibe estos elementos como si formaran parte de la realidad que está visualizando. Las aplicaciones de RA en dispositivos móviles permiten visualizar el contenido virtual a través de la cámara del dispositivo. La RA es una herramienta de divulgación muy potente ya que permite añadir a la realidad cualquier tipo de información, desde un simple texto informativo a un modelo 3D interactivo. Tiene infinitas utilidades, puede servir de guía en un museo, puede mostrar la recreación de un monumento destruido, o como en el caso de estudio aquí presentado, ayudar a la interpretación de pinturas rupestres.

Esta tesis parte de la idea de que la RA puede mejorar mucho la interpretación del arte rupestre sin alterar ni dañar las pinturas. Puede servir para atraer a un público mayor, dar a conocer la historia de las pinturas rupestres y que al mismo tiempo el visitante tenga una experiencia mucho más enriquecedora.

A lo largo de la tesis se ha estudiado en profundidad la técnica de visualización de RA mediante dispositivos móviles. Se han analizado las diferentes librerías de programación mediante casos de estudio en entornos reales y examinado los factores que pueden afectar al reconocimiento de las pinturas. Se ha desarrollado una aplicación de RA aplicada a un caso real de pinturas rupestres y posteriormente ha sido evaluada por un grupo de personas. Finalmente, se ha estudiado el efecto de la luz solar y sus cambios a lo largo del día sobre el reconocimiento de imágenes en entornos al aire libre.

Este trabajo proporciona un punto de partida para el desarrollo de aplicaciones de RA aplicadas a la difusión del patrimonio cultural, especialmente centrado en el arte rupestre, un 
entorno que sufre de unas dificultades añadidas debido a su localización, dificultad de reconocimiento de puntos característicos en las pinturas y los cambios en la luz solar, problemas que se han tratado de resolver a lo largo del estudio.

Las principales conclusiones han sido muy favorables, partiendo de librerías de programación disponibles y gratuitas. Se han podido desarrollar un conjunto de aplicaciones de RA en diferentes lugares. Las valoraciones han sido muy positivas, los usuarios que han probado las aplicaciones afirman que la interpretación de las pinturas les resulta más fácil y consiguen entender mejor el propósito de las mismas. El principal inconveniente encontrado es la falta de conocimiento sobre esta técnica y la pérdida de realismo en algunos casos debido a la oclusión, es decir, que los objetos virtuales no se posicionen por detrás de los objetos reales. La buena noticia es que esta tecnología evoluciona muy rápido y durante el desarrollo de la tesis ha habido avances muy grandes, entre ellos, el desarrollo de nuevas librerías de programación desarrolladas por Google y Apple, que proporcionan las herramientas necesarias para crear aplicaciones muy potentes e immersivas, donde el usuario se sentirá parte de los entornos creados. 


\section{Resum}

L'art rupestre forma part del nostre patrimoni cultural, és una de les primeres expressions artístiques de l'ésser humà i aporta coneixement sobre èpoques passades. Les pintures rupestres es troben en abrics no sempre de fàcil accés exposat a agents climàtics que al llarg dels anys degraden aquest art. A causa del seu gran interés cultural i a la seua fragilitat, és important trobar tècniques de documentació i difusió que no danyen ni la pintura ni el seu entorn. És fonamental mantindre i conservar aquestes manifestacions artístiques, però al mateix temps s'han d'acostar al públic d'una forma segura. Actualment, la majoria de jaciments arqueològics proporcionen guies que expliquen in situ les pintures rupestres $\mathrm{i}$ la seua interpretació, encara que sol ser difícil identificar les figures representades a causa del seu deteriorat estat. Hui en dia existeixen eines que poden facilitar l'accés a l'art rupestre i millorar la interpretació de les pintures, simplement utilitzant dispositius mòbils que pràcticament tothom porta en la seua butxaca.

En l'última dècada, l'evolució dels dispositius mòbils ha sigut sorprenent. En els últims anys els mòbils han passat de ser una simple eina de comunicació a un dispositiu intel-ligent que integra diverses càmeres d'alta resolució, GPS, una gran varietat de sensors com l'acceleròmetre, giroscopi o infraroig a més de connexió a internet entre moltes altres coses. Això ha suposat una revolució en el desenvolupament d'aplicacions i ha aconseguit que la realitat augmentada (RA) es torne una realitat. El primer dispositiu de RA es va crear en 1957 amb la màquina Sensorama però no ha sigut fins a mig segle després quan la tecnologia ha permés l'enlairament d'aquesta tècnica de visualització.

La RA consisteix en la superposició d'elements virtuals sobre l'entorn real, de manera que I'usuari percep aquests elements com si formaren part de la realitat que està visualitzant. Les aplicacions de RA en dispositius mòbils permeten visualitzar el contingut virtual a través de la cambra del dispositiu. La RA és una eina de divulgació molt potent ja que permet afegir a la realitat qualsevol tipus d'informació, des d'un simple text informatiu a un model 3D interactiu. Té infinites utilitats, pot servir de guia en un museu, pot mostrar la recreació d'un monument destruït, o com en el cas d'estudi ací presentat, ajudar a la interpretació de pintures rupestres.

Aquesta tesi parteix de la idea que la RA pot millorar molt la interpretació de l'art rupestre sense alterar ni danyar les pintures. Pot servir per a atraure a un públic major, donar a conéixer la història de les pintures rupestres i que al mateix temps el visitant tinga una experiència molt més enriquidora.

Al llarg de la tesi s'ha estudiat en profunditat la tècnica de visualització de RA mitjançant dispositius mòbils. S'han analitzat les diferents llibreries de programació mitjançant casos d'estudi en entorns reals $i$ analitzat els factors que poden afectar el reconeixement de les pintures. S'ha desenvolupat una aplicació de RA aplicada a un cas real de pintures rupestres i posteriorment ha sigut avaluada per un grup de persones. Finalment, s'ha estudiat l'efecte de la llum solar i els seus canvis al llarg del dia sobre el reconeixement d'imatges en entorns a l'aire lliure.

Aquest treball proporciona un punt de partida per al desenvolupament d'aplicacions de RA aplicades a la difusió del patrimoni cultural, especialment centrat en l'art rupestre, un entorn que pateix d'unes dificultats afegides a causa de la seua localització, dificultat de reconeixement 
de punts característics en les pintures i els canvis en la llum solar, problemes que s'han tractat de resoldre al llarg de l'estudi.

Les principals conclusions han sigut molt favorables, partint de llibreries de programació disponibles i gratuïtes. S'han pogut desenvolupar un conjunt d'aplicacions de RA en diferents Ilocs. Les valoracions han sigut molt positives, els usuaris que han provat les aplicacions afirmen que la interpretació de les pintures els resulta més fàcil i aconsegueixen entendre millor el propòsit d'aquestes. El principal inconvenient trobat és la falta de coneixement sobre aquesta tècnica i la perduda de realisme en alguns casos a causa de l'oclusió, és a dir, que els objectes virtuals no es posicionen per darrere dels objectes reals. La bona notícia és que aquesta tecnologia evoluciona molt ràpid i durant el desenvolupament de la tesi hi ha hagut avanços molt grans, entre ells, el desenvolupament de noves llibreries de programació per Google i Apple, que proporcionen les eines necessàries per a crear aplicacions molt potents i immersives, on l'usuari se sentirà part dels entorns creats. 


\section{Contents}

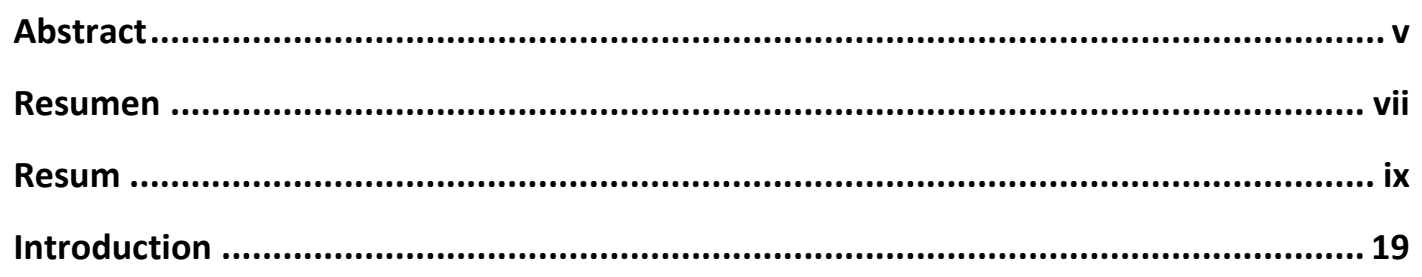

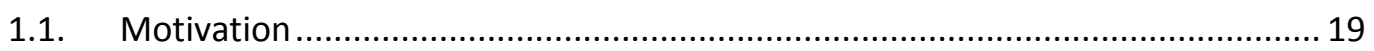

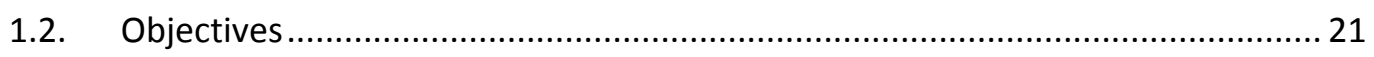

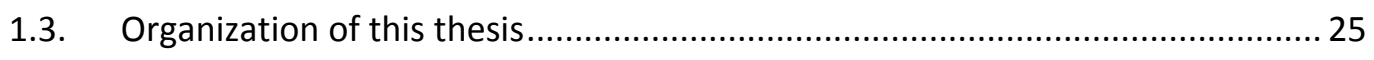

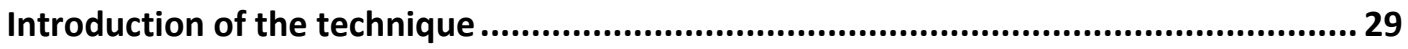

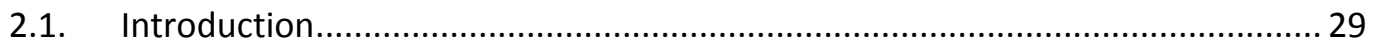

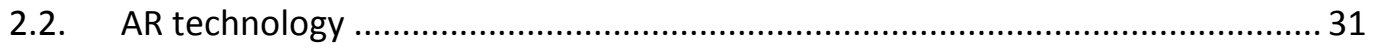

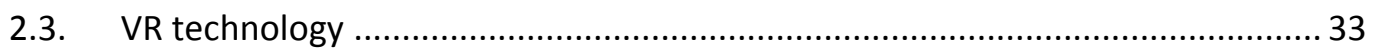

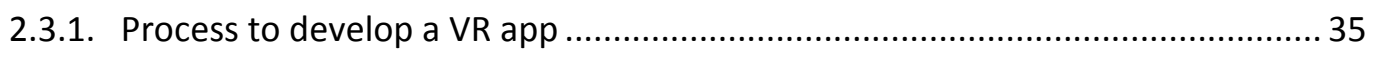

2.3.2. Modelling and texturing the virtual elements .................................................. 35

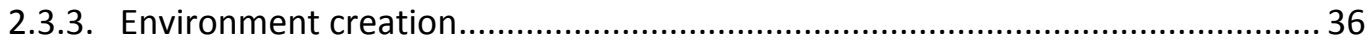

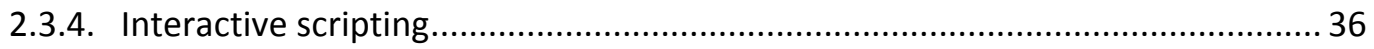

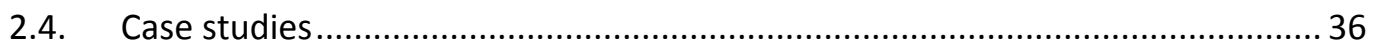

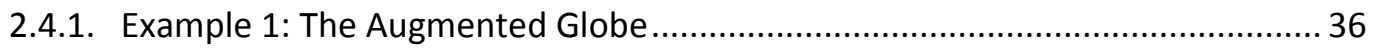

2.4.2. Example 2: Interactive visit to a rock art shelter................................................ 37

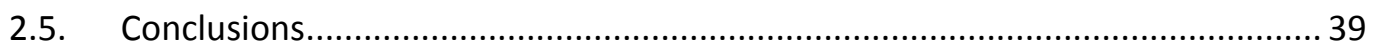

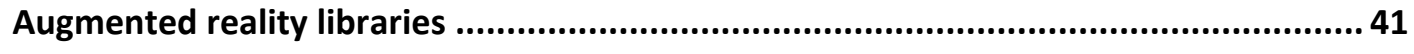

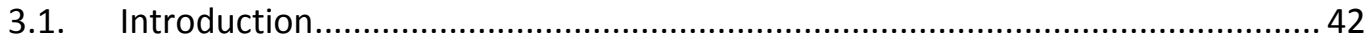

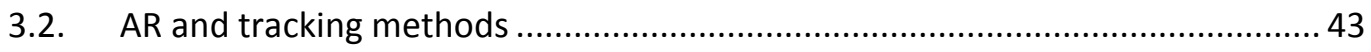

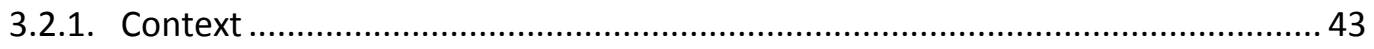

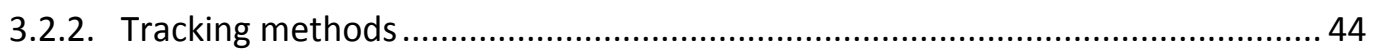

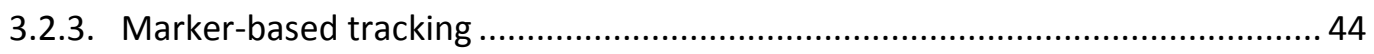

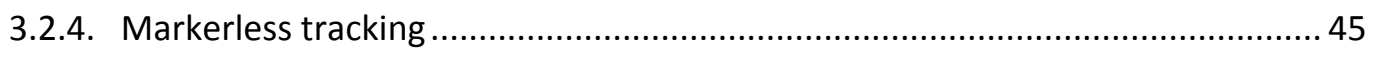

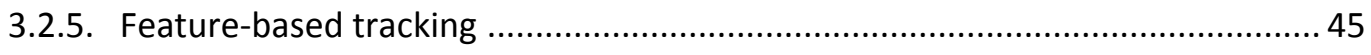

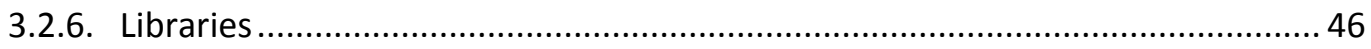

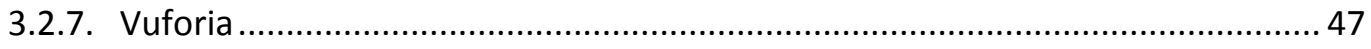

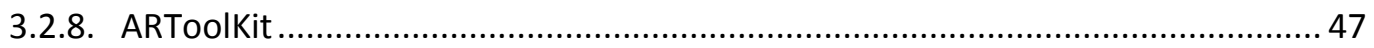




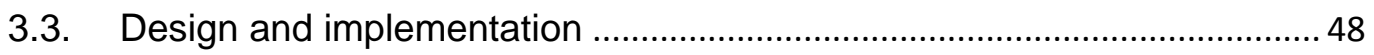

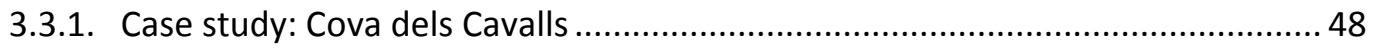

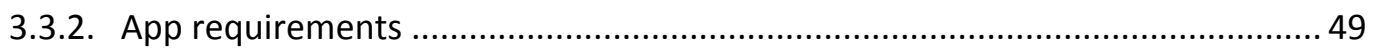

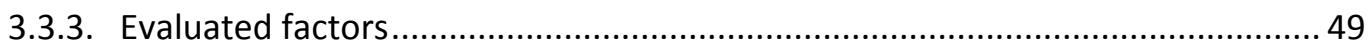

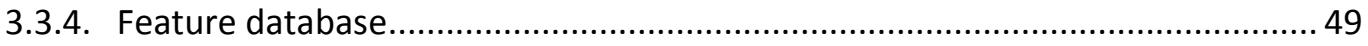

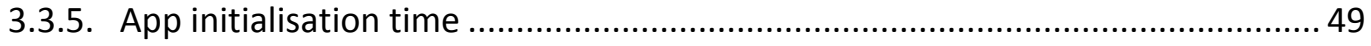

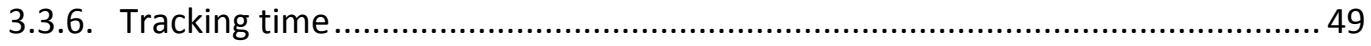

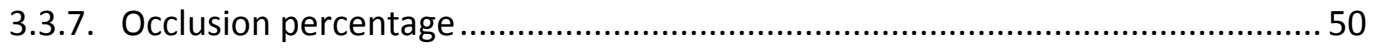

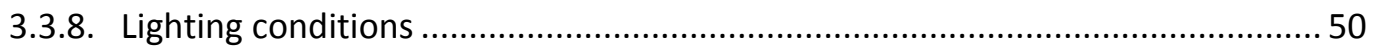

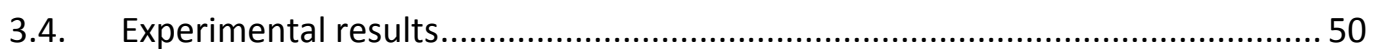

3.4.1. Indoor AR app dealing with printed colour image of a rock art scene ............... 50

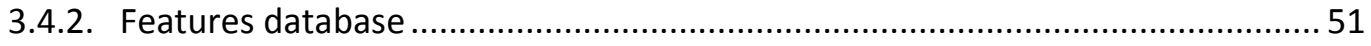

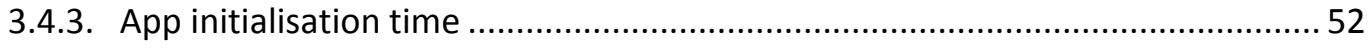

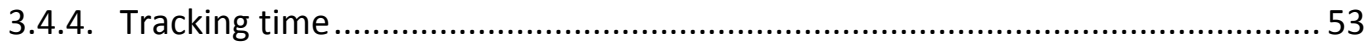

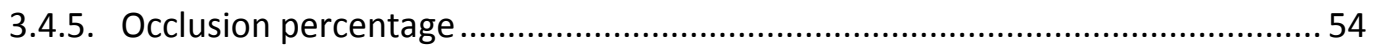

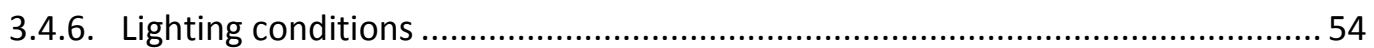

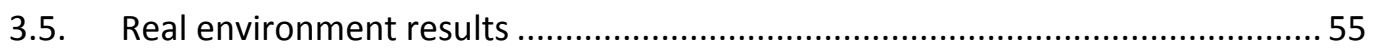

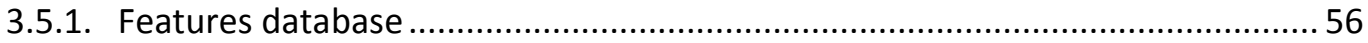

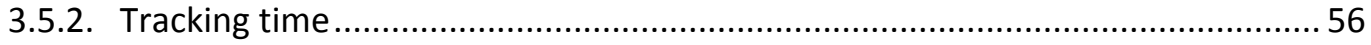

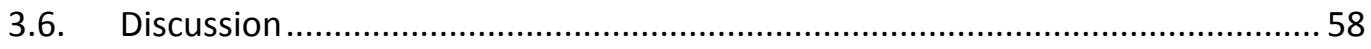

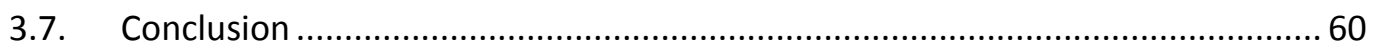

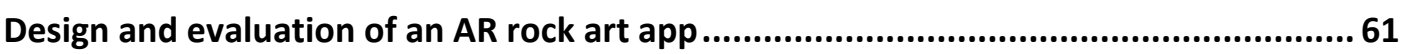

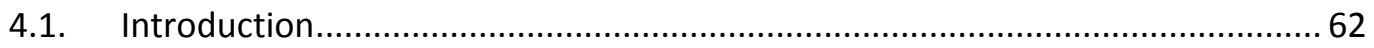

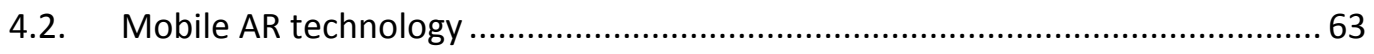

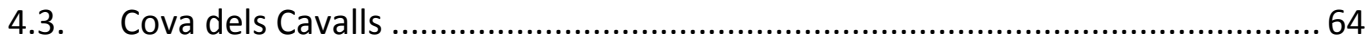

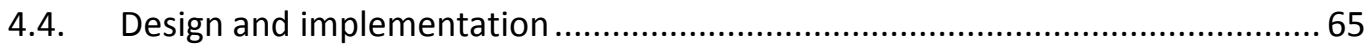

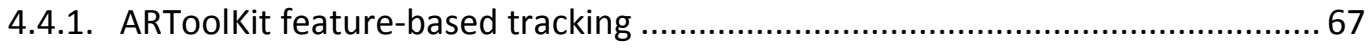

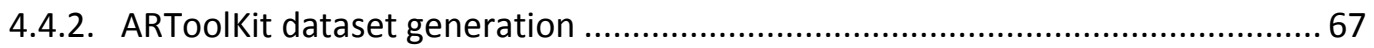

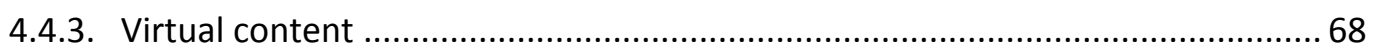

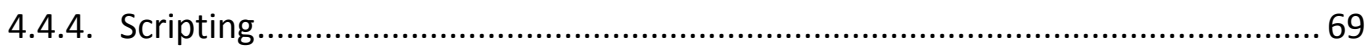

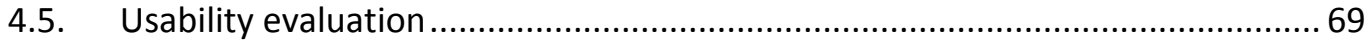

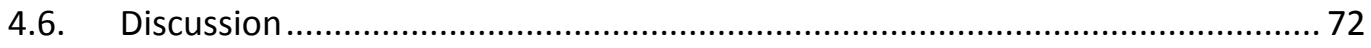

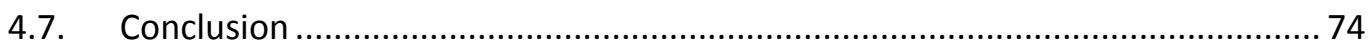




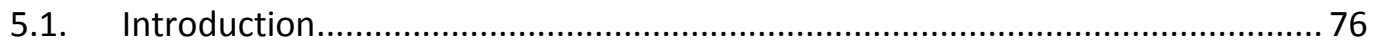

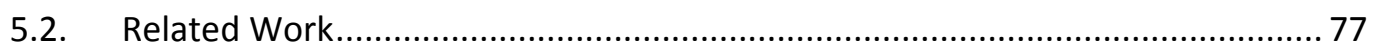

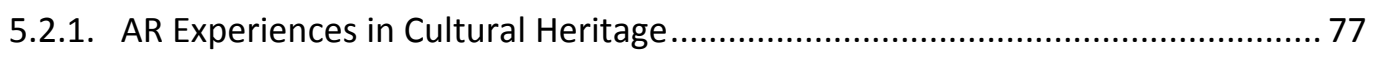

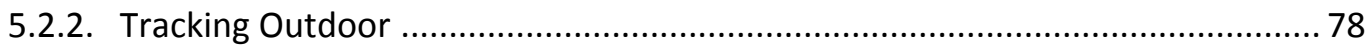

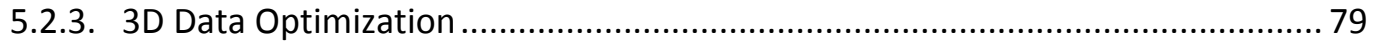

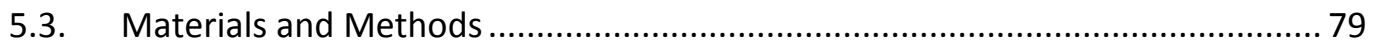

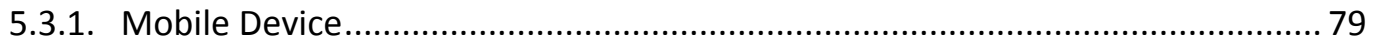

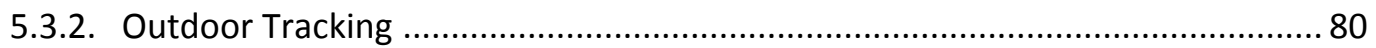

5.3.3. Multitarget Outdoor Testing on Parliament Hill .................................................. 81

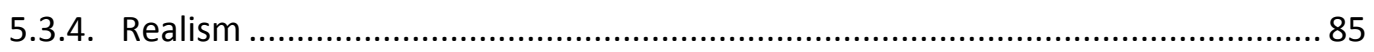

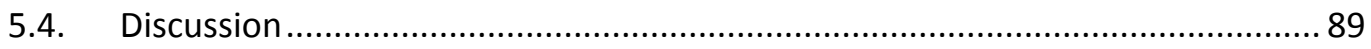

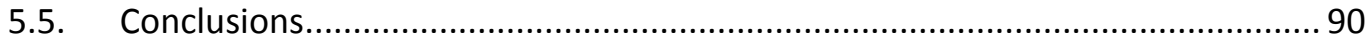

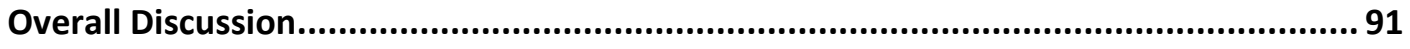

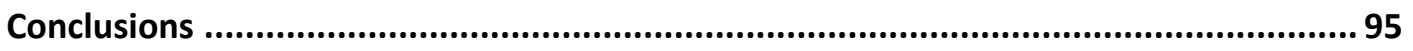

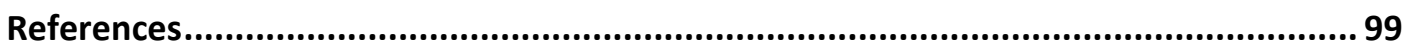




\section{List of Figures}

Figure 1.1 Number of smartphones users worldwide from 2015 to 2021 (in billions). Source: https://www.statista.com/statistics/330695/number-of-smartphone-users-worldwide/.

Figure 1.2 Augmented reality (AR) and virtual reality (VR) market size in Europe in 2018 and 2026. Source: https://www.statista.com/statistics/1121370/european-augmented-virtualreality-market-size/.

Figure 1.3 Boost to gross domestic product (GDP) from VR and AR worldwide from 2019 to 2030. Source: https://www.statista.com/statistics/1121740/boost-to-gdp-from-vr-and-arworldwide/.

Figure 2.1. Frame marker provided by Vuforia SDK.

Figure 2.2. Smartphone screenshots: a) screenshot before the augmented globe; b) screenshot with the augmented globe. 37

Figure 2.3. The interior of a shelter: a) 3D point cloud; b) photorealistic 3D model. 38

Figure 2.4. Smartphone screenshot. 39

Figure 3.1. Visual markers already implemented in Vuforia (a) and ARToolKit (b) libraries. ..... 44

Figure 3.2. Overview of the natural feature tracking system.

Figure 3.3. Cova dels Cavalls: a) Scene 1: Hunting scene. b) Scene 2: Overview of motifs found on Shelter 2.

Figure 3.4. a) Input image was taken with a smartphone in Cova dels Cavalls. b) Enhanced image used to track the corresponding hunting scene.

Figure 3.5. Indoor testing setup, using a smartphone in front of the printed image.

Figure 3.6. Features detected in the database by Vuforia.

Figure 3.7. Time taken to run the AR app on the three smartphones.

Figure 3.8. Samsung A3, Samsung Galaxy and Aquaris E4 virtual information loading times at different distances; no differences were found among smartphones with Vuforia.

Figure 3.9. Samsung Galaxy A3 loading times with different occlusion percentages: left $25 \%$, centre $50 \%$ and right $75 \%$.

Figure 3.10 Galaxy A3 loading times with different exposure times.

Figure 3.11 Typical scenario in situ at the Cova dels Cavalls: camera in front of one of the shelters.

Figure 3.12 Example of features detected with Vuforia in different scenes of the Cova dels Cavalls: a) Image target scored with 0 stars; b) Image target scored with 4 stars; c) Image target scored with 0 stars.

Figure 3.13 Camera-scene distances on site used to run the AR app. 57

Figure 3.14 Tracking times obtained with the three smartphones at different distances; no differences were found among smartphones with Vuforia. 
Figure 4.1 Cova dels Cavalls: a) Geographic location in Tirig (Castellón, Valencian Community, Spain). b) View of the environment in a cliff on the east bank of the Valltorta Ravine. 64

Figure 4.2 a) Hunting scene according to [75]. b) Photographic scene at present...................... 65

Figure 4.3 AR app interface and screenshots taken on site...................................................66

Figure 4.4 a) Example of a training image taken on-site; b) Features extracted from the training

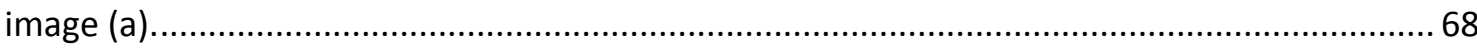

Figure 4.5 Idealised hunting scene according to Obermaier and Wernert (1919) ......................68

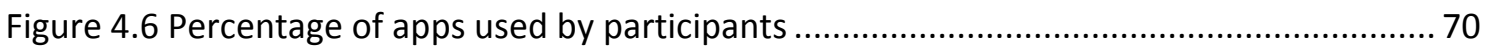

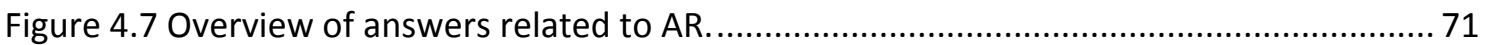

Figure 4.8 Answers related to questions about the cultural heritage site. ................................ 72

Figure 5.1 Parliament Hill (Ottawa): a) History Centre Block AR experience located at the Centre Block, b) grotesque AR experience located at the West Block, c) OWL AR experience located at the East Block, and d) geographic location of the buildings and AR experiences location

Figure 5.2 West Block Shadow Study at different times of day.

Figure 5.3 Centre Block Shadow Study at different times of the day

Figure 5.4 East Block Shadow Study at different times of the day.

Figure 5.5 Image targets of West Block taken approximately $14 \mathrm{~m}$ away: a) Sunny 8 AM, b) Sunny 1 PM, and c) Sunny 6 PM.

Figure 5.6 Image targets of Centre Block taken approximately $100 \mathrm{~m}$ away: a) Sunny 8 AM, b) Sunny 1 PM, c) Cloudy 6 PM, and d) Cloudy 9 PM.

Figure 5.7 Image target of East Block taken approximately 10 m away

Figure 5.8 Centre Block: a) Tourist photography (2018) and b) simulated photography merging historic and present (2018) content as a deliverable of the History Centre Block AR app. This app was developed with the Vuforia AR Library.

Figure 5.9 Screenshot taken with the Grotesque AR experience in which the hotspot appears. 


\section{List of Tables}

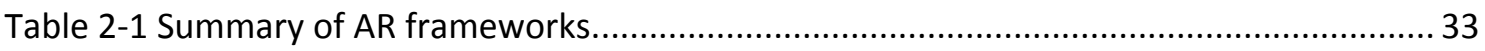

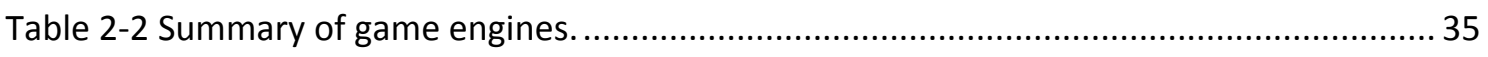

Table 3-1 Main results from the ARToolkit and Vuforia comparison.jError! Marcador no definido.

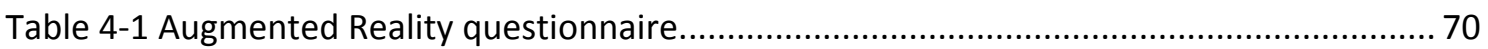

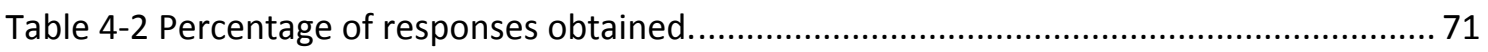

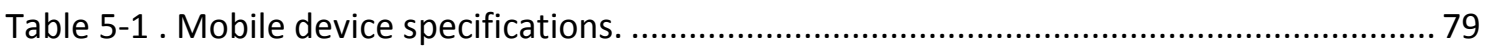

Table 5-2 Summary of the tests carried out at different times of the day on sunny and cloudy

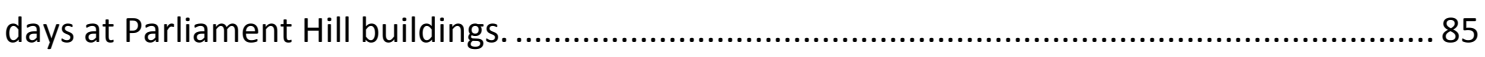




\section{Glossary}

AR Augmented Reality

MAR Mobile Augmented Reality

VR Virtual Reality

ICOMOS International Council on Monuments and Sites

HMD Head-Mounted Display

IT Information technology

APP Application

NFT Natural Feature Tracking

POI points of interest

SDK Software Development Kit

GUI Graphic User Interface

Al Artificial Intelligence

SfM Structure From Motion

GNSS Global Navigation Satellite Systems

TLS Terrestrial Laser Scanning

UX User Experience

MR Mixed Reality

TOF Time of Flight 


\section{1 \\ Introduction}

\subsection{MOTIVATION}

Augmented Reality (AR) is a visualization technique that involves the superimposition of digital information onto the real world. The digital information, such as 3D models, images, text, audio or videos, is displayed through the smartphone camera and placed in a specific position [1]. The user can simultaneously perceive the real world and virtual elements superimposed in real-time.

AR is not a new technology, in fact, its first appearance dates back to 1950 and it was not until 2000 when it began its evolution with the first AR game. A few years later, with the evolution of mobile devices and the integration of cameras, the AR truly began to expand [2] and year after year numerous new applications are researched.

The first prototypes were very uncomfortable to use, the hardware was very complex and heavy and difficult to access for most users. This changed dramatically with the development of today's smartphones, which integrate all the necessary hardware into a small portable device, i.e. a variety of sensors that receive orientation, acceleration and location, Internet connection for information sharing or cloud computing, sufficient memory and storage space and a built-in camera. In addition, these devices improve every year by being more and more powerful and therefore, making the augmented reality more powerful too. Smartphones have become the perfect tool for the development of AR applications and that is why the evolution of these devices has encouraged the increase of mobile augmented reality (MAR) applications.

There are numerous fields of application where AR is developing overwhelmingly. A wide variety of literature shows some examples of these applications, such as [3,4]. Some of the most relevant fields of application are tourism, advertising, entertainment, education, architecture, archaeology and medicine. 
Medicine is one of the fields where AR has more projection and could be focused on different approaches. One is medical training, the use of AR to improve the way of learning practical medicine $[5,6]$. Other is surgery, where AR could supply the relevant guidance to the surgeon and in the last years, related investigations have skyrocketed [7].

Tourism, architecture and archaeology are fields where AR can enhance the user experience attracting more tourist to visit a site, showing interesting information grouped in different layers. In short, enriching the visit to a city, monument or archaeological site, with wellstructured data shown in a comfortable and intuitive way. AR can provide customized information based on a tourist's specific location [1,8], enhance historical learning by motivating students and stimulating their interest [9] as well as provide interactive museum experiences [10].

This technology can be very useful to show hidden or lost information as it is the case of destroyed places or objects, where the AR can show a reconstruction of them $[11,12]$ or rock art where the paintings are quite difficult to visualize and interpret.

Rock art of the Iberian Mediterranean Basin, also known as Levantine art, was declared World Heritage Site by UNESCO in 1998. Is the largest group of rock art sites in Europe as well as a unique cultural demonstration of a prehistoric society, whose representations are dated between 10,000 and 3,500 BC [13]. Levantine art is mainly located in open-air rock shelters and has huge historical, cultural and artistic value [14]. The major problem is its great fragility and therefore it is very important both to preserve it and to spread it in a non-intrusive way that encourages its non-deterioration.

This thesis arises from a problem; the fragility of rock art and the need for new, nonintrusive dissemination methods, and a possible solution: AR. It is a technology that has great future prospects, since the emergence of smartphones, AR has grown exponentially, the recognition technology improves every year as well as the power of mobile devices so everything suggests that it will continue to grow and evolve. In addition, it has been shown that it is a powerful tool for dissemination as it can be used to display virtual content anywhere and on any object in the reality. It works as a tool to improve and show in an easy and intuitive way virtual elements over the reality, creating an improved reality, with informative elements added to the existing ones.

The present study aims to deepen in this visualization technology applied in the cultural heritage field, and focuses on outdoor environments, where changes in lighting play an important role. This has been studied in two scenarios, the Levantine rock art in the Iberian Peninsula and the Canada Parliament Buildings, one the most important cultural sites of Ottawa. The Levantine art representations are presented in rocky shelters, with paintings exposed to sunlight, in whose compositions the human figure is integrated into everyday scenes such as hunting and gathering, usually small figures in mainly reddish colours similar to the base rock, with the occasional presence of black and white [15]. In many cases, these representations are quite damaged even partially destroyed by the passage of time. In short, these artistic manifestations are very difficult to visualize and interpret their meaning by the visitors who also have to keep a distance to avoid damaging the paintings.

A tool such as AR applied to these sites can help enormously in the visualization and interpretation by users who access these places with the intention of knowing the history of the 
paintings. AR can be very useful to show, through the user's smartphone screen, the depicted elements in the precise position in which they are. In addition, since any digital element can be added, these paintings can be complemented with texts, animations or recreations that can help the user to understand much better the history of the paintings, creating a book of contents over the rock painting itself.

With this idea arises the need to study in-depth AR applied to a real and changing environment such as rock art, where sunlight and other meteorological factors have a huge influence. There are many studies on AR and several programming libraries have been developed in order to build mobile AR applications much faster. This encourages the creation of new applications. But despite the advances of this technology, there is not much literature of application in the rock art field and therefore, detailed studies of how it could work in these environments and their particular problems. Moreover, it is not always easy to develop applications based on this technology. It is necessary to study each case since there are different methods of positioning and tracking and it will be necessary to know which is the most suitable.

Therefore, it will be necessary to study which library of the existing ones is the most appropriate and which is the optimal methodology to develop an application of these characteristics. In the following chapters, each of the problems will be analysed and a solution will be proposed.

\subsection{OBJECTIVES}

Smartphone users are increasing every year. In the last 5 years, there has been an increase of 1,000 million users. Nowadays the smartphone is one of the most used devices in the world (Figure 1.1) and is increasingly used as a means of internet access in front of computers and tablets (source https://www.statista.com/chart/1651/mobile-internet-subscriptions/). 


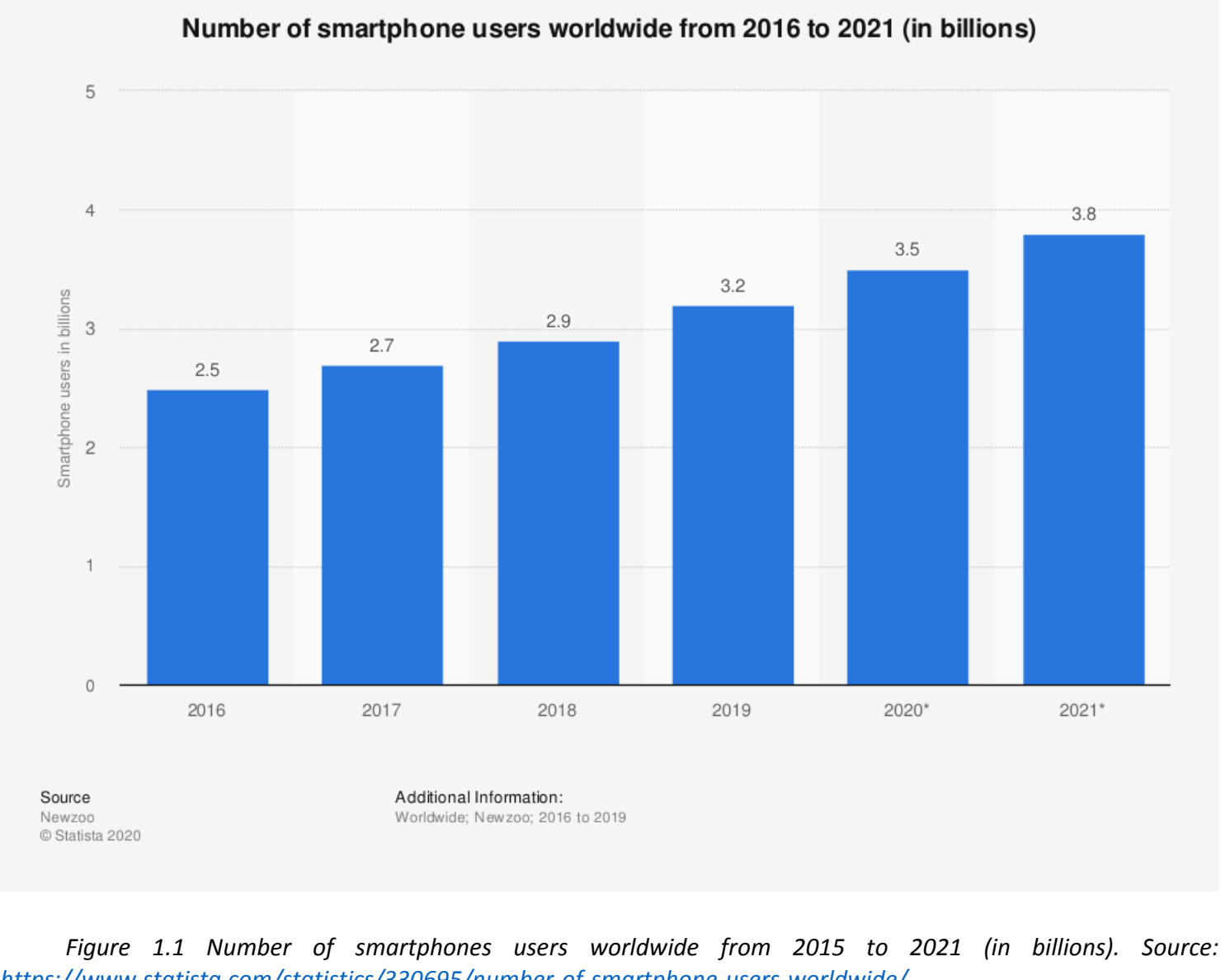
https://www.statista.com/statistics/330695/number-of-smartphone-users-worldwide/.

By 2026, the AR and virtual reality (VR) market in Europe is expected to reach $\$ 50.55$ billion, an increase of $\$ 46$ billion over 2018 (Figure 1.2). These technologies will boost GDP in the coming years to over $\$ 1.5$ trillion by 2030 (Figure 1.3). These forecasts are very encouraging and place $A R$ as one of the technologies of the future. 


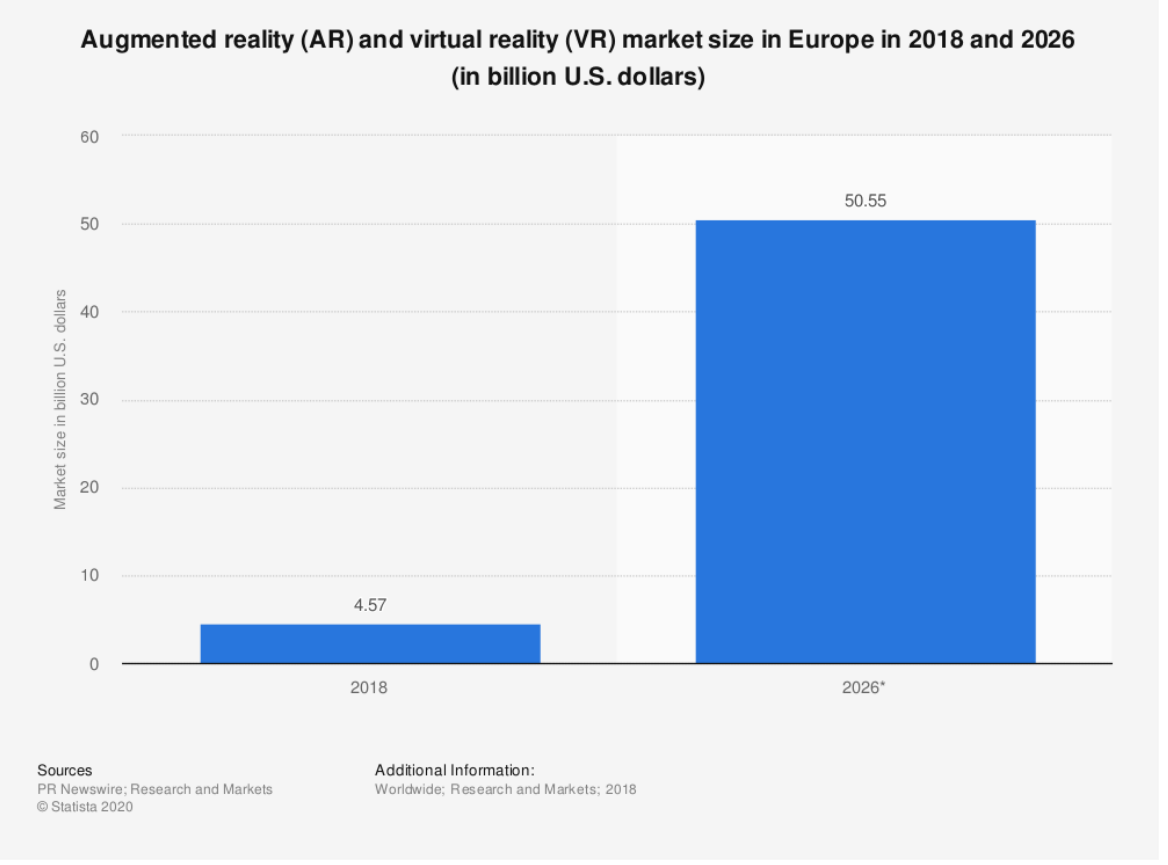

Figure 1.2 AR and VR market size in Europe in 2018 and 2026. Source:

https://www.statista.com/statistics/1121370/european-augmented-virtual-reality-market-size/.

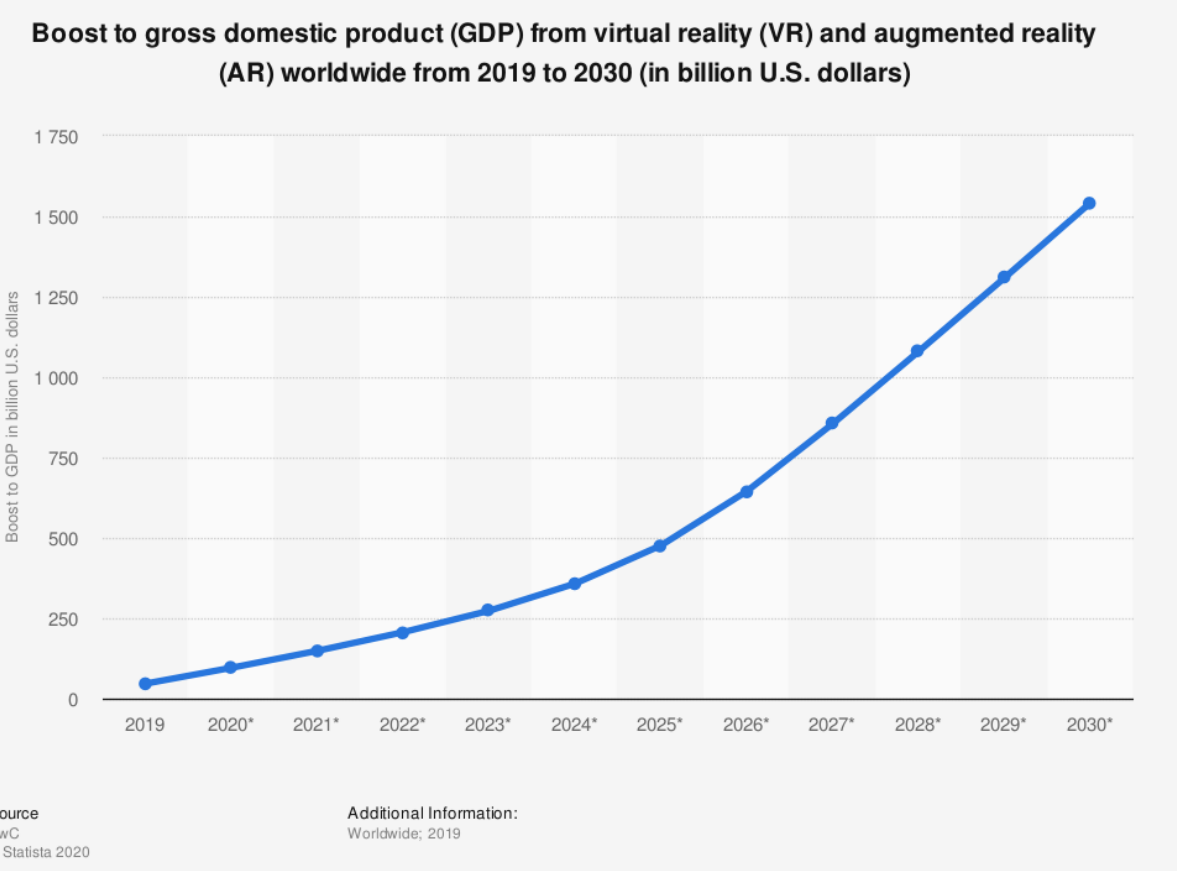

Figure 1.3 Boost to gross domestic product (GDP) from VR and AR worldwide from 2019 to 2030. Source: https://www.statista.com/statistics/1121740/boost-to-gdp-from-vr-and-ar-worldwide/.

The aim of this thesis is to find new means of disseminating cultural heritage. Since smartphones are becoming an indispensable tool for human beings, new ways of dissemination have to be 
oriented to these devices. Moreover, the previous predictions show an exponential growth of the AR.

Based on this hypothesis and the data presented above, this research seeks to expand the methods of disseminating cultural heritage, focusing on the latest visualization techniques, based on AR through the use of smartphones. The thesis focuses mainly on rock art since, $a$ priori, AR seem to be the ideal way to disseminate and present this art. The rock art paintings are located in shelters exposed to external agents and the passage of time causes its degradation. The visualization and understanding of these paintings are usually very complicated due to their deterioration. AR can provide a tool to enhance, reconstruct and real location the paintings helping their better comprehension.

To carry out this research, first of all, it is necessary to study in-depth the visualization technologies and their applicability in the rock art field (Chapter 2 ), in order to know the state of the art of these trendy technologies.

Focusing research on AR and thanks to advances in tracking methods and smartphone sensors, the next step is to study existing programming libraries to establish the optimal methodology for the development of mobile applications in rock art (Chapter 3). Once the application requirements are defined and the methodology established, it is fundamental to design and develop an AR application to a real case and then evaluate it by the end-user, with the main objective of knowing how this type of application helps in the visualization and understanding of rock art paintings (Chapter 4).

As the study progressed, it became necessary to evaluate how lighting affects the methodology developed since rock art, specifically Levantine art (case studies used in this thesis) is characterized by being located in rocky shelters, where sunlight penetrates without difficulty, exposed to climatic and lighting changes (Chapter 5).

Assessing the necessary requirements to carry out the objective of the thesis, the specific study objectives are listed below:

1. Study of 3D visualization techniques based on AR and VR, as well as real applications in cultural heritage.

In order to know the state of the art of this technology in the cultural heritage field, specifically in rock art, the first goal is the evaluation of the current applications and means of dissemination to use as a starting point for this thesis.

2. Analysis of the main AR programming libraries aiming to define which library is the most suitable for the development of AR applications in open-air rock art.

Considering the evolution of this technology and the proliferation of new programming libraries, it is important to know which one is best suited to the case studies evaluated.

3. Design and development of an application based on the rock art paintings visualization through AR in a real rock art site. 
With all the data collected and knowing the most appropriate programming library, it is essential to develop an application to a real case of rock art and thus define the methodology and problems inherent in this type of location.

\section{Usability evaluation of the AR application developed in a real site}

One of the fundamental objectives is to evaluate the result of the application by the end-users in order to know if these applications really favour the dissemination of cultural heritage and if there is an interest on the behalf of the consumer.

\section{Assessment of the lighting change effect on image recognition and tracking in outdoor} applications.

Since rock art paintings are in a changing environment, exposed to external agents and changes in lighting during the day and throughout the year, it is important to consider whether these factors can affect object recognition and tracking and explore possible solutions.

\subsection{ORGANIZATION OF THIS THESIS}

The present thesis is structured in six chapters, the current one being an introduction on the problem of rock art disclosure and the proposed solution to be developed in the following four chapters. These are the edited versions of a published international conference paper (Chapter 2) and three international scientific papers (Chapters 3 to 5), where the study and the results obtained are described. Finally, Chapter 6 contains a discussion of the previous chapters and the overall conclusions.

Chapter 2 presents the trendy immersion technologies applied in the rock art field. This section reviews $A R$ and VR technologies and the most common programming libraries, summarizing the main factors of each of them as well as the process to develop rock art applications based on these technologies. This preliminary study helps to define the programming libraries to be used in the following research, as well as the different tracking technologies. VR requires the use of head-mounted displays making the experience a little uncomfortable whereas AR is more suitable for on-site use, therefore, the following chapters focus on the analysis of this technique in-depth.

Chapter 3 discusses the programming libraries best suited for use in rock art applications (Artoolkit and Vuforia). These libraries were chosen at the time of the study (2017) but every year new technological advances are discovered and these programing libraries change (in the last chapter the information concerning the current programming libraries will be updated). First of all, the tracking methods are studied, concluding that natural features tracking is the most appropriate, since it is a non-intrusive approach that only uses natural features easily detectable at the scene. Then, a comparative study of the two libraries was carried out by analyzing a list of factors that affect the recognition of real rock art scenes such as distance to the paintings, occlusion and lighting conditions. The analysis confirms that the user experience is better, faster and flicker-free with Vuforia, but it does not work properly on site. Therefore, to develop AR 
applications in complex outdoor environments such as rock art sites, the application should be developed using ARToolKit.

Chapter 4 explains the methodology for designing and developing an AR application applied to a real case for later in-depth evaluation. Based on the main factors to be taken into account when applying the AR techniques in the rock art field analyzed in Chapter 2 and using the best programming library for the case study obtained in Chapter 3, the first part of this chapter focuses on the whole process of developing the application in the Cova dels Cavalls, Castellón (Spain). The second part of this chapter (Section 4.5) focuses on usability evaluation by a group of potential users. It is crucial to know the users' opinion about $A R$ as a means of disseminating rock art and the use of new technologies. This application aims to assess whether AR improves guided tours and promotes a better understanding of the paintings represented.

Chapter 5 studies the effect of lighting on object recognition. Since the AR techniques studied in this thesis are based on the recognition of outdoor scenes, the images of the object will change dramatically from one hour of the day to another due to sunlight, therefore it is logical to think that the same image will not be valid for the whole day and the different times of the year. Taking advantage of the international stay at the CIMS research centre at Carleton University (Ottawa), the impact of the variation in lighting on the different facades of the Parliament Hill of Ottawa was analysed. Providing a solution to outdoor scene recognition is critical to the case of rock art, as most paintings are located in open shelters. Chapter 6 discusses the problems identified through this research and evaluates possible solutions.

Chapter 7 summarizes the results obtained from the studies carried out and the conclusions after these years of study, as well as future lines to continue with the research. 


\section{(C) Copyright disclaimer}

The doctoral thesis developed is presented by a compendium of articles, based on the papers listed below with the approval of the co-authors. This compilation satisfies the PhD requirements of the Universitat Politècnica de València, Spain.

\section{Chapter 2:}

Blanco-Pons, Silvia \& Carrión-Ruiz, Berta \& Lerma, José Luis. Review of augmented reality and virtual reality techniques in rock art (2016). In 8th International Congress on Archaeology, Computer Graphics, Cultural Heritage and Innovation. Editorial Universitat Politècnica de València. 176-183. https://doi.org/10.4995/arqueologica8.2016.3561

\section{Chapter 3:}

Blanco-Pons, Silvia \& Carrión-Ruiz, Berta \& Lerma, José Luis. Augmented reality application assessment for disseminating rock art (2019). In Multimedia Tools and Applications 78, 10265-10286. DOI: 10.1007/s11042-018-6609-x

\section{Chapter 4:}

Blanco-Pons, Silvia \& Carrión-Ruiz, Berta \& Lerma, José \& Villaverde, Valentín. Design and implementation of an augmented reality application for rock art visualization in Cova dels Cavalls (Spain) (2019). In Journal of Cultural Heritage 39, 177-185. DOI:10.1016/j.culher.2019.03.014.

\section{Chapter 5:}

Blanco-Pons, Silvia \& Carrión-Ruiz, Berta \& Duong, Michelle \& Chartrand, Joshua \& Fai, Stephen \& Lerma, José. Augmented Reality Markerless Multi-Image Outdoor Tracking System for the Historical Buildings on Parliament Hill (2019). In Sustainability, 11(16): 4268. DOI: 10.3390/su11164268. 


\section{2}

\section{Introduction of the}

\section{technique}

This chapter is based on the publication entitled "Review of augmented reality and virtual reality techniques in rock art". This chapter is introductory and serves to know the state of the art of the new visualization techniques applied to rock art. In this section, AR and VR are evaluated, both of which are growing techniques that are very suitable for the diffusion of cultural heritage.

The usage of AR and VR technologies began to grow when smartphones appeared. Until then, the number of portable devices capable of incorporating these technologies was reduced. Video games are the main field where these technologies are applied, but in other fields such as archaeology, these technologies can offer many advantages. Ruins reconstruction, ancient life simulation, highly detailed 3D models visualisation of valuable objects from the past or even user free movement in missing places are just some examples found in the literature.

At this point, both technologies will be studied, concluding the basic steps for the development of a mobile application.

\subsection{INTRODUCTION}

The International Council on Monuments and Sites (ICOMOS) defines cultural heritage as follows: "Cultural Heritage is an expression of the ways of living developed by a community and passed on from generation to generation, including customs, practices, places, objects, artistic expression and values. Cultural Heritage is often expressed as either Intangible or Tangible Cultural Heritage" [16]. 
Tangible cultural heritage is formed by features such as buildings, structures, artworks, documents, artefacts and rock art paintings. It is everyone's responsibility to understand, appreciate and conserve cultural heritage. For this purpose, this study describes new ways to understand and disseminate the cultural heritage, and specifically, rock art paintings, based on the fast development of both AR and VR technologies. These new technologies allow users to show highly accurate 3D models of tangible cultural heritage through realistic immersive environments.

$A R$ is a visualisation technique in which virtual contents such as 3D models, text, video and other multimedia formats, are placed on top of the real world camera view [1]. The user simultaneously can perceive the real environment and virtual elements overlaid in real-time. AR technology provides a new way to show cultural heritage. An example of this is Archeoguide [17]. It offers AR tours of archaeological sites and uses this technique to enhance information presentation, reconstruct ruined sites and simulate ancient life.

Nowadays, AR technology is used in many fields, such as entertainment, education or medicine but, it is also used in the tourism sector to enrich and enhance the user experience. There are several examples making use of this approach. An AR museum guide is presented by Miyashita et al. in [18]. This AR guide provides the visitor with a basic knowledge of some artworks and drives the visitor through the exhibition. Another example is described by Gutierrez et al. [10] who presented an AR application to release information about historical graffiti in the Temple of Debod.

VR technology immerses completely users in a virtual world, a world created by computers. The difference between these two technologies is that while AR technology combines the virtual world with the real world, VR only shows virtual elements. VR offers the possibility to visit inaccessible sites or sites that no longer exist. The visualization process of the generated VR is carried out through head-mounted displays (HMDs). These HMDs have dramatically improved and nowadays are lightweight glasses. An example of this is the VR glasses Oculus Rift, developed by Oculus VR. Although this last generation of HMD is focused on the field of gaming and entertainment, its application in other fields is worth mentioning. Specifically, in the field of medicine, Draganov and Boumbarov [19] investigate a medical assistive system for motor disabled patients through an Oculus Rift VR Display. Other research is focused on disseminating the cultural heritage content through the virtual reconstruction of a typical theatre of the time [20] or through a 3D virtual museum tour of the Santa Maria Della Scala using the Oculus Rift [21].

Both 3D visualisation techniques are quite similar. VR users go into a completely immersive virtual world outside of the real world, meanwhile AR users stay in a semi-immersive environment where they can interact with virtual objects around them in the real world.

In the 1950s appeared the first VR system, but until recently these technologies were rarely used. The user had to carry a computer and an HMD as well as a GPS, webcam, wireless LAN and other components. This hardware was complex and heavy. Besides hardly accessible for the majority of users. Nowadays, the breakthrough in mobile technologies and information technology (IT) infrastructure has allowed the growth of these technologies, especially with smartphone development. A smartphone is a small computer that is fully equipped with a variety of devices such as GPS, wireless internet, Bluetooth, high resolution video camera, accelerometers, gyroscopes, digital compass, barometer, proximity sensors, and other components. Due to hardware features, smartphones have emerged as potential platforms for 
implementing mobile AR and VR [22]. The user is acquainted with the use of a smartphone as a tool for its daily tasks. Furthermore, it is a friendly and portable device. For all these reasons, the smartphone is a perfect tool to implement these kinds of visualization technologies.

The following sections describe AR and VR technologies in detail, and also the current 3D frameworks and processes to develop an application. To test these solutions a smartphone app is developed that aims to teach and disseminate rock art paintings located in an inaccessible shelter.

\subsection{AR TECHNOLOGY}

In the first AR systems, the user used to carry a computer and an HMD, and this entailed many limitations. Firstly, the hardware was uncomfortable and not very portable. Secondly, the HMD used to interrupt the user's natural view and prone to cause discomforts such as nausea or dizziness. Finally, AR systems implementation for that particular hardware required much time and effort from the developers [22].

These limitations were improved with the appearance and fast evolution of smartphones. Nowadays there are powerful smartphones on the market which work as a computer and HMD. As a consequence, the user does not have to carry special hardware and improves users' mobility. Therefore, at present, there are many mobile AR applications (apps) on the market.

A mobile AR app consists of overlaying digital information in the real world. The digital information is shown through the smartphone camera and is placed in a specific position. There are different ways to position information, such as mobile location. All current smartphones are equipped with GNSS localization systems and orientation sensors, among others.

The orientation sensor obtains information by processing the raw sensor data from the accelerometer and the geomagnetic field sensor. The orientation sensor provides the azimuth (degrees of rotation around the z-axis), pitch (degrees of rotation around the x-axis) and roll (degrees of rotation around the $y$-axis) values. These values set out the direction of the device.

When a smartphone is placed in a location with known coordinates and orientation, the digital information is visualised on the camera. The disadvantage of this method is the accuracy of the GNSS positioning. In areas with tall buildings or with many trees, the signal bounces off and accuracy decreases. If it occurs, the digital information will be badly placed. Besides, this system does not work inside buildings.

Another way of showing digital information is through the use of markers. A marker is a square frame made up of light coloured usually white, surrounded by a dark coloured, usually black. Each marker is formed by a different pattern which makes them unique. For example, in the Vuforia markers, the unique ID is encoded into a binary pattern along the border of the marker image (Figure 2.1). In the marker recognition process, the first smartphone camera collects and processes the images in real-time with aim of finding a pattern known. The image recognition techniques are based on finding patterns of known shapes, colour detection, geometries and repeated patterns. When a maker is detected, the virtual information overlaps on the camera.

Finally, using images or objects instead of markers is possible. This is known as Natural Feature Tracking (NFT). NFT allows users to recognise and track natural features on images and 
objects. This is very useful because it can be used for example, in advertising to augment the images of a brochure.

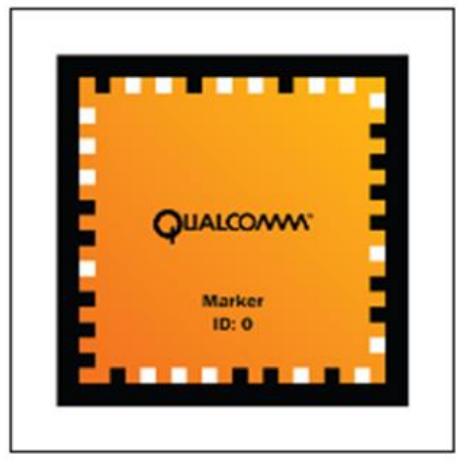

Figure 2.1. Frame marker provided by Vuforia SDK.

Digital information can be of any type, such as 2D images, 3D models, text, animation, video, music, etc. This opens up the possibility of creating many and varied applications. [2] review the main AR apps. In advertising, it is used to promote new products online. In entertainment and education, $A R$ is applied to develop cultural learning games, which are games with educational purposes. In medicine, AR apps are utilized to assist surgery in achieving, thus, a minimum invasive surgery with improved precision, dexterity, and visualisation.

Nowadays, AR development apps are easier than some years ago. An advantage is that everybody is able to create apps for the same hardware (smartphone). This enables to advance towards best app development due to the large number growth of software frameworks. A framework generally provides some base functionality that can be used and extend to make more complex applications. The main advantages of using frameworks are: they provide an overall application structure, they facilitate the collaboration between developers, and there are many available tools and libraries adapted to frameworks.

At present, there are many available frameworks to develop easily AR applications. The choice of one or another depends on application functionality and eventually, the OS used. [1] show some of the publicly available frameworks. In this study, current free solutions have been analysed and are presented below:

- ARToolkit is an open-source AR library for iOS, Android, Linux, Windows, Mac OS X and it has a plug-in for Unity3D. Includes OpenGL ES2.x support, integration with GPS and compass, and automatic camera calibration utilities. It offers marker detection, multimarker tracking and natural feature tracking (NFT). Furthermore, it features extensive documentation, examples and tutorials. Includes development for Smart Glasses [23].

- BeyondAR is an open-source AR framework based on mobile location for Android [24].

- DroidAR is an open-source AR framework for Android only, it features location-based $A R$ and recognition markers [25].

- Mixare is an open-source AR engine for Android and iPhone, which displays Wikipedia points of interest (POIs) of the surroundings and lets you add your own POls database [26]. 
- Vuforia is an AR software development kit (SDK) for Android and iOS as well as digital eyewear, and it also offers an extension for Unity3d. Vuforia provides great recognition capabilities as recognises objects, images, cylinders, text, boxes and frame markers. Also includes background effects, video playback, virtual buttons and occlusion management. Vuforia has free and commercial license [27].

Table 2-1 summarizes current free features on AR frameworks. This list changes very fast since many frameworks stop being maintained and are outdated quickly or end up being bought by big companies such as Metaio SDK recently acquired by Apple. The most complete and easy to use tools are Vuforia and ARToolKit but if the goal is to make a location-based app will have to choose other frameworks presented.

\begin{tabular}{c|cccc}
\multicolumn{2}{c}{ OPERATING SYSTEM } & $\begin{array}{c}\text { LOCATION } \\
\text { BASED }\end{array}$ & $\begin{array}{c}\text { MARKER } \\
\text { BASED }\end{array}$ & NFT \\
\hline ARTOOLKIT & iOS, Android, Linux, Windows, Mac OS X and & & $\mathrm{X}$ \\
BEYONDAR & Unity 3D & $\mathrm{X}$ & \\
DROIDAR & Android & $\mathrm{X}$ & $\mathrm{X}$ \\
MIXARE & Android & $\mathrm{X}$ & & \\
VUFORIA & Android and iPhone & & $\mathrm{X}$ & $\mathrm{X}$ \\
\end{tabular}

Table 2-1 Summary of AR frameworks.

Finally, and to conclude, AR apps are experiencing rapid development and their applications are endless. In addition, these enhance reality users' perception and surrounding environment. In this way, information becomes interactive and easily manipulated digitally.

\subsection{VR TECHNOLOGY}

Although AR and VR are quite similar technologies, both represent different realities. While $A R$ adds elements to reality, VR creates a new reality that does not exist. VR is an artificial environment created with software and presented to the user such as a real environment. The VR is represented in a 3D image that can be explored interactively, by means of gloves with sensors, controls such as a game console or a computer mouse so that image content moves in any direction or zooms in/out.

The VR apps require using an HMD, such as glasses, to visualise the virtual environment. The first systems of VR needed a complex HMD and the graphics quality was very low. Nowadays, thanks to technological advances, the HMD has evolved considerably and there are currently powerful solutions in the market such as Oculus Rift [28]. The Oculus Rift is a VR HMD developed by Oculus VR. Its operation is based on stereoscopic vision (imitating natural vision). Stereoscopic vision is any technique capable of collecting 3D visual information and creates the illusion of depth in an image.

In the natural stereo vision, the eyes, due to their separation (interpupillary distance), obtained two images with small differences between them. These differences are processed in the brain to produce depth perception. 
The HMD projects stereoscopic vision. The screen displays two images side by side, one for each eye. A small controller on the basis of the display is used to adjust the interpupillary distance. The eyes separation varies between individuals and is an important element to give a realistic sense of stereoscopic vision. The HMD feature a virtual surround sound system and sensors that control the movements of the user's head and adjust the picture accordingly. For the time being, this device is intended to connect the computer and the smartphone.

This type of totally immersive 3D vision makes some users experience effects such as motion sickness and headaches. To avoid this, it is necessary to adjust the lens to each person vision, but even so, prolonged use might cause discomfort.

Visualising the VR with an HMD is sometimes a bit annoying. However, it is possible to create a semi-immersive app where the 3D model is shown in the mobile display and the user can interact with it through the touch screen.

There are some frameworks that allow users to load 3D models and interact with them. These frameworks are useful to create simple semi-immersive apps. However, the best solution is a game engine in order to work with 3D models and for rendering, creating animations, and so on. A game engine is a software framework designed for the creation and development of video games ready to be used on multiple platforms. The engine primary components are rendering, loading, animation, collision detection between objects, physics, inputs, GUI (Graphic User Interface) and Al (Artificial Intelligence). Besides, the game engine has other tools that make the actual game: characters and terrains, real-world object behaviours, etc. [29]. The game engine includes all the required tools to create a virtual reality app. In addition, many game engines incorporate stereoscopic vision. Some frameworks that handle 3D models are:

- Mind3d is a lightweight 3D library/framework for Android based on OpenGL ES $\mathrm{v} 1.0 / 1.1$. It provides the tools to load an .obj, . $\mathrm{m} 2 \mathrm{~d}$ and .3ds files and add functionality. Nowadays it is not maintained.

- Rajawali is a 3D framework for Android based on OpenGL ES 2.0/3.0. Compatible with the Google Cardboard SDK v0.6.0 and includes full documentation and tutorials.

The disadvantage is that these before-mentioned frameworks are only compatible with Android and it is difficult to develop apps for inexperienced programmers. On the other hand, the game engine is the best solution to create a virtual environment and develop basic functionality.

Currently, the most popular game engines are Unity, Unreal Engine 4 and CryENGINE. These game engines are extremely powerful and each one has its advantages and disadvantages, but all are compatible with VR glasses. Unity [30] is the easiest to use and is compatible with all mobile platforms, but the graphics quality is inferior and does not allow real-time modelling. Unreal Engine 4 [31] has incredible graphics capabilities, allows hyper-realistic scenes generation and is simple to use but it is only compatible with iOS and Android. Finally, CryENGINE [32] is more suitable for expert developers as the learning curve of this engine is elevated but graphics quality is very high. Table 2-2 summarizes the principal features of these game engines. 


\begin{tabular}{c|ccc} 
& $\begin{array}{c}\text { MOBILE } \\
\text { PLATFORMS }\end{array}$ & OTHER PLATFORM & $\begin{array}{c}\text { LANGUAGE } \\
\text { SUPPORT }\end{array}$ \\
\hline CRYENGINE & PC, PlayStation, Xbox, VR & C++, Lua, C\#. \\
UNITY & $\begin{array}{c}\text { Android, iOS, } \\
\text { Windows }\end{array}$ & $\begin{array}{c}\text { PC, PlayStation, Xbox, Wii, 3DS, VR, } \\
\text { TV, Web }\end{array}$ & $\begin{array}{c}\text { JavaScript, C\# } \\
\text { and Boo }\end{array}$ \\
$\begin{array}{c}\text { UNREAL } \\
\text { ENGINE 4 }\end{array}$ & Android, iOS, & PC, PlayStation, Xbox, VR & C++
\end{tabular}

Table 2-2 Summary of game engines.

\subsubsection{PROCESS TO DEVELOP A VR APP}

The process of creating a virtual world requires more time than for one AR app as a complete environment must be created by the computer.

The process followed in this chapter is divided into three phases: 1) Modelling and texturing the virtual element; 2) Environment creation; and 3) Interactive scripting. Unity was chosen to carry out these phases due to its compatibility with multiple platforms. Unity is a cross-platform used to develop games and interactive worlds in $3 \mathrm{D}$ and $2 \mathrm{D}$ for $\mathrm{PC}$, consoles, mobile devices, VR and websites.

The main features of the Unity game engine are:

- Dedicated tools for creating 2D and 3D content.

- Importation of models and animations made with other 3D applications such as Blender, Maya, 3DS Max and Cinema 4D.

- Easy programming through a variety of scripting languages and comprehensive documentation.

- The inclusion of a physics engine enables users to create convincing physical behaviour. In this way, the objects in the scene will be affected by collisions, gravity and other forces.

Although Unity is focused on the design and development of video games, it is a complete tool to create interactive 3D environments and smartphone apps.

\subsubsection{MODELLING AND TEXTURING THE VIRTUAL ELEMENTS}

Any application that requires showing a real environment as a virtual tour, involves the generation of a realistic 3D model. Typical examples are ruins reconstruction [17], the museum interior $[18,21]$, interesting cultural monuments or shelters with rock art paintings. In order to create an accurate and detailed 3D model, it is recommended to use photogrammetry or terrestrial laser scanning techniques [33].

Photogrammetry enables accurate measurements and 2D and 3D reconstructions of all types of existing objects using images at different scales. Through structure from motion (SfM) algorithms, it is possible to obtain accurate 3D models quickly and easily. Only overlapping images from multiple perspectives are needed and dense 3D point clouds with real texture are generated automatically in a few minutes [34,35]. 
Laser scanning is an efficient, high-precision and ultrafast active remote sensing technique used to acquire dense 3D point clouds [36]. These instruments can generate quickly vast amounts of 3D data. The usage of the laser scanner is justified mainly for objects, monuments and sites with complex geometry.

Both photogrammetry and laser scanning techniques can be used to generate dense 3D point clouds from which real texture can be draped. In order to use these data in apps, it is necessary to convert the point clouds into more practical triangular meshes. This is possible with commercial as well as with open-source software.

Another possibility to generate a simple 3D model is through CAD tools. CAD software is recommended in order to create simple 3D models since planar features are requested for simplified 3D modelling. The planes are imported into the software and all surfaces must be converted to solid objects as far as the extrusion command is available. Finally, a texture must be added to the surface of the object.

\subsubsection{ENVIRONMENT CREATION}

Once the 3D model is generated it should be placed in a real environment to add more realism. Unity includes several tools for this purpose such as terrains on which positioning the object, different lights to illuminate the scene, skyboxes and atmospheric effects.

\subsubsection{INTERACTIVE SCRIPTING}

In order to create an interactive scene, Unity provides programing scripts in either C\#, JavaScript or Boo. In this phase, physical properties should be added to the objects with Unity physics engine tools. The most important is the "Mesh Colliders". This property ensures the player will not be able to walk through the created walls. Besides, the interaction with the elements of the scene (e.g. opening a door, moving an object...) must be developed through scripts.

\subsection{CASE STUDIES}

Two simple apps are developed in order to test both AR and VR technologies. In example 1 , an AR app is developed to show an augmented globe. The goal is to know the steps to perform a complete AR app that might be expanded to disseminate rock art. In example 2 , an interactive app is developed with the aim to show through a virtual tour, rock art paintings located in areas with limited access.

\subsubsection{EXAMPLE 1: THE AUGMENTED GLOBE}

The application was developed using Vuforia SDK for Unity. The process followed to create an AR app is very simple. First, a frame marker is added to the scene. The app will use it to place the elements of AR. Then, the virtual elements (augmented elements) are added. On this application is used a simple object such as a globe. The object geometry is very simple (a sphere); it can be created in Unity. Creating complex models with other image-based, range-based or 
CAD software and import the results into Unity is also possible. In order to improve the realism effect on the object, a texture is projected onto it. Finally, to visualize the object, a light is added to the scene. Furthermore, a simple script is developed to make the sphere turning around. With these steps, it is possible to visualise an object through a smartphone camera pointing towards a frame marker (Figure 2.2a) and then the augmented globe will be displayed (Figure 2.2b).

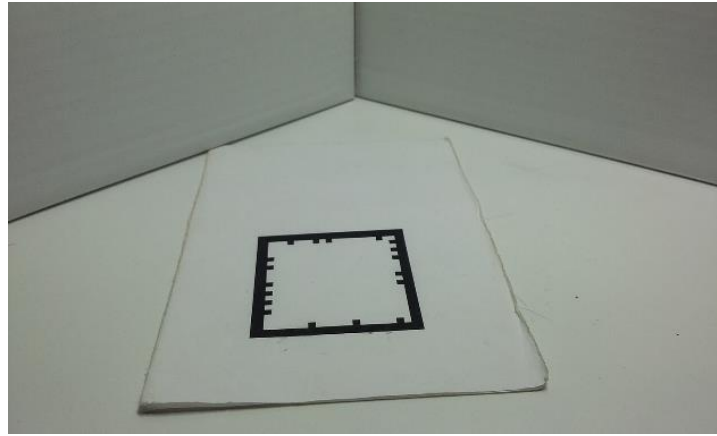

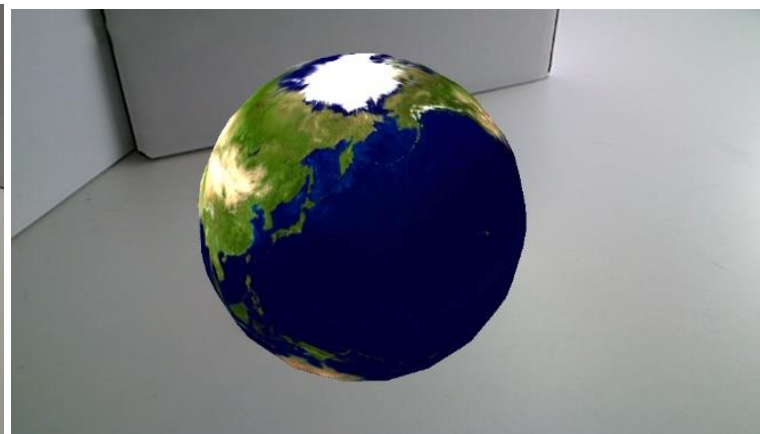

$b$

Figure 2.2. Smartphone screenshots: a) screenshot before the augmented globe; b) screenshot with the augmented globe.

Using Vuforia SDK and Unity software, the steps to develop AR apps are pretty simple. This AR app can be adapted to another project after changing the virtual object to be shown.

In the rock art field, an app of this type can be used to teach and disseminate rock art paintings. This simple example can be used to create an application that, instead of displaying a 3D object, displays e.g. 2D images of rock art motifs. Through a smartphone camera, the rock art motifs can be projected onto a wall in real size. This app makes it possible to show in a comfortable way, rock art paintings that cannot be visited, or that are hardly visible.

\subsubsection{EXAMPLE 2: INTERACTIVE VISIT TO A ROCK ART SHELTER}

Many interesting rock art paintings are located in rugged mountains and access to the public is either difficult or limited. In other cases, the rock art sites are closed to the public for protection and conservation, and the visitors are not allowed to visit them. For this reason, the aim of this example is to create an app where the user can make a complete virtual visit to a site.

For this example, were tested two different frameworks: Unity game engine and min3d. Each can be used for a different purpose as already explained. In both cases, the first part of the process involves obtaining the 3D model.

The 3D model of a shelter was obtained from multiple images by means of a photogrammetric SfM approaches. A point cloud of low density was created (Figure 2.3a). Obtaining the 3D model using CAD tools is impossible due to the complexity of its shape. On the other hand, laser scanning is ruled out as it generates point clouds too big for a mobile application. An important limitation in this type of application is the generated 3D model size. Most of the times, it will be necessary to simplify the 3D model to reduce its size. 
The triangular mesh has been created using MeshLab. First normal vectors associated with each vertex are determined. Using the original point cloud with the computed normals, a surface reconstruction at the highest resolution is created. Finally, the texture from the colour images is generated after draping the images onto the 3D model. Following this way, a photorealistic 3D model of great detail and texture is achieved (Figure 2.3b).

The 3D model is imported to Unity to create a surrounding environment. The shelter is located on rugged terrain on the hillside of a mountain. In Unity, with terrain tool, a similar terrain is created and the scene is illuminated with some lights. Finally, to give greater realism to the scene a sky is added through the skybox tool. The skybox is a complete wrapper around the scene which can be edited for changing the colour, exposure, adding clouds, etc.

The user has to move around the scene for the virtual tour. Unity has a standard asset (3D object motion script) for first-person characters. Once added the first character into the scene, a person is able to move in all directions within the project. It is possible to obtain stereoscopic vision using the Oculus Rift SDK for Unity.

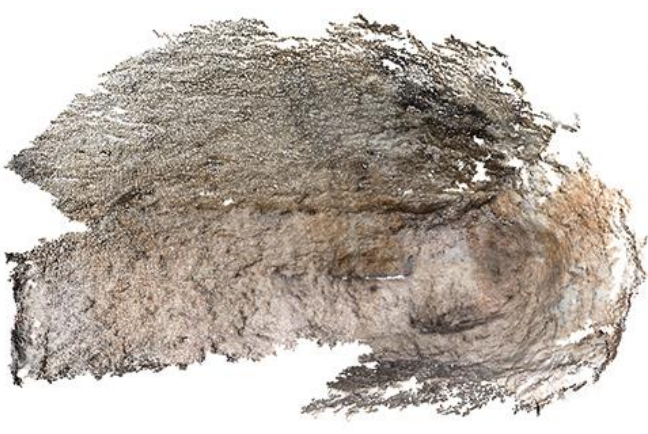

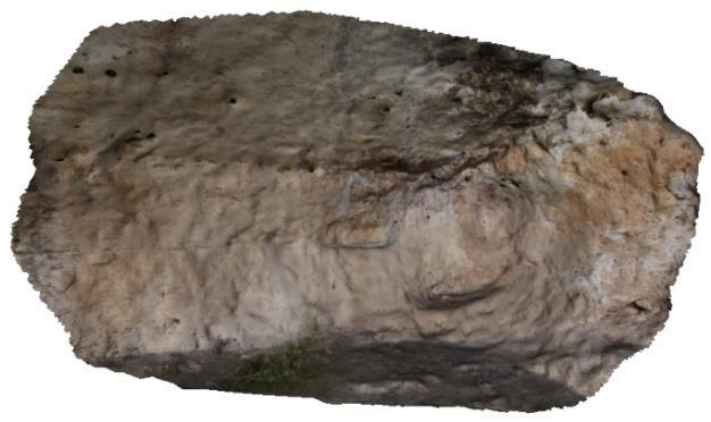

b

Figure 2.3. The interior of a shelter: a) 3D point cloud; b) photorealistic 3D model.

Since not everyone has virtual reality glasses, a version for smartphones has been created through mind3d framework. In this version, the user will see on the smartphone screen the shelter 3D model and the rock art paintings. Besides the user is able to move in all directions and zoom with touching gestures. Figure 2.4 shows an app screenshot where the photorealistic model is visualised. The icon home returns home, and two icons allow users to zoom in/out. Additional icons are presented in other scenes to localise and how to reach the site, to get historical values as well as neat depictions of the rock art paintings. 


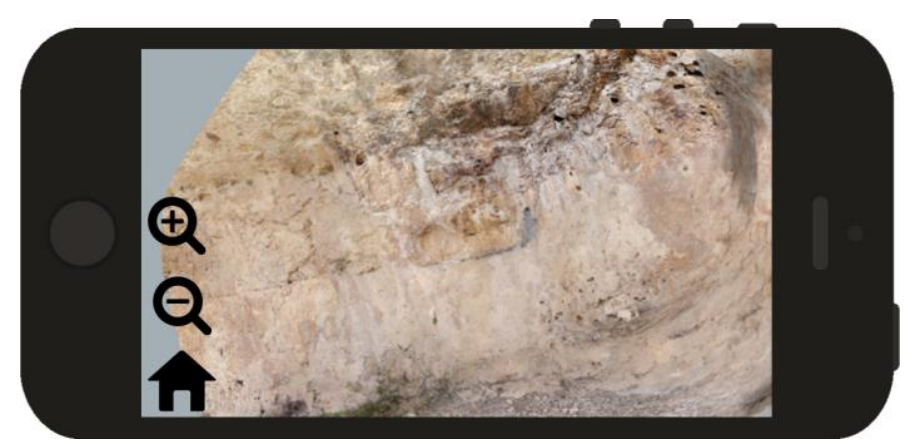

Figure 2.4. Smartphone screenshot.

\subsection{CONCLUSIONS}

This chapter reviews the latest technologies for 3D models visualisation. These technologies provide the user with real and enriching experiences for the visualisation of 3D objects. Besides, the amount of possible fields that can benefit from these technologies is very great. Specifically, these technologies have been applied in the rock art field.

These apps, particularly those involving the use of VR glasses, can cause discomfort and inconvenience to some users. Therefore, some users may either prefer AR apps or display 3D models using the mobile screen. The next chapters are focused on AR technology.

On the other hand, the creation of a photorealistic 3D model is just the first step. Creating complex and/or very large models can be approached with image-based photogrammetric techniques. Nevertheless, the point clouds obtained are so big that the hardware of a mobile phone does not support them. Therefore, optimisation of 3D models is crucial to create photorealistic models for smartphone apps. Enriching the apps with additional user-friendly tools is a step that will be developed in the new future. 


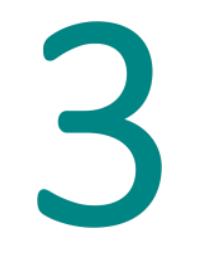

\section{Augmented reality libraries}

This chapter is based on the publication entitled "Augmented reality application assessment for disseminating rock art". AR libraries have proliferated in recent years, and they work increasingly well. This chapter reviews the AR libraries, how they work, and compares the most widely used (at the date of this paper, 2017).

The analysed libraries were those that at the time of the study were the most optimal and responded best to the requirements. As the technologies advance, these libraries change and even some disappear as is the case of Artoolkit. With the development of ArCore by Google, the Artoolkit library was no longer maintained. Even so, ArCore is not the same as Artoolkit so in many cases this library will not be able to do the same job. In the last chapter, the information about the programming libraries will be updated and the main factors of each one of them will be summarized.

Currently, marker-based tracking is the most used method to develop AR applications. However, this method cannot be applied in some complex and outdoor settings such as prehistoric rock art sites owing to the fact that the usage of markers is restricted on-site. Thus, natural feature tracking methods have to be used. There is a wide range of libraries to develop AR apps based on natural feature tracking. In this chapter, a comparative study of Vuforia and ARToolKit libraries is carried out, analysing factors such as distance, occlusion and lighting conditions that affect user experience in both indoor and outdoor environments, and eventually the app developer. This analysis confirms that Vuforia's user experience indoor is better, faster and flicker-free whether the images are properly enhanced, but it does not work properly on site. Therefore, the development of AR apps for complex outdoor environments such as rock art sites should be performed with ARToolKit. 


\subsection{INTRODUCTION}

AR refers to the computer device visualisation technology that allows the user to combine information coming from both the real world and the virtual world in real-time. Nowadays, one of the most common ways of using AR is through either smartphones or tablets. These portable devices are highly extended worldwide and integrate one or two digital cameras. Smartphones and tablets can be considered the most suitable devices nowadays to implement visualisation technologies. Moreover, it is possible to add in its real position [37] any virtual content such as 3D models, 2D images or text information on top of the scene captured by the smartphone/tablet camera since the device position is calculated in real-time to place the virtual content properly. Simultaneous visualisation of both real and virtual objects helps the users to understand quickly the added information and contributes to enhancing their experiences.

Smartphones are fully equipped with a wide range of sensors such as Global Navigation Satellite Systems (GNSS) (namely GPS and Glonass), Bluetooth, high-resolution video camera, accelerometers and gyroscopes, and wireless technology ready to connect to the internet e.g. through $4 \mathrm{G} / 5 \mathrm{G}$, among other common components. Due to this hardware evolution, the number of platforms for developing mobile AR apps is steadily increasing [22].

AR technology is the result of many years of evolution. As Carmigniani et al. [2] pointed out, AR technology already has some years of evolution and improvement. The beginnings of this technology date back to the 1950s, when Morton Heilig, a cinematographer, was interested in enriching the cinema experience and from his vision, he built "sensorama". Throughout all these years, this technology has been changing and improving and many authors have given their own AR definition.

According to [38], AR places virtual elements in the camera scene and allows the user to see the real world, with virtual objects superimposed supplementing reality. AR is a very useful information tool, in which digital images, computer graphics and multimedia elements can be combined in an interactive way [39]. Moreover, Azuma et al. [40] established the essential features of an AR system: it combines real and virtual objects in a real environment, in real-time and registers real and virtual objects with each other.

Nowadays, there are many AR apps in all sorts of fields, such as medicine, manufacturing, education, robot path planning, military aircraft, entertainment and even tourism. Moreover, $A R$ provides a new way to show the cultural heritage that provides the user enriching experiences $[41,42]$. In recent years, many $A R$ apps are developed especially mobile apps to disseminate cultural heritage. Gutierrez et al. [10] described an example of an app to show and disseminate cultural heritage about historical graffiti in the Temple of Debod. Ridel et al. [43] applied a projected 3D visualisation to a physical archaeological artefact that highlights its features. AR was also used by [44] for enhancement and visualisation of a wooden sculpture. Visualisation of 3D models in-situ is another type of $A R$ app that offers the chance to the user to observe archaeological findings [11].

These types of apps in the archaeological museums' field have become very popular in recent years due to the fact that the visit is highly enriched [45]. However, when AR apps are used to visit rock art sites, it is necessary to take into account the special (singular) features of this type of environment. Generally, rock art sites are located in remote areas constantly exposed to direct sunlight and different altering agents are gradually threatening and degrading 
the art $[46,47]$. This means that there are sites with very poor coverage, limited (if any) broadband signal and heterogeneous lighting where high contrasts can be found especially in shelters. In addition, due to the fragility of conservation and the similarity between the paintings and the rock that supports them, it is extremely difficult in most cases to recognise painted features. On the other hand, it should be noted that the visitor must be a minimum distance away from the motifs; there is usually a minimum and maximum distance rate to visualise the paintings. The main motivation behind this work is to find an AR library that works fine in these rough and harsh environments, allowing the development of future apps to disseminate the rock art scenes full of faint motifs.

Several libraries can be found to develop AR apps running with markers so that the camera on a mobile device can recognise an image pattern and project the virtual object over the marker. The literature reports numerous research on the factors that can affect markers recognition. Khan et al. [48] analysed eleven factors that affect the marker quality and evaluated the effects of each factor on the quality of the marker tracking system. Also, several studies $[49,50]$ analysed other factors such as distance between marker and device camera, number of markers, shape and size of the markers or lighting conditions; other authors published a comparison of several libraries for AR implementation [1,39]. However, there is a lack of comparative user and developer assessment reporting the experience of using AR apps to disseminate complex cultural heritage sites.

The final goal of this section was to create an AR app able to show the user a recreation and interpretation of the paintings found in a prehistoric rock art site. In order to achieve this, this research assesses the factors affecting the user's experience in two scenarios: 1) indoor, trying to test its usefulness for purpose in either a museum, exhibition, gallery or laboratory, making use of a printed colour paper of a rock art scene; and 2) outdoor on-site in a rock art cave (shelter). In addition, the assessment can be used by the developers to confirm which library is expected to run better in both scenarios. Hereby, the aim of this chapter is to assess the implemented rock art app on prehistoric rock art features, using the Unity3D engine platform, and both ARToolKit [51] and Vuforia [52] libraries.

The chapter is structured as follows. Section 3.2 tackles the subject of AR for rock art sites and both ARToolKit and Vuforia graphic libraries are presented with emphasis on visual-based tracking. Section 3.3 explains the design and implementation of the AR rock art app, considering two environments, one indoor and another outdoor. Section 3.4 presents the results achieved with both libraries. Section 3.5 discusses the results and summarises them. Finally, Section 3.6 draws some conclusions.

\subsection{AR AND TRACKING METHODS}

\subsubsection{CONTEXT}

This chapter is focused on AR apps to improve both the knowledge and the dissemination of prehistoric rock art sites. The motifs represented in rock art are usually rather difficult to visualise without any help from archaeological experts because the paintings are severely damaged. Moreover, the paintings are usually located in open-air sites. AR rock art apps can 
show the current state of the paintings or even a simulation of the real paintings, making easier the understanding of the represented motifs. Furthermore, these apps should run on smartphones and tablets, so they are conceived to be used in situ under a wide range of unexpected circumstances.

In order to achieve a spatially correct overlap of virtual information, the main AR challenge is the tracking of the users' camera: the virtual content must be perfectly aligned with the real world. Therefore, it is necessary an accurate estimate of the position and orientation of the digital camera [53]. The objective of the tracking system is to determine the pose of the camera in real-time. Whenever the user moves the AR device, the tracking system recalculates the new pose in real-time and thus the virtual contents have to remain aligned with the real object. The camera pose is calculated with six degrees of freedom, three translation parameters $x, y, z$ and three orientation parameters yaw, pitch, roll [54].

The proper visualisation of virtual contents depends on the tracking method. Vision-based tracking is a widely used AR method for camera tracking. This method calculates the camera pose from the data received by the camera view. The six degrees of freedom are calculated from the known geometric features of the objects and their 3D geometric relations. Depending on the feature type, vision-based tracking is categorised into marker-based tracking -i.e. detection of a known pattern- and markerless -i.e. detection of natural features in a scene [55].

\subsubsection{TRACKING METHODS}

\subsubsection{MARKER-BASED TRACKING}

Fiducial Marker-Based Tracking [39], mostly known as marker-based tracking, is currently the most used tracking method. This method makes the use of markers easily recognisable. Typical markers are black and white squares with high contrast, which are placed in the scene to be augmented. The main advantage of this marker-based tracking is that quickly recognises the markers because of the high contrast between the markers and the environment.

Both ARToolKit and Vuforia have predefined square markers (Figure 3.1), but they allow the user to design their own markers. In ARToolKit, markers must be squares with continuous edges. In Vuforia, the latest release includes VuMarks which allows the users to create completely customised branding design marks [56].

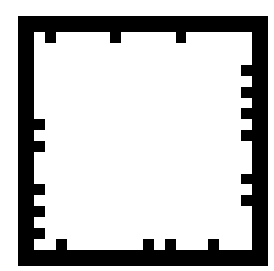

$a$

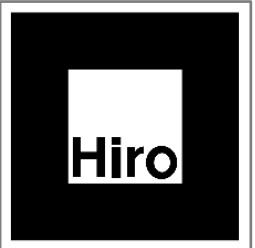

$b$

Figure 3.1. Visual markers already implemented in Vuforia (a) and ARToolKit (b) libraries. 
Partial marker occlusions originate the main problem in visual-based tracking methods. If the marker is partially obscured, the library will not recognise the marker, and therefore, the AR app will become unstable. Other factors that can affect the correct marker detection are, for instance, the marker size, the camera-marker distance or the scene lighting.

In some cases, marker-based tracking cannot be used owing to the fact that placing (fixing) markers in protected places or outdoor environments is restricted or not feasible. Therefore, another tracking method is required to deal with such afore-mentioned cases.

\subsubsection{MARKERLESS TRACKING}

Scene recognition without markers is also employed with AR technologies; it is applied to facial recognition, gesture recognition and image recognition. Markerless tracking requires high computational cost, as well as demanding and complex processing to recognise enough matching features to enable pose estimation and tracking.

Markerless tracking can be classified into two methods: feature-based and model-based tracking. Feature-based tracking consists of finding natural features in the scene. Model-based methods make use of the 3D model to estimate the camera pose; this method is commonly used for tracking 3D objects without texture [57]. This study focuses on tracking 2D features due to several reasons: 1) rock art paintings are usually located in protected archaeological areas, which must not be altered in any way and hence markers are not allowed to be placed on-site; 2 ) the scene is full of texture and details; and 3 ) the motifs in the shelter are split in small units (panels) that can usually be assumed as flat.

\subsubsection{FEATURE-BASED TRACKING}

Also called Natural Feature Tracking (NFT) [54,58], this method only uses natural features easily detectable in the scene such as edges or corners; hence, this is a non-intrusive approach. The scene to be recognised must be rich in details and have preferably high contrast. It is necessary to obtain a sufficient number of features in order to determine correctly the camera pose.

Figure 3.2 presents an overview of the NFT method. This method requires a known reference image which is computed offline before the tracking to extract the keypoints and describe the feature vectors; these data are stored in the feature database. Then, the keypoints of each acquired image in real-time (with the mobile device) are extracted and described, and these feature vectors are matched with those of the feature database. Finally, the camera pose is obtained with this set of correspondences, after applying homography between pairs of views (reference image and acquired images) [59].

There are several types of feature detectors and descriptors aimed at identifying keypoints and the calculation of feature vector that fully describes the keypoint and its local neighbourhood [60,61]. Once keypoints are located (with the feature extraction), a vector that describes the feature of a keypoint is computed (with the feature description). The most popular descriptor is SIFT [62] but there are other such as SURF, FAST, ORB, PCA-SIFT, ASIFT described in 
[59-61,63]. ARToolKit uses the FREAK descriptor, which is faster to compute with lower memory load and more robust than other descriptors [64].

Large errors in pose determination cause incorrect alignment of the virtual content. This is one of the challenges, because rock art paintings do not usually have high contrast and there are no large colour differences in the scene (Figure 3.3a). Nevertheless, the user is excited once he/she is able to visualise the motifs in situ, because they are hard to visualise in a particular moment (during the visit to the archaeological site). Therefore, the relevance here is to get the experience of getting the motifs on; the relevance of aligning the motifs perfectly is drastically reduced. Once the visitor knows what to look for in a particular panel, it is easier to identify the paintings under real conditions.

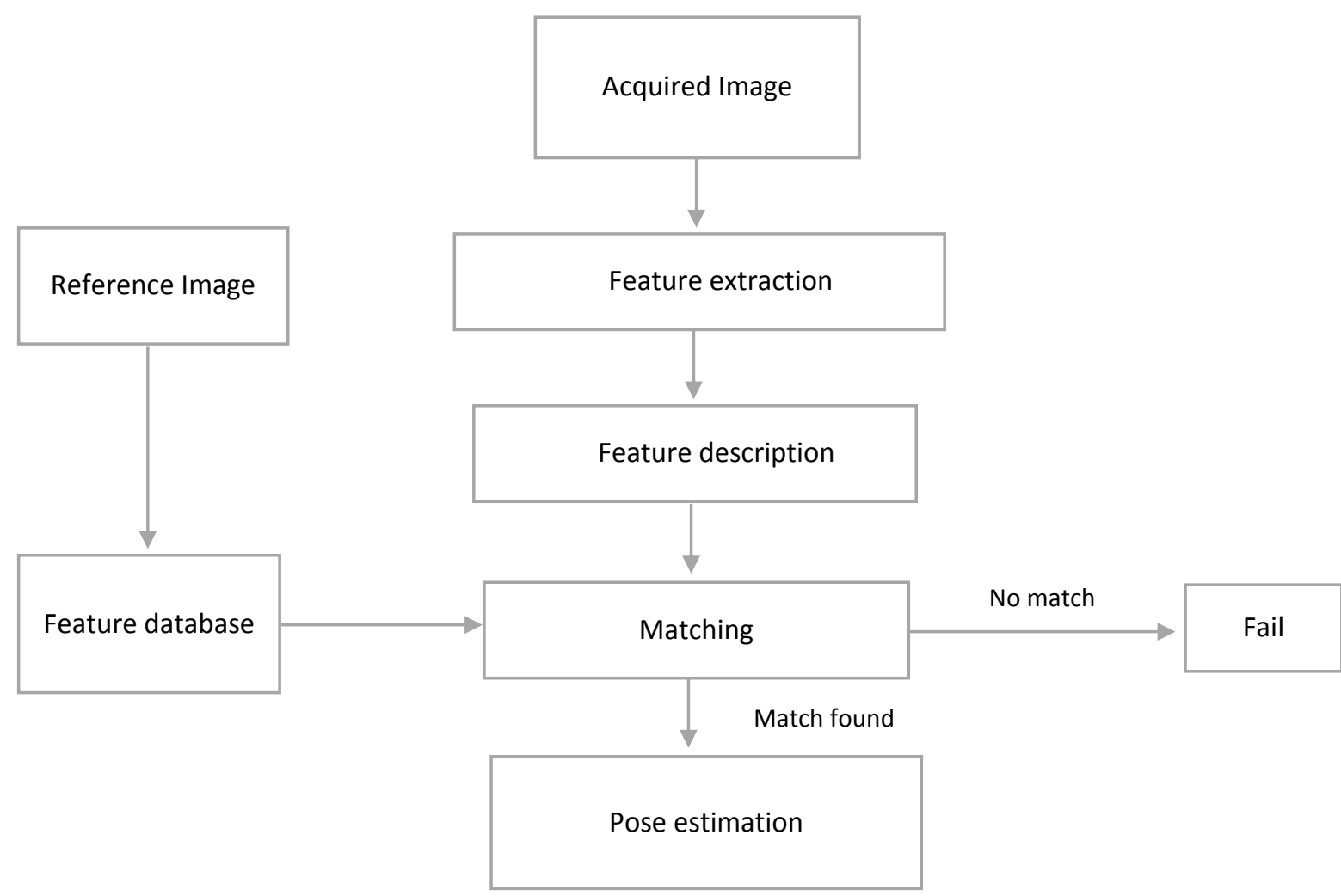

Figure 3.2. Overview of the natural feature tracking system.

\subsubsection{LIBRARIES}

In order to achieve the goal, the AR app will be used in situ hence it must work on mobile devices. One of the quickest and easiest ways to develop a cross-platform app is using Unity software game engine [65], although another alternative exists such as Unreal Engine [66] and CryENGINE [67]. Unity is one the most used game engines, allows the user to work easily with 2D images and 3D models, and is compatible with all mobile platforms.

AR libraries provide facilities for markers recognition and tracking, such as $2 \mathrm{D}$ features and even 3D objects. It is possible only with the library components to make a basic AR app. In recent years, the number of AR libraries has increased greatly thus, there is a wide range of them. For our approach, the library should meet the following requirements: 
- Open source or free license.

- NFT or image recognition.

- Plugin for Unity.

- Complete documentation.

Currently, there are a large number of AR libraries; ARTag [68], ArUco [69] and DroidAR [25] are examples of AR marker-based libraries; Metaio, Vuforia, Wikitude, D'Fusion, ARToolkit and ARmedia are studied in [39], but many libraries disappeared or became obsolete over time, such as Metaio that was acquired in 2015 by Apple. After analysing the current AR libraries, it can be stated that the most used libraries meeting our requirements nowadays are both Vuforia and ARToolKit.

\subsubsection{VUFORIA}

Vuforia is probably the most used AR platform. Currently, it is not free, but it has a free license for apps in development, thus all its facilities can be used and tested. Vuforia provides great recognition capabilities based on image recognition, such as Image Target by Vuforia. Vuforia detects natural features in an image and compares them with a database of known target resources. In order to create this database, Vuforia provides a web service (Vuforia Target Manager) to upload the Image Target for processing and evaluation. Image Target is evaluated with stars based on the features detected. Whenever the Image Target does not display stars is because there are not detected enough features for image tracking. Therefore, recognition and tracking are both impossible within this image. On the contrary, an Image Target evaluated with five stars means that markerless tracking is perfect for this image [70]. Furthermore, Vuforia can be used with Android, iOS, UWP mobile systems and digital eyewear; also it can also be built with Unity software.

\subsubsection{ARTOOLKIT}

Hirokazu Kato developed ARToolKit, the most popular library for AR app, in 1999. Two years later, the Human Interface Technology Laboratory (HIT Lab) of Washington University supported it. Next in 2015, it was acquired by DAQRI, who released all ARToolKit features, such as natural feature tracking libraries for iOS, Android and Unity versions. It is available free and open-source under an LGPL v. 3 License. Since then, ARToolKit is maintained by this company and they will soon release version 6 with a new feature [71]. Therefore, ARToolKit is currently a welldocumented open-source library where the code can be studied and modified.

ARToolKit includes NFT for image recognition, just like Vuforia; the first step is to generate an ARToolKit NFT dataset from the digital image, with the features detected. For this purpose, ARToolKit provides genTexData tool, which generates the necessary files for tracking. First, the source image is resampled at multiple resolutions, generating an image set (iset) file. Then, the detected features are saved in two files (.fset and .fset3): .fset contains the features used in continuous tracking, and .fset 3 contains the features used for identifying the pages and initialising the tracking [72].

ARToolkit provides a camera calibration service, a cloud-and-crowd-based solution for generating and downloading calibration parameters for different smartphones [73]. Nevertheless, in order to achieve accurate results, it is important to calibrate each camera 
correctly for each camera resolution. To carry out the camera calibration, ARToolkit provides an Android app on Google Play called ARToolKit Camera Calibrator. In this study, all three smartphones have been calibrated for image resolutions of 320x240 and $720 \times 480$ pixels.

\subsection{DESIGN AND IMPLEMENTATION}

The great challenge in AR apps is to recognise enough features in a real environment to determine the pose and orientation of the camera in real-time. Therefore, the tracking image should have a great number of edges and surface details. This is quite difficult in rock art motifs because rock art scenes are faint, poor in details and there is no colour contrast. Thus, to study this problem in-depth, some rock art scenes have been analysed in the Cova dels Cavalls (Figure 3.3), where the whole scene is in red and brownish colours.

In this study, ARToolKit and Vuforia libraries have been evaluated in order to know which is best to develop AR apps dealing with Levantine rock art motifs. Several experiments have been performed to analyse the user experience in both indoor and outdoor environments. Users are usually annoyed by apps that delay running too much (a few second holding in front of the motifs). That is why key factors have been selected for estimating the user's experience (vid. Section 3.3.2). For each factor, a different experimental setup has been designed. As stated before, these factors are evaluated in two scenarios, one indoor and another outdoor in order to cover a wide range of applications from the same smartphone app.

\subsubsection{CASE STUDY: COVA DELS CAVALLS}

The Cova dels Cavalls is located in Castellón (Spain), in the Valltorta ravine. It was one of the most important discoveries at the time because of the quantity and variety of its rupestrian manifestations. However, nowadays the paintings are faint, highly deteriorated and it is difficult to recognise them [74].

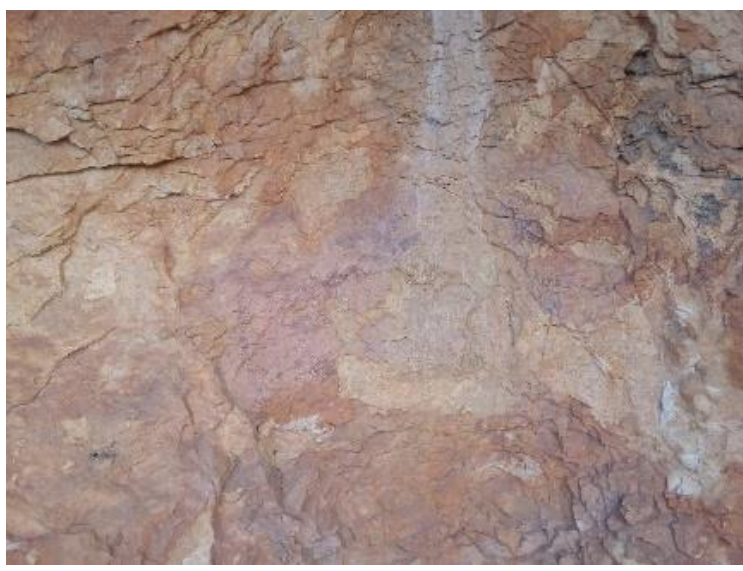

a

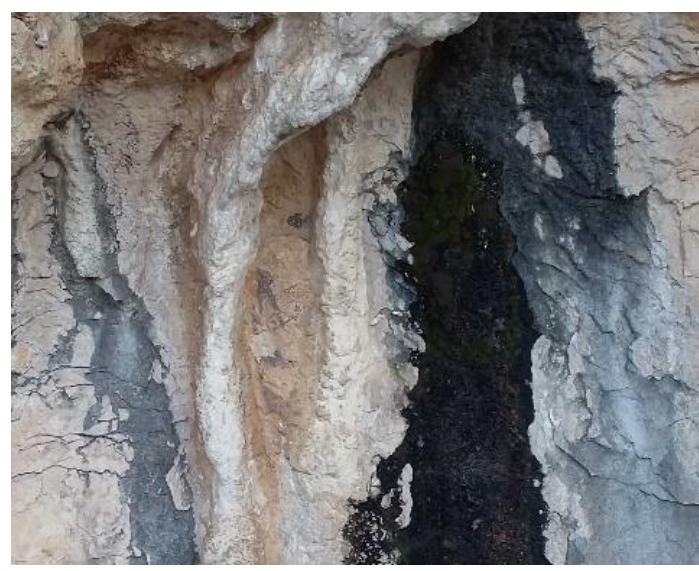

$b$

Figure 3.3. Cova dels Cavalls: a) Scene 1: Hunting scene. b) Scene 2: Overview of motifs found on Shelter 2. 


\subsubsection{APP REQUIREMENTS}

There are some indispensable requirements that the AR app must meet in order to achieve a proper user experience. The most important ones are summarised next:

- Keypoints identification in the rock art scenes.

- Positioning of the 2D image (virtual content) at the right target in the real world.

- Quick computation of the pose estimation (tracking process).

- Working in different lighting conditions

\subsubsection{EVALUATED FACTORS}

Taking into account the apps requirements, a list of factors have been evaluated using both libraries in different smartphones: 1) Samsung Galaxy 4; 2) Samsung A3; and 3) BQ Aquaris E4. The factors evaluated are described next.

\subsubsection{FEATURE DATABASE}

The image tracking will be possible if the reference image contains enough distinctive features. For this reason, the first step is the generation of the feature database with the keypoints extracted from the reference image. The number of keypoints generated will be evaluated to run the NFT.

\subsubsection{APP INITIALISATION TIME}

The time elapsed from pressing the icon on the screen until the app is ready to run depends on the app initialisation time and data loading. The AR initialisation takes a while; an AR app usually has heavy data files such as 3D models, 2D images and databases for tracking. Hence, the initialisation time can last longer depending on the number and type of data so this waiting time might confuse the user unless he/she is not alerted.

\subsubsection{TRACKING TIME}

The tracking time is the processing time required to calculate the camera pose and show the virtual information on the display. The processing amount of time depends on the type and number of descriptors used and can vary with the distance. Although we know that ARToolKit uses FREAK descriptor, it is not possible to know which descriptor Vuforia integrates because this library is not open source and this information is a kind of black box. Anyway, the tracking time will be measured using both libraries in order to know which is faster. This factor is evaluated indoor and outdoor. 


\subsubsection{OCCLUSION PERCENTAGE}

If the scene is not fully visible, the recognition may not work properly because the tracking system requires enough features to obtain the pose estimation. In a partially occluded scene, the tracking may be lost or the virtual image jittering may increase. The occlusion percentage is also tested with an image.

\subsubsection{LIGHTING CONDITIONS}

In real outdoor environments, lighting conditions cannot be controlled hence, according to the daytime and the weather conditions, the sun's angle can affect the visualisation and tracking. Images with different exposure time are printed to evaluate this factor.

\subsection{EXPERIMENTAL RESULTS}

\subsubsection{INDOOR AR APP DEALING WITH PRINTED COLOUR IMAGE OF A ROCK ART SCENE}

First, both libraries were assessed in the laboratory recreating similar scene content that a user would have found in a real environment. Thus, a photograph of a hunting scene of "La Cova dels Cavalls" had been printed in colour. It is worth noting that the original image had not enough contrast to highlight the paintings from the support rock (Figure 3.4a). Therefore, this input image was enhanced to emphasize paintings (Figure 3.4b). The printing area was $28 \times 19$ $\mathrm{cm}$ (Din A4 page size) and the tests were undertaken after focusing the smartphone's camera towards the photograph presented in Figure 3.4b.

Generally, the rock art paintings are heavily deteriorated hence its interpretation is difficult. In addition, the lighting effects can complicate the reading e.g. if there is direct sunlight. Thus, it is usually difficult to guess or infer what the drawn figure represents. The indoor AR app shows a simulation of the original state of the paintings in the smartphone camera view (Figure 3.5); the rightness of the simulation is not discussed here. It is displayed to clarify to citizens how it might seem in the past during the Neolithic period. With the developed AR app, visitors can quickly visualise and understand the rock art paintings, i.e. the scene with the motifs. 


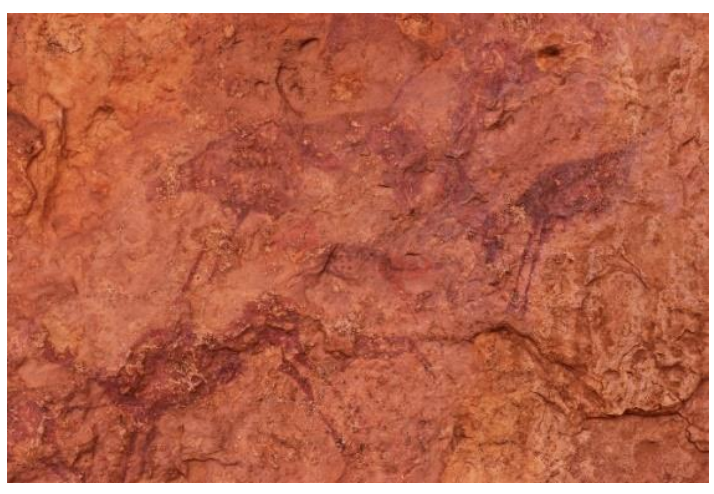

$a$

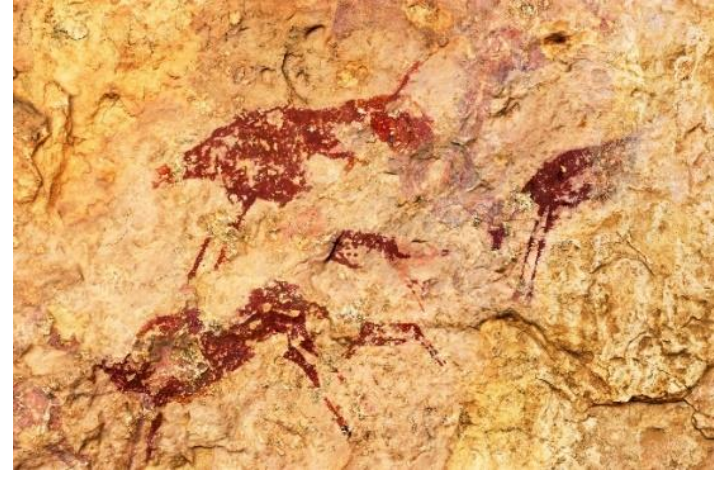

$b$

Figure 3.4. a) Input image was taken with a smartphone in Cova dels Cavalls. b) Enhanced image used to track the corresponding hunting scene.

\subsubsection{FEATURES DATABASE}

Both tested libraries provide an offline method to generate the database with the extracted keypoints.

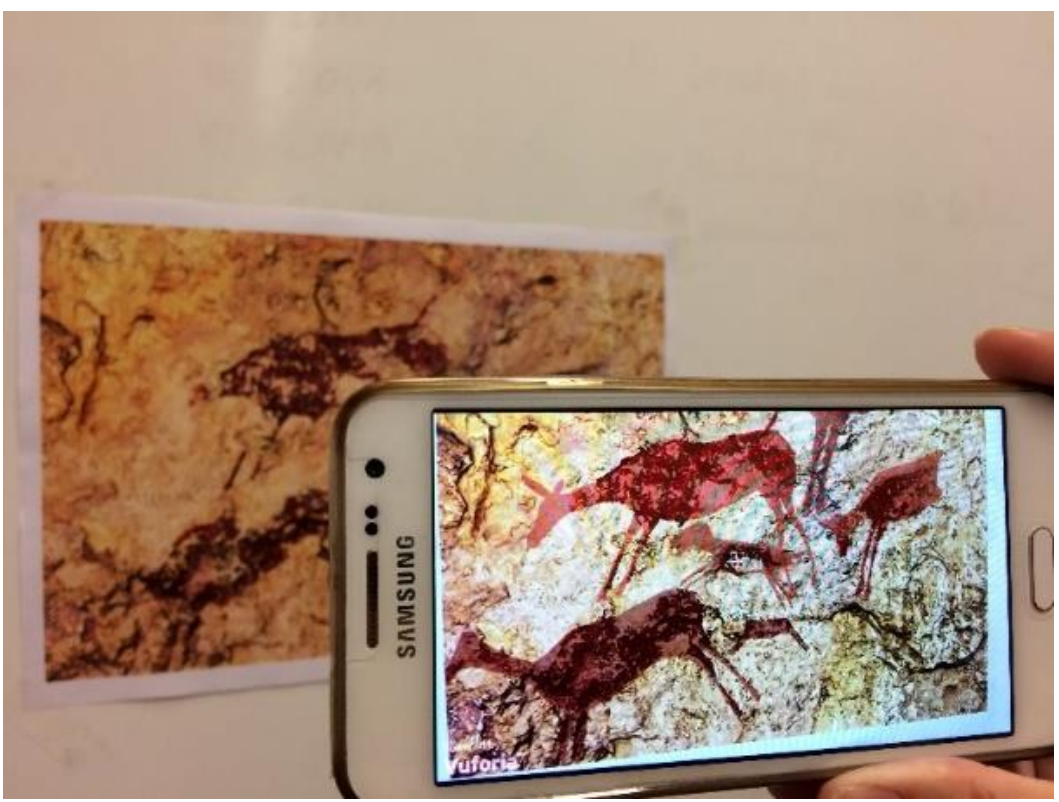

Figure 3.5. Indoor testing setup, using a smartphone in front of the printed image.

ARToolKit provides the genTexData program to generate the features data files. This program allows users to select the level of feature extraction for tracking and initialisation, being 0 the minimum level and 4 the maximum. This step determines the amount of extracted features. In this case, the maximum level was specified to achieve more tracking features owing 
to the fact that the study scene is far from ideal. Therefore, a great number of known features were obtained in the database; 9111 keypoints fset and 765 keypoints fset3.

On the other hand, with Vuforia Target Manager was generated the database for the tracking, and the image used was evaluated with five stars, which means that the features database contains a large number of keypoints (Figure 3.6).

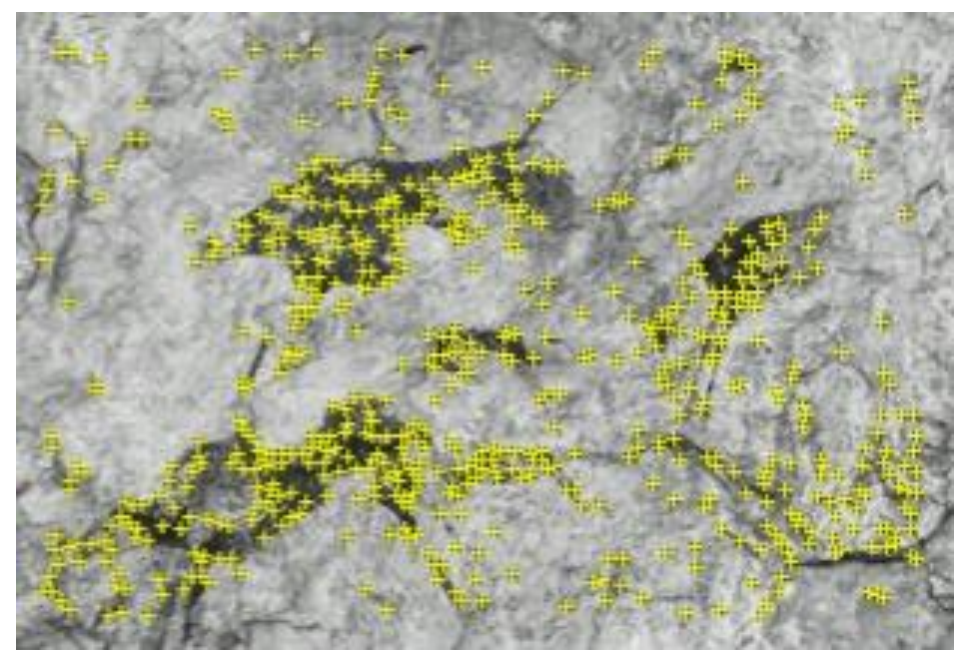

Figure 3.6. Features detected in the database by Vuforia.

\subsubsection{APP INITIALISATION TIME}

Trying to determine how long the user had to wait to use the app, the initialisation time was measured (Figure 3.7). The initialisation time takes longer with ARToolKit than with Vuforia. Regarding the smartphone used, the fastest smartphone was the Samsung A3, and the slowest the BQ Aquaris E4.

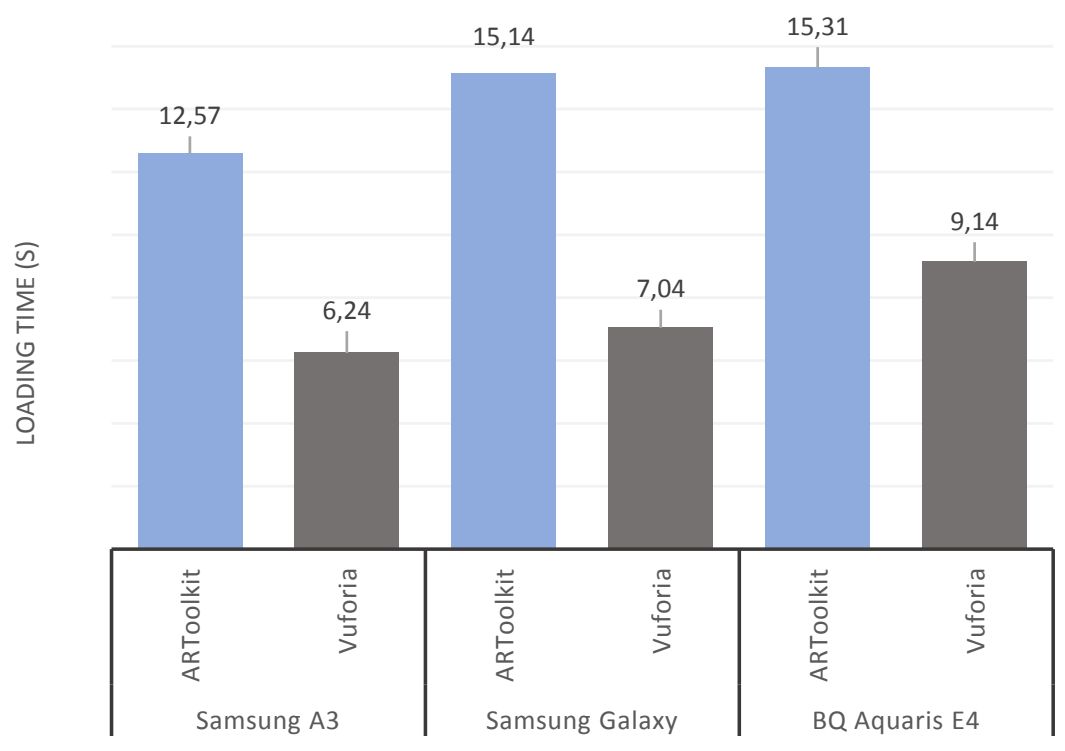

Figure 3.7. Time taken to run the AR app on the three smartphones. 


\subsubsection{TRACKING TIME}

Tracking time was measured in each of the three smartphones used in this study at different distances of the image. The minimum distance employed to begin the test was $20 \mathrm{~cm}$ and then the tracking time was measured every $10 \mathrm{~cm}$ up to $100 \mathrm{~cm}$.

In all Samsung A3 cases, the time measured was less than $5 \mathrm{~s}$ with the ARToolKit library, with the exception of distances equal to or longer than $90 \mathrm{~cm}$ (Figure 3.8). Therefore, that distance was considered the maximum distance that the app supports for this smartphone. From $90 \mathrm{~cm}$, the app was not running, that is, stops loading the virtual information. It is also interesting to highlight that the lowest loading time was obtained at $80 \mathrm{~cm}$.

Concerning the Samsung Galaxy, generally lower ARToolKit loading times are obtained than with the Samsung $A 3$ times (Figure 3.8). In most cases, the times are less than $2 \mathrm{~s}$ and the lowest time $(1.20 \mathrm{~s})$ has also been obtained at $60 \mathrm{~cm}$. On shorter distances, loading times are higher even though they remain below $4 \mathrm{~s}$. On the other hand, at distances longer than $95 \mathrm{~cm}$, the app stops loading the virtual information.

For all experiments performed with the BQ Aquaris E4 (Figure 3.8.), loading time with ARToolKit is less than $3 \mathrm{~s}$; the lowest time is $1.20 \mathrm{~s}$ and again at a distance of $80 \mathrm{~cm}$. Furthermore, $95 \mathrm{~cm}$ is considered the maximum distance that the app supports in this smartphone.

On the other hand, the loading time achieved with Vuforia library is kept constant ( $0.35 \mathrm{~s})$ and minimum independently of the smartphone used (Figure 3.8, solid line). It can be reported that with Vuforia the tracking computation is faster, almost instantaneous.

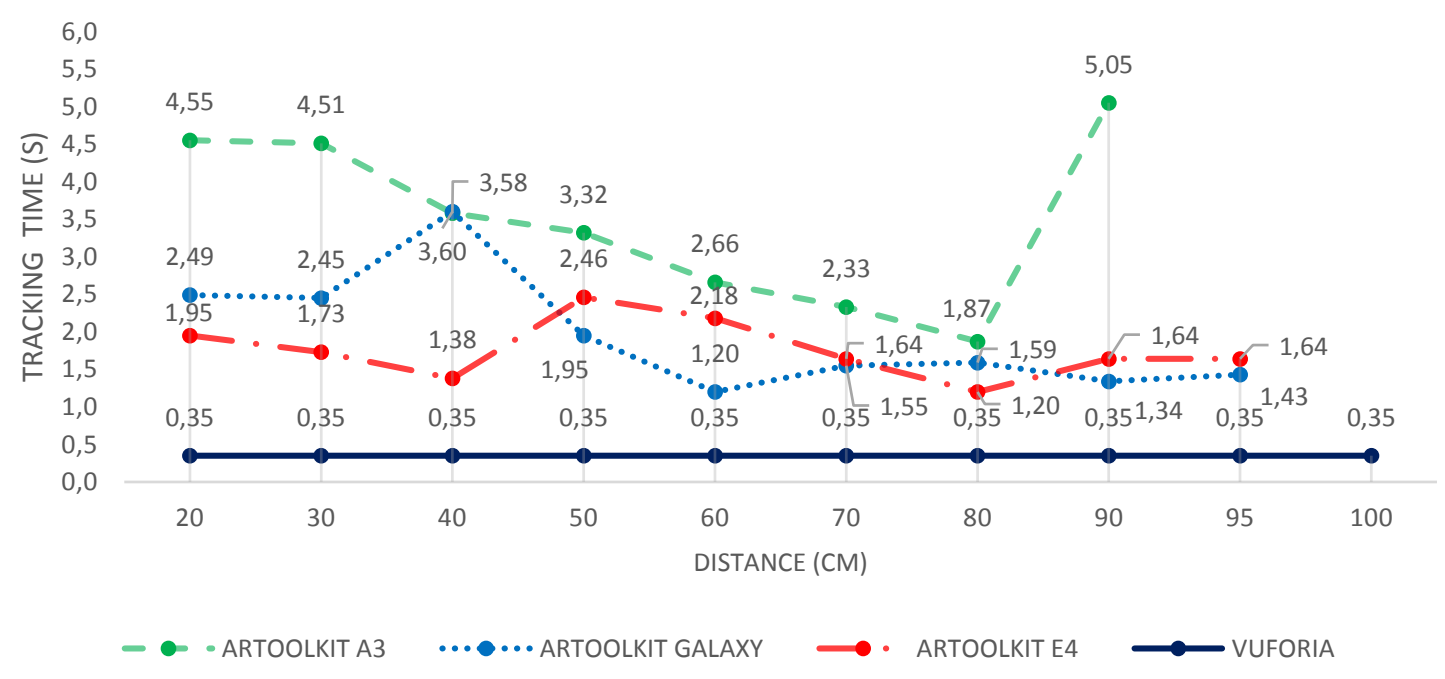

Figure 3.8. Samsung A3, Samsung Galaxy and Aquaris E4 virtual information loading times at different distances; no differences were found among smartphones with Vuforia. 


\subsubsection{OCCLUSION PERCENTAGE}

Some parts of the image are deliberately hidden, in a way that a percentage of the image is visible and another part is completely occluded. Three occlusion percentages were applied: $25 \%, 50 \%$ and $75 \%$.

With both libraries, the tracking time does not vary when a part of the image is hidden (Figure 3.9). Thus, in this experimental case, the occlusion percentage does not affect the virtual content loading time.

Moreover, all the loading times are again minimum and flat with Vuforia library (Figure 3.9) on Samsung Galaxy A3, as well as less than $1 \mathrm{~s}$ (in particular $0.32 \mathrm{~s}$ ).

\subsubsection{LIGHTING CONDITIONS}

In order to test changes in the ambient illumination, a simulation was also prepared in the laboratory. Thus, the changes that the paints suffer in their real environment due to changes in lighting have been simulated varying the exposure time. For this purpose, the exposure time of the input image (in RAW mode) is intentionally modified with Adobe Photoshop software. Once saved the image with each varying exposure, the images are printed in colour.

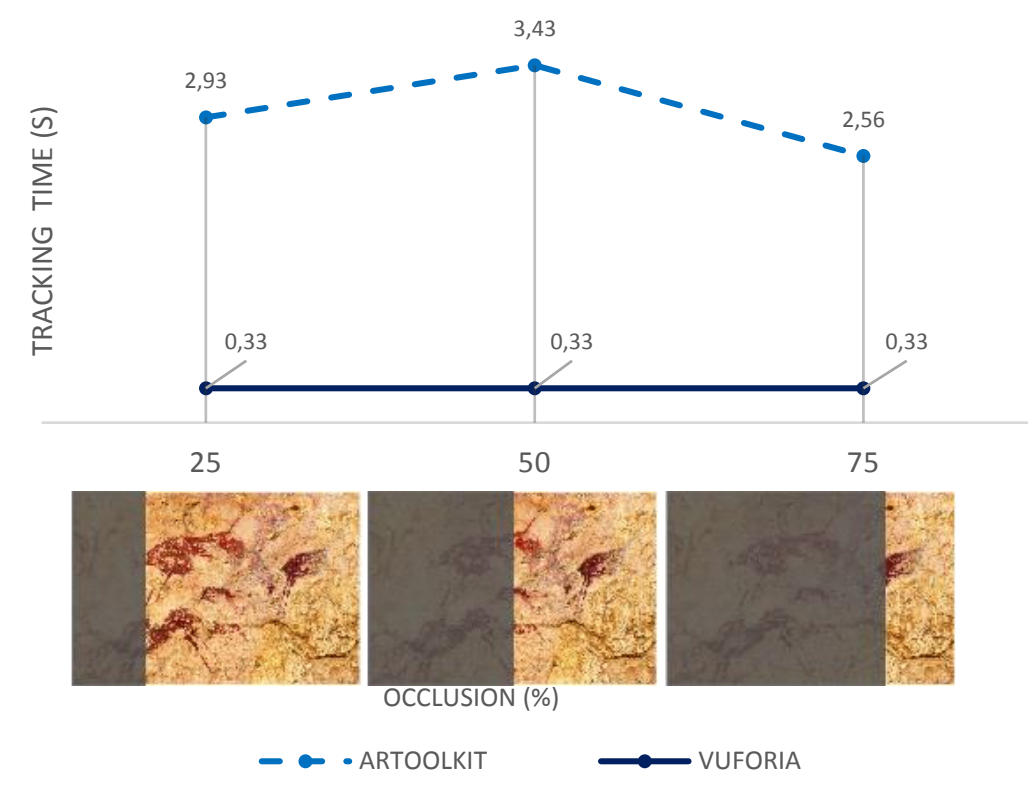

Figure 3.9. Samsung Galaxy A3 loading times with different occlusion percentages: left $25 \%$, centre $50 \%$ and right $75 \%$.

Figure 3.10 shows the exposure values used and the tracking times obtained for each image exposure. Using ARToolKit, the tracking times increases a lot as the exposure time is balanced away from the original (ideal) exposure. However, using Vuforia, tracking times were kept minimum and flat $(0.33 \mathrm{~s})$ in all cases except the first one (extremely under exposure image). 


\subsection{REAL ENVIRONMENT RESULTS}

Both libraries are tested on-site under real environment conditions (Figure 3.11) where there are problems such as surface roughness, lighting variations due to sun or even a wide range of camera-object distances. In addition, the real environment cannot be considered as a flat surface whether the whole cave is considered, although the rock art paintings used in this study belong to a panel, as a small area (within a shelter) they can be assumed as laying on a 2D plane. Nevertheless, this might cause failures during the tracking and this feature is exactly what it is going to be tested next.

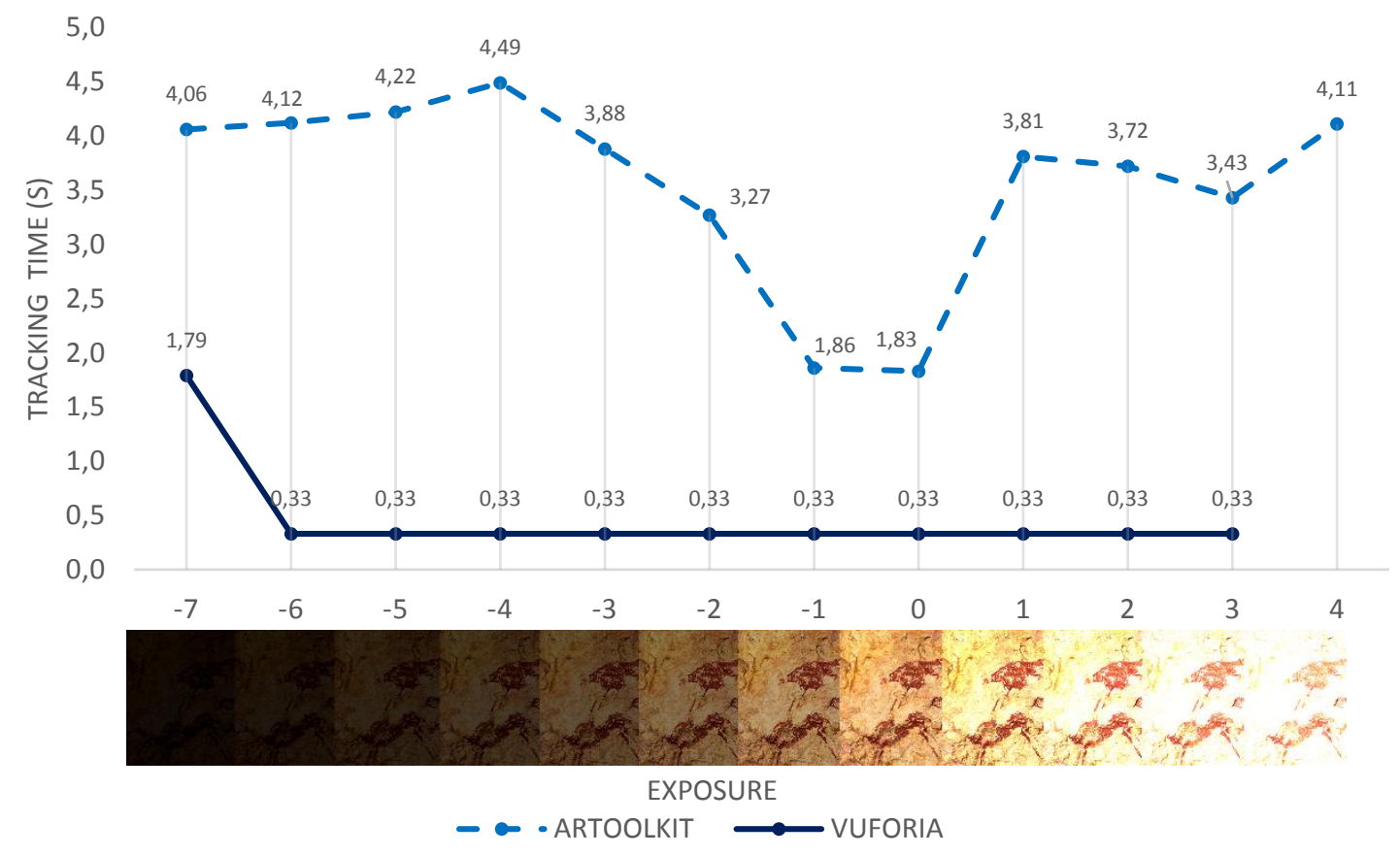

Figure 3.10 Galaxy A3 loading times with different exposure times. 


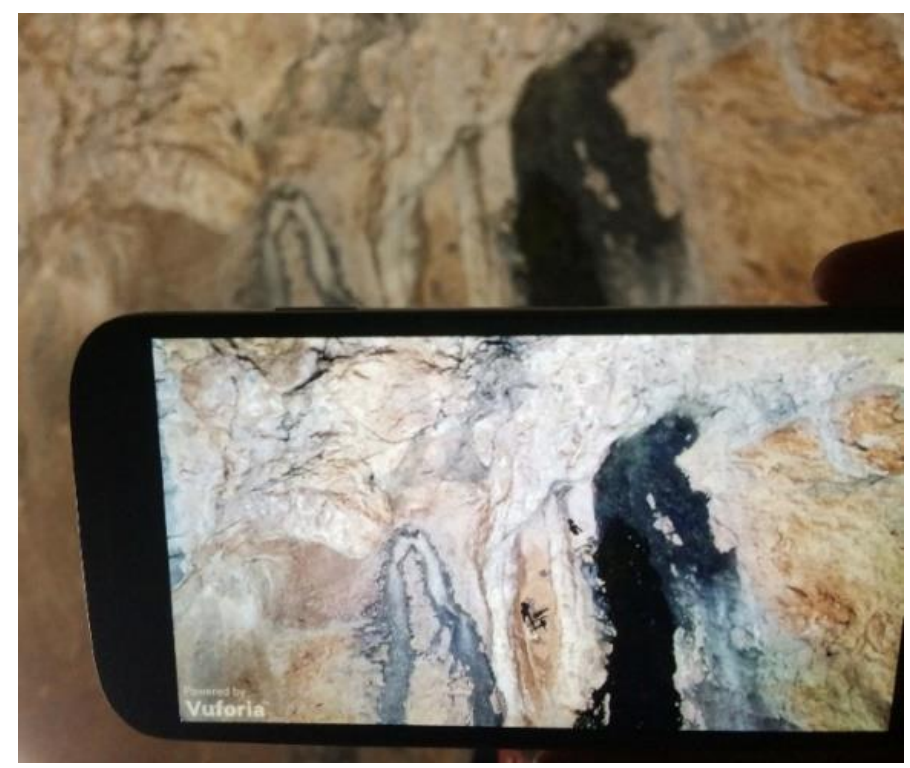

Figure 3.11 Typical scenario in situ at the Cova dels Cavalls: camera in front of one of the shelters.

\subsubsection{FEATURES DATABASE}

Different images were taken in the Cova dels Cavalls to test both libraries in an outdoor environment. These images were analysed with the tool Vuforia Target Manager (Figure 3.12) and ARtoolkit genTexData to extract the features and generate the database. While ARToolKit tool extracted a lot of features in each image, Vuforia only extracted enough features for one single image (Figure 3.12b), the other images were not valid for developing an AR rock art app with Vuforia library (Figure 3.12a and Figure 3.12c).

\subsubsection{TRACKING TIME}

Tracking time is measured in situ, consequently, five positions have been established at different distances from the scene. The five established positions are shown in Figure 3.13 and are summarised next:

- Position 1: At a distance of $50 \mathrm{~cm}$ from the scene. The visitors cannot be placed; it is restricted to technicians and museum staff members (Figure 3.13).

- Position 2: At a distance of $100 \mathrm{~cm}$ from the scene. Visitors are not authorised to be in this position but they can reach this position if they lean forward and extend their arms from the walkway (Figure 3.13).

- Position 3: At a distance of $150 \mathrm{~cm}$ from the scene. This position corresponds to the end of the walkway (Figure 3.13).

- Position 4: At a distance of $200 \mathrm{~cm}$ from the scene. Position in the centre of the walkway (Figure 3.13).

- Position 5: At a distance of $250 \mathrm{~cm}$ from the scene. Position at the outermost part of the walkway, next to the railing (Figure 3.13). 


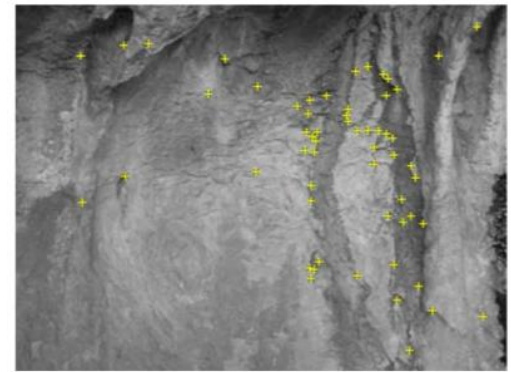

a

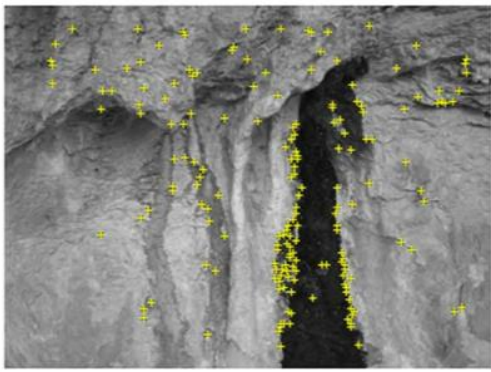

$b$

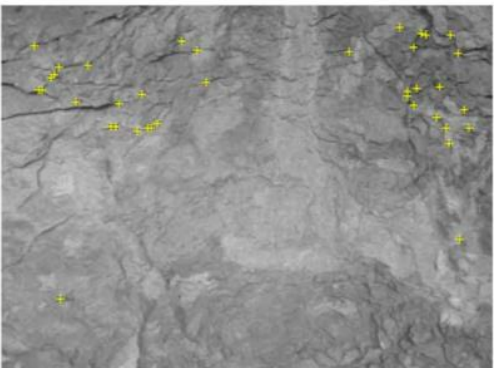

C

Figure 3.12 Example of features detected with Vuforia in different scenes of the Cova dels Cavalls: a) Image target scored with 0 stars; $b$ ) Image target scored with 4 stars; $c$ ) Image target scored with 0 stars.

The minimum detectable distance for tracking in ARToolKit was $50 \mathrm{~cm}$ (Position 1); in Vuforia, $100 \mathrm{~cm}$ (Position 2). However, Positions 1 and 2 were discarded because these positions are not accessible for visitors. Regarding tracking times measured at Positions 3, 4 and 5, a difference is observed between the two libraries used (Figure 3.14). Vuforia was always faster than ARToolKit and stable, $0.2 \mathrm{~s}$. The tracking time was nearly immediate in any of the smartphones employed.

The tracking times measured with ARToolKit library were around $2 \mathrm{~s}$ in almost all positions, although there were some differences depending on the smartphone used. In this case, the tracking times obtained range between 1.5 and $2.5 \mathrm{~s}$ (Figure 3.14).

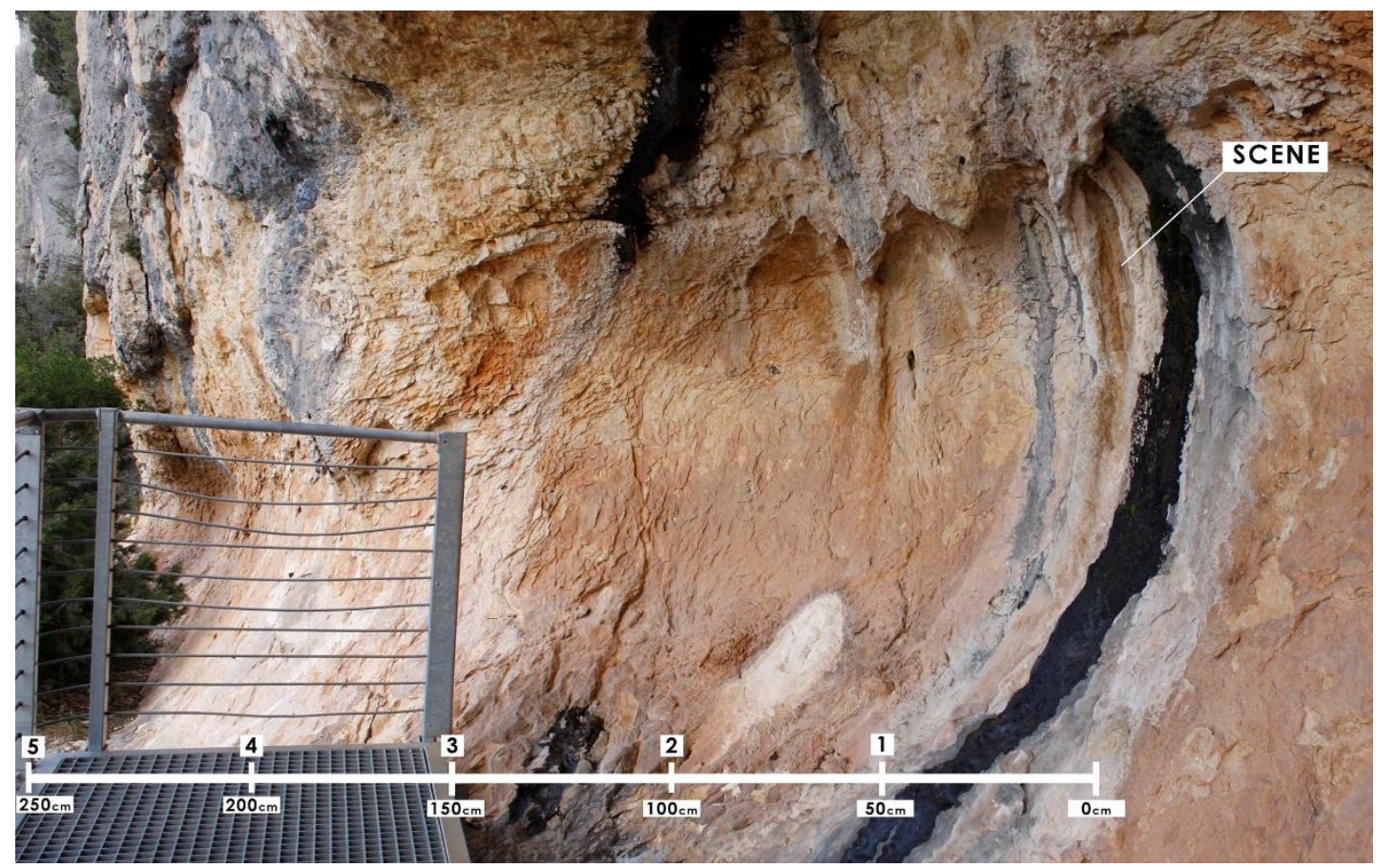

Figure 3.13 Camera-scene distances on site used to run the AR app. 


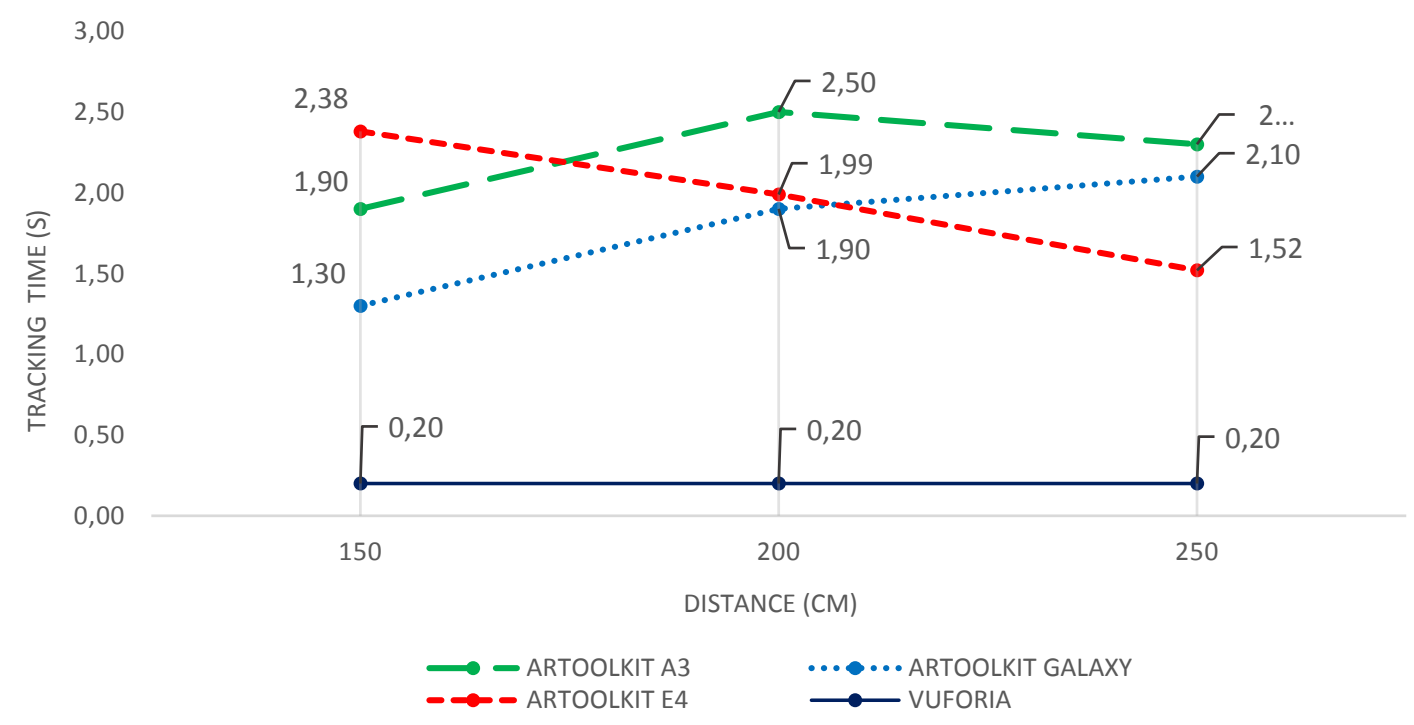

Figure 3.14 Tracking times obtained with the three smartphones at different distances; no differences were found among smartphones with Vuforia.

\subsection{DISCUSSION}

This chapter evaluates a list of factors that affect the user experience in an AR app for disseminating rock art paintings. While other studies are focused on marker-based tracking assessment (listed in Section 3.1), the present study is aimed at environments where the use of markers is not allowed at all.

Some studies analyse the effect of marker-camera distances. Dos Santos et al. [49] analysed the distance between marker and camera and conclude that the minimum and maximum distance reached with Vuforia is better than ARToolKit. In the case of image tracking, there are not relevant differences between the evaluated libraries; the maximum camera-scene distance is shorter than $10 \mathrm{~cm}$. Rabbi et al. [50] proved that the error increases as marker distance is longer, causing marker tracking failure. In the image tracking studied herein, the tracking time remains more or less constant with increasing distance, thus the user can be placed at different distances from the paintings.

The tracking time with Vuforia was minimum, less than $1 / 2 \mathrm{~s}$, regardless of the camerascene distance. ARToolKit required more time to obtain the camera pose and load virtual content, around 2 or $3 \mathrm{~s}$, depending on the smartphone used. These longer times may be owing to the great number of features detected by ARToolKit. The feature database was calculated using the highest accuracy, obtaining the maximum number of possible features. Hence, the ARToolKit database was definitely much larger than Vuforia's. This meant that the app had to recognise more points in real-time to calculate the camera pose, increasing the tracking time. Surely with fewer points (smaller datasets), ARToolKit would work faster. In addition, the app initialisation time in ARToolKit lasted twice as Vuforia, about $15 \mathrm{~s}$ to be ready to be used.

Some authors studied common problems in marker-based trackings, such as marker occlusions $[75,76]$. As demonstrated in this study, the image occlusion does not affect the 
markerless tracking; tracking time remains unchanged with different occlusion percentages. This result is achieved because markerless tracking makes use of a great number of features welldistributed throughout the image. Nevertheless, this statement may vary depending on the number of features covered in the targeting area.

On the other hand, extreme changes in lighting conditions can affect the detection of features. According to Khan et al. [48], higher light intensity in a shadow environment provided faster marker detection while direct sunlight over yielded greater errors. This also happened in our study, where the experiments demonstrated that the ARToolKit's tracking time increases when the image exposure changes. However, different exposures did not affect Vuforia's tracking system.

The tracking system requires a previous image feature extraction to generate the features database. ARToolKit detected a large number of features in all the images that were tested. Thus, the scene identification and tracking were possible with both scenarios, indoor using a printed colour image and outdoor on-site in the real shelter. Instead, Vuforia did not always detect enough features. The printed colour images presented in Figure 3.4a for the indoor assessment had to be enhanced to allow the software to detect enough features and thus to make possible scene recognition and tracking (Figure 3.4b). Others scenes were tested in Cova dels Cavalls (Figure 3.12), but Vuforia only worked in the scene studied. Therefore, it can be stated that it is not recommended to develop with Vuforia an AR rock art app containing all the paintings presented in Cova dels Cavalls as a case study. However, ARToolKit was ready to find and match many features in all scenes.

The proper positioning of a $2 \mathrm{D}$ image into the $3 \mathrm{D}$ world depends on the camera calibration. If the intrinsic and extrinsic camera parameters were unknown, virtual content would not be placed in the exact 3D position. ARToolkit provides a server with calibration parameters for some smartphones, but it is advisable to calibrate the camera to achieve better results. In the cases analysed, the virtual content was not correctly placed on top of the screen without camera calibration, hence the three smartphones had to be calibrated. Conversely, the virtual content was accurately positioned without prior calibration using Vuforia library.

On the other hand, ARToolKit library did not include camera autofocus, hence the image was usually blurred. In addition, without autofocus, image recognition did not work at the medium range. This was an ARToolKit fault, but it can be solved by modifying the camera script.

Regarding image flickering, after testing both libraries, flickering and blurring of the virtual image were practically non-existent on Vuforia. However, ARToolKit results were a bit worse.

Finally, ARToolKit is one of the most important open-source AR library available nowadays; this is a great advantage because the whole code is completely open. Thus, the programmer can modify and adapt it to his/her needs. In ARToolKit, for instance, the programmer is free to modify the tracking algorithm. In addition, currently, new improvements will be hopefully released in version 6. However, this freedom is not expected in Vuforia, where it is not possible to access the AR code and modify it.

Overall, Table 3-1 summarises the main results achieved after this user and provider (developer) experience assessing our developed AR app for disseminating rock art with both libraries, ARToolkit and Vuforia. 


\subsection{CONCLUSION}

In this chapter, a comparative study of ARToolKit and Vuforia libraries applied to the recognition of natural features in rock art scenarios has been presented. Several experiments have been performed in both indoor and outdoor environments to analyse the factors that affect the user experience. Thus, it is easier to decide from a provider (developer) point of view which of the two libraries is the best to continue developing AR apps to disseminate rock art paintings.

Taking into account the assessment results summarised in Table 3-1, Vuforia provided a better user experience and developers will also be able to design AR apps more quickly. However, Vuforia's feature extraction did not work well in images containing poor details, as is the case with rock art paintings. For complex outdoor environments such as the ones presented in prehistoric rock art sites with paintings, the AR apps cannot be developed with Vuforia, however, ARToolKit library recognised many features in each of the Cova dels Cavalls scenes, hence it is recommended to apply ARToolKit to develop AR apps in outdoor rock art environments. In addition, as ARToolKit is an open-source library, there is no limitation (far beyond its maintenance in the future) because the source code can be modified. Moreover, its documentation is comprehensive and a good user forum exists at present.

\begin{tabular}{ccc} 
Features & Vuforia & ARToolKit \\
\hline App initialisation time & Around $7.5 \mathrm{~s}$ & Around $14.5 \mathrm{~s}$ \\
Image occlusion & Does not affect & Does not affect \\
Tracking time & $0.35 \mathrm{~s}$ & $4.5 \mathrm{~s}-1.2 \mathrm{~s}$ \\
Lighting conditions & Does not affect & $\begin{array}{c}\text { Tracking time increases } \\
\text { with the exposure }\end{array}$ \\
$\begin{array}{c}\text { Poor detail reference image } \\
\text { (feature database) }\end{array}$ & Low number of keypoints \\
$\begin{array}{c}\text { Required camera calibration } \\
\text { Camera autofocus }\end{array}$ & No & High number of keypoints \\
Flickering and blurring & Yes & No \\
Open source / the code can be \\
modified
\end{tabular}

Table 3-1 Main results from the ARToolkit and Vuforia comparison.

In the next chapters, an AR app related to Levantine prehistoric rock art motifs using the ARToolKit library will be developed. To reduce the unfavourable tracking time on some devices using ARToolKit, additional research will be devoted to determining the right number of features (threshold) able to guarantee a correct pose estimation and subsequent image reprojection. 


\section{4}

\section{Design and \\ evaluation of an AR \\ rock art app}

This chapter is based on the publication entitled "Design and implementation of an augmented reality application for rock art visualization in Cova dels Cavalls (Spain)". After concluding in the previous chapter that ARtoolkit is the library that best suits the requirements of a rock art shelter, this chapter focuses on the complete development of the AR application.

Prehistoric rock art paintings, specifically rock-shelters exposed to environmental and anthropogenic factors, are usually faint and severely damaged, being them difficult to identify and understand by visitors. AR supplements reality with virtual information superimposed onto the real world. This sensor-based technology in smartphones/tablets can improve the experience of the painting displaying the 2D digital tracings overlapped onto the real scene (rock with faint paintings). This chapter presents an AR application developed in Cova dels Cavalls that shows a recreation of a possible original composition full of motifs with descriptive information to improve current guided tour user experiences. This case study aims to evaluate the rock art $A R$ app targeting non-expert visitors as a means of improving rock art knowledge and sensibility of a fragile archaeological UNESCO Work Heritage site. To achieve this, a variety of participants with different backgrounds and interests tested the AR app on-site and answered a complete questionnaire about the use of AR mobile apps. 
Overall, the results showed great acceptance of this AR app, mainly because in addition to adding new information interactively, helps to identify the rock art motifs, as well as to recognise them quickly, improving their understanding.

\subsection{INTRODUCTION}

Tangible cultural heritage such as historical buildings, archaeological sites and artefacts is a fundamental expression of the richness and diversity of a group or society from the past. Wars, natural disasters, anthropogenic factors seriously endanger heritage, hence many technicians, curators and researchers are focused on its preservation, documentation and dissemination. Over the last two decades, technological advances have significantly improved the process of documentation and dissemination of cultural heritage, obtaining accurate 3D models in a short time and their dissemination through different forms of digital deliverables.

The advent of both image-based technology (photogrammetry) and range-based technology such as terrestrial laser scanning (TLS) meant a radical change in 3D documentation. Both techniques provide dense point clouds through automatic processing. TLS has been used in many cultural heritage projects in order to obtain accurate documentation of complex monuments or sites [77-79]. However, this technique requires expensive equipment and a long time to process data. Unlike TLS, photogrammetry provides a low-cost method to produce highquality $3 \mathrm{D}$ models $[80,81]$, although the final quality is not always guaranteed (depends on multiple parameters such as a number of images, image network, texture...) and must be validated by the user. The 3D models obtained through these techniques can assist in the conservation, preservation, and documentation, as well as dissemination for both scholars (experts) and the general public (non-experts).

Next to the development of data acquisition methodologies with low and high-end imaging and ranging sensors, new technologies and advances in 3D virtual reconstructions, semiimmersive environments, serious games [82] or AR [83] have offered new ways of performance. These new approaches are being widely applied in the cultural heritage field, improving user experience and serving as a tool to show how heritage was in the past. There are numerous examples of 3D virtual reconstructions of archaeological sites [84-86] and monuments [87]. Furthermore, in some cases, the 3D reconstruction provides the basis for the development of virtual reality apps $[21,88]$ which allow users to plan, visit, analyse and experience an archaeological park [89], even know how a lost site was [90] through immersive visualisation systems. Other examples are focused on teaching cultural heritage with serious games [91,92] and semi-immersive environments [93] due to fact that students are more eager to computerbased learning, although they may not be exhaustive enough.

With the smartphones evolution, AR apps have increased a lot in the cultural heritage field. Some researchers have implemented this kind of apps in museums [94], outdoor environments [95] or archaeological sites to understand the past [96]. Unlike virtual reality, where a world completely immersive is created by a computer, AR allows the user to combine information from the real world with virtual information in real-time; thus the user perceives both realities, virtual and real simultaneously [38]. This technology is really intuitive and is very useful for visualising reconstructions of lost sites in situ [17]. Last trends in AR applications integrate information on 
the ground and underground combining terrestrial laser scanning 3D models and ground penetrating radar (GPR) to identify buried structures on-site [97].

AR technology offers many advantages in cultural heritage dissemination, helping specialists to preserve history, improving visitor satisfaction as well as attracting new visitors [98], and it has also a positive impact on the students' motivation to learn [99]. For all these reasons, the proposal of this chapter is to disseminate the rock art paintings through this visualisation technology.

Levantine rock art is found in the Mediterranean side of the Iberian Peninsula and is usually located in open-air sites exposed to external agents (both natural and human) that are damaging the paintings. Over the years, rock art paintings are fainting and in some cases, part or the whole motifs have disappeared; hence its interpretation is actually very difficult. Therefore, swift action in terms of documentation, preservation and dissemination is crucial. Furthermore, Levantine rock art was declared World Heritage by UNESCO in 1998; this fact meant an increase in responsibilities and obligations towards the preservation and dissemination of this cultural heritage [74]. Much progress has been made in the rock art documentation [46,47,100-103], but dissemination must be part of the whole process as well [104] to achieve attracting more visitors and make them more aware of the historical background. In this regard, AR apps can help to promote Levantine art in an innovative way. Moreover, due to the poor conservation of the paintings, AR can help to identify better the archaeological motifs, showing on the smartphone display the real location of the paintings on site. The e-ART project arose in 2015 [105] in Spain with the same objective, although at present it is not available for downloading, as well as the MARCH project [106], whose AR app based on marker tracking that allowed users to superimpose the expert's drawings on the prehistoric cave images. Despite the limited examples of AR apps applied to this field, the number of AR apps in cultural heritage has grown significantly in recent years, as pointed out by [107]

The present study uses the case study of the Cova dels Cavalls that houses many motifs heavily deteriorated or, as a consequence of the calcite that covers them, are difficult to see. Due to these facts, the identification of the motifs is very difficult thus, visitors can neither fully enjoy the visit to this archaeological site nor understand the motifs represented. Therefore, the $A R$ app development aims to improve the rock art visualization on-site through different information layers overlapping the real scene. Finally, in order to evaluate the AR app as a dissemination method, a mixed group of people tested the AR app on-site and answered a complete questionnaire.

\subsection{MOBILE AR TECHNOLOGY}

$A R$ is a visualisation technology that supplements reality with virtual information superimposed on the real world [38]. Thus, the real world is enhanced with all kinds of virtual content such as 3D models, 2D images or text information, which are placed in their real position in real-time and are displayed through the device display. The whole AR visualisation process can be divided into different steps: image acquisition, calibration, tracking, registration and display as is described in [83].

The main strength of an AR app is the ability to visualise the virtual content aligned with the real object. This is achieved through tracking methods, which determine the position and orientation of the camera relative to the real-world coordinate system [53]. Whenever the user 
moves the camera, the tracking method recalculates the new pose in real-time to adapt the projected $2 \mathrm{D}$ image to the new camera view.

Nowadays, vision-based tracking is a method widely used to calculate camera pose from the data received by the camera view. There are different solutions to solve the camera pose estimation $[59,60,108]$, depending on the available data, vision-based tracking can be classified in marker-based tracking and markerless tracking [55].

Marker-based tracking relies on markers; images or patterns easily detectable in a scene. Through image processing, pattern recognition and computer vision techniques, the marker is detected and the camera pose is calculated [109]. The use of markers is not always possible because there are places that cannot be altered with any image or marker, thus several markerless approaches emerged. These approaches can be divided into two groups: featurebased tracking, which only uses natural features easily detectable in the scene such as edges or corners; and model-based tracking, which uses a 3D model.

The AR application developed in this study implements the feature-based tracking approach. This method requires a database of previously extracted features of an image and then, with the set of correspondences between database features and their homologous features obtained by the camera and process in run-time, the camera pose is obtained and the virtual content is projected.

\subsection{COVA DELS CAVALLS}

This study uses the Cova dels Cavalls as a case study because it is in an accessible location, close to the Valltorta museum, and is one of the most important Levantine rock art sites [74].

The Cova dels Cavalls rock shelter is located on the Valltorta Ravine, in Tirig, Castellón Province (Spain) (Figure 1a). Since its discovery in 1917, the Cova dels Cavalls has become one of the best-known depictions of universal rock art. Moreover, it was one of the rock art sets where the Levantine Art knowledge began [74]. This shelter highlights due to the quantity and variety of its rock art depictions with some Schematic art and more abundant Levantine figures (http://www.prehistour.eu/carp-guide/valtorta--gasulla).

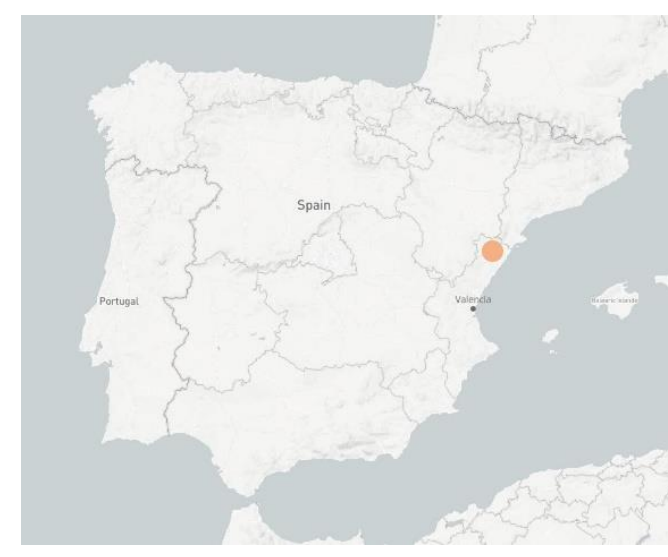

a

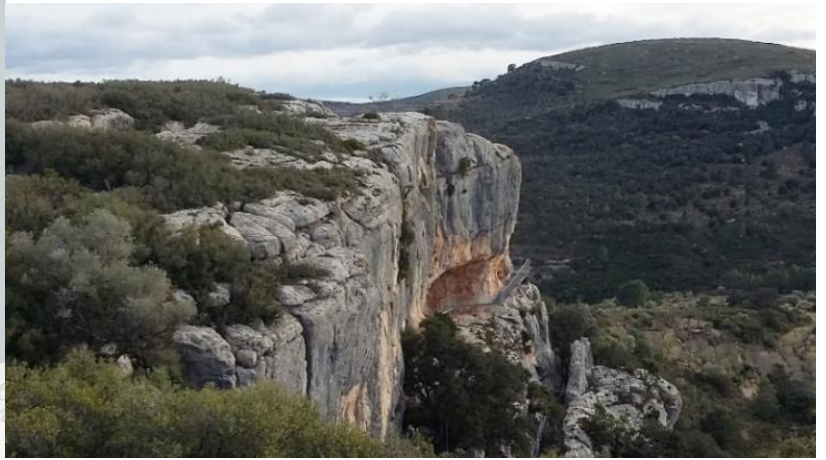

b

Figure 4.1 Cova dels Cavalls: a) Geographic location in Tirig (Castellón, Valencian Community, Spain). b) View of the environment in a cliff on the east bank of the Valltorta Ravine. 
In 1994, the Valltorta museum was created to improve the conservation and dissemination of this and other rock art sites of the Valencian Community, recognised by UNESCO as World Heritage. The museum was located in the Cultural Park of Valltorta-Gasulla (Tirig, Castellón) and it offers regular guided tours to the protected Cova dels Cavalls (Figure 4.1b) as well as other rock art paintings in the area.

The research presented herein is focused on the famous hunting scene of Cova dels Cavalls where an archers group faces a herd of deer (Figure 4.2a); in 1998 this rock-shelter was conserved by art restorers. This scene is one of the graphic references used most in Prehistory hunting illustrations [74], but its interpretation is difficult for the inexperienced public (Figure $4.2 b)$.

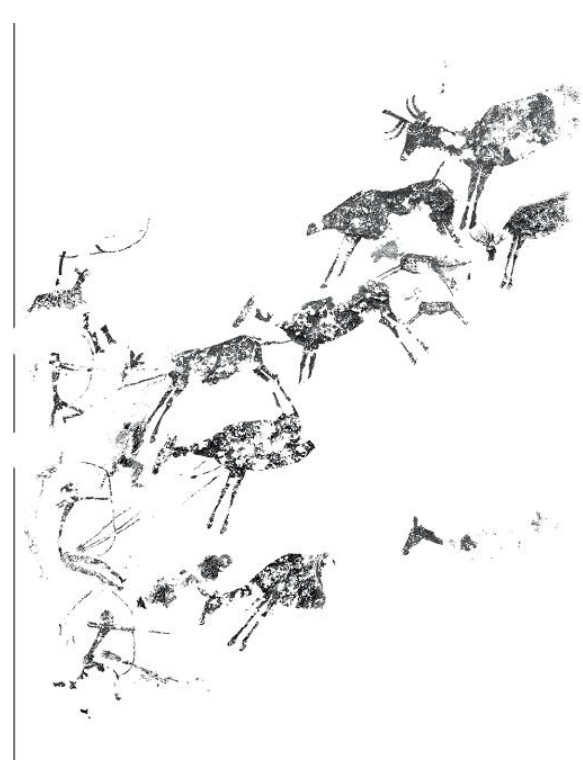

a

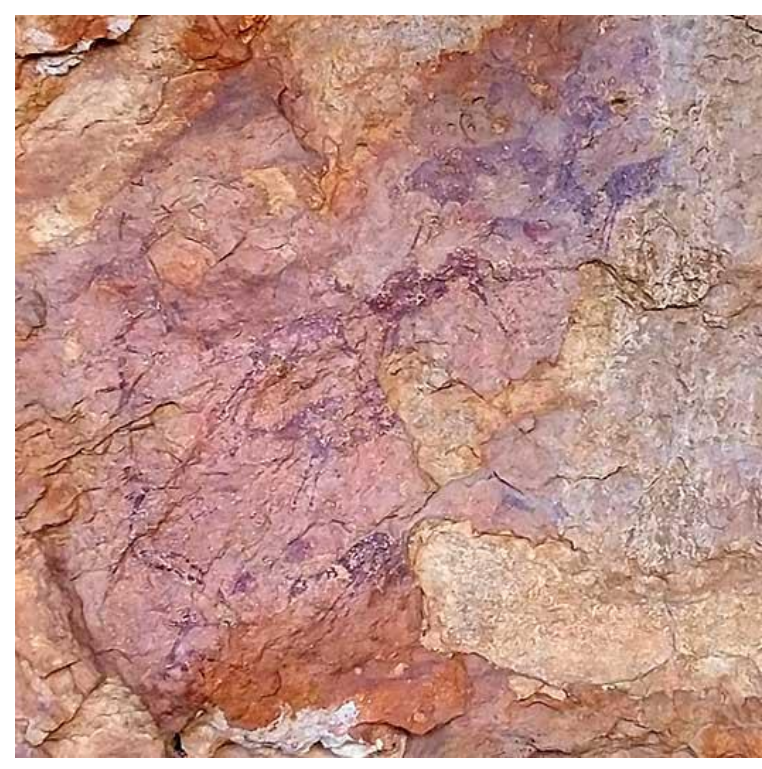

b

Figure 4.2 a) Hunting scene according to [75]. b) Photographic scene at present.

\subsection{DESIGN AND IMPLEMENTATION}

The app structure is very simple seeking a user-friendly interface that allows a quick understanding. Visitors should only point their phone camera at the scene and the current state of the paintings should be displayed on the camera view over its real position. In addition, there are three buttons located on the right-hand side of the camera view (Figure 4.3) to interchange the virtual content between the current state, possible original state and descriptive archaeological information about the paintings. This virtual content manifests clearly the damage that paintings have suffered over time and is enriched including not only a recreation of the motifs but also historical information about them. 


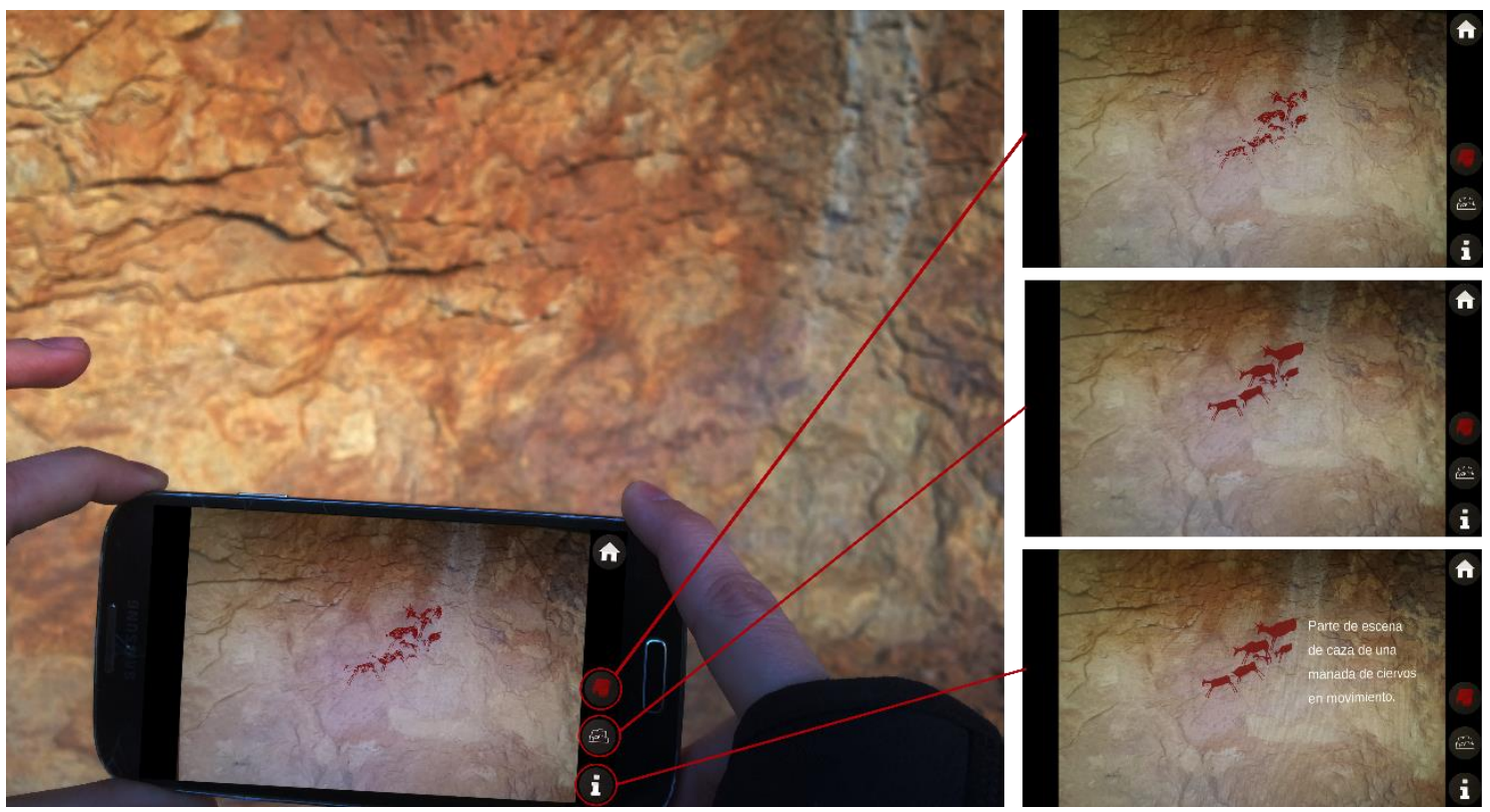

Figure 4.3 AR app interface and screenshots taken on site.

The app was developed using ARToolKit's AR for Unity game engine. Unity is a crossplatform game engine that supports $2 \mathrm{D}$ and $3 \mathrm{D}$ graphics, physics engine, graphics rendering and scripting, thus the creation of interactive $3 D$ content is easier than with other platforms. Moreover, app development through Unity software is faster and required far less programming [22]. For these reasons, nowadays it is used for almost all sorts of 3D projects (game or not) such as virtual reconstructions $[90,110,111]$ and AR projects $[41,112]$.

Thanks to AR libraries, the development of apps is greatly simplified. AR library provides developers functions and data structures implemented in a specific language. There are a large number of AR libraries such as ARTag [68], ArUco [113] and DroidAR [25] marker-based libraries or ARToolKit [23], Vuforia [114], Wikitude [115] and ARmedia [116], which do not just recognise markers but also real scenes [39].

ARToolKit 5 is an open-source library that supports markers recognition, multimarker tracking and feature-based tracking, called natural feature tracking (NFT), for image recognition. In addition, this library provides a plugin for Unity and extensive documentation. However, its major limitation is that it currently does not support model-based tracking.

In order to decide which library was best for this project, some preliminary tests were conducted. Libraries based on markers recognition were discarded because the rock art sites must not be altered with any object or marker, since they are protected places. Therefore, for this kind of project, the app must be based on image recognition. Despite the fact that the recognition scene is not flat, the motifs are split into small units (panels) that can usually be assumed as flat, hence feature-based tracking was tested. Vuforia failed on creating the database of known features whereas ARToolKit extracted many features of the training image and the recognition and tracking worked successfully.

The app implementation is greatly simplified thanks to the ARToolKit library. The process of recognition and tracking required the database generation of the known features, later the app is designed in Unity, where the virtual contents and different functionalities are added. These steps are described below. 


\subsubsection{ARTOOLKIT FEATURE-BASED TRACKING}

The goal of the feature tracking system is to determine the camera pose in real-time from the features of the real scene, in order to project the virtual content correctly. The process is based on matching keypoints from training images (images known in advance) with keypoints obtained in run-time [117]. Thus, the first thing is the creation of the features database extracted from the training image through genTexData program included in ARToolkit.

This program allows users to select the level of feature extraction for tracking and initialisation, being 0 the minimum level and 4 the maximum. This step determines the amount of extracted features; too many features usually slow down the recognition process. The features are extracted from a set of images with different resolutions and are stored in three different files: iset file with the image set resolutions, .fset file with the features used in continuous tracking and.fset 3 file with the features used for identifying the pages and initialising the tracking [118]. These files contain the keypoints required at run-time to calculate the camera pose.

In order to achieve proper results in the recognition and tracking process, intrinsic and extrinsic camera parameters are required as well. These parameters are obtained in the calibration process. To do this, ARToolKit provides an app called ARToolKit Camera Calibrator on Google Play which guides the user to take a set of photos of a calibration pattern.

\subsubsection{ARTOOLKIT DATASET GENERATION}

The training image is the scene that launches the app, therefore this image was taken perpendicular to the hunting scene of Cova dels Cavalls (Figure 4a) from where the visitors will launch the AR app. This image was processed with the ARToolKit genTexData program to generate the features data files.

Level 2 was chosen for tracking, obtaining 3182 features and level 1 was chosen for initialisation, obtaining 688 features (Figure 4.4b). Selecting these levels, the program default values, a large number of features distributed throughout the image was obtained. These features are stored in different files into the app and are used in run-time to calculate the camera pose. 


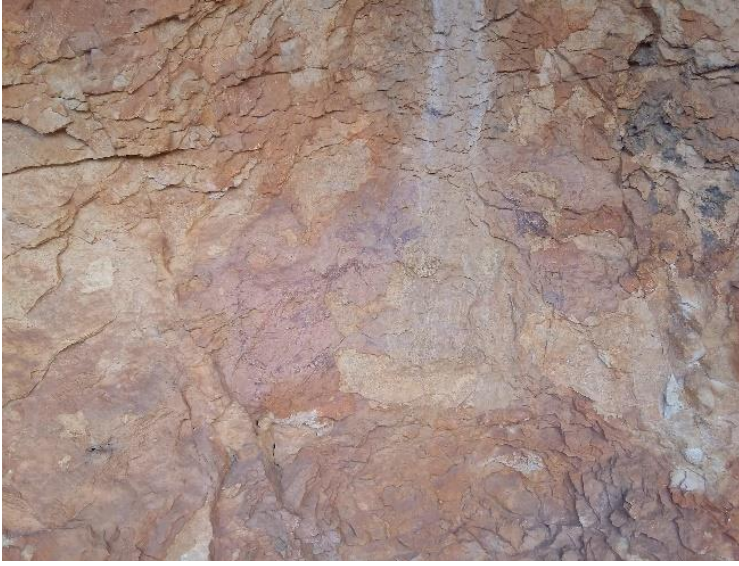

a

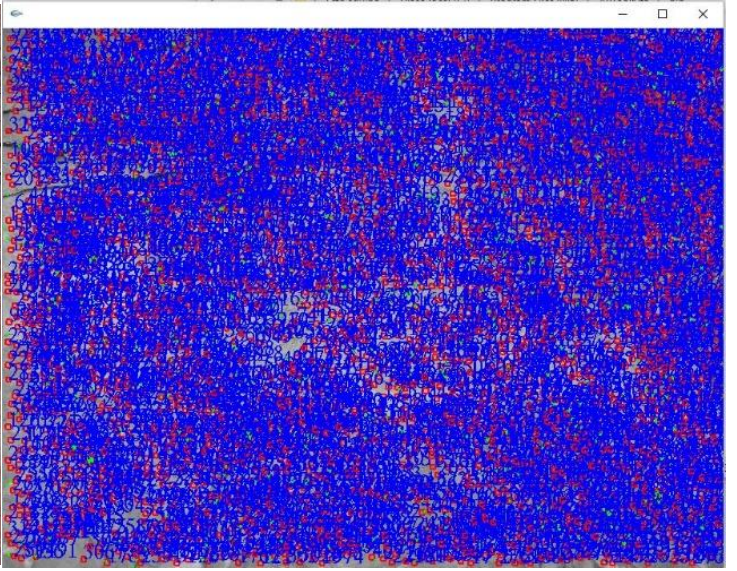

b

Figure 4.4 a) Example of a training image taken on-site; b) Features extracted from the training image (a).

\subsubsection{VIRTUAL CONTENT}

An AR app adds information to reality displaying any kind of virtual information such as $2 \mathrm{D}$ images, 3D models, texts, audios, or/and videos. The app developed in this study shows two different images of the hunting scene of the Cova dels Cavalls, one with the remaining pigments and another with its possible original state (Figure 4.3); the idealised scene obtained by Obermaier and Wernert in 1919 (Figure 4.5) might also be displayed, as well as others such as a final idealised scene taken from Martínez and Villaverde [74]. In addition, the app shows a descriptive text about the scene: "Part of hunting scene of a herd of moving deer".

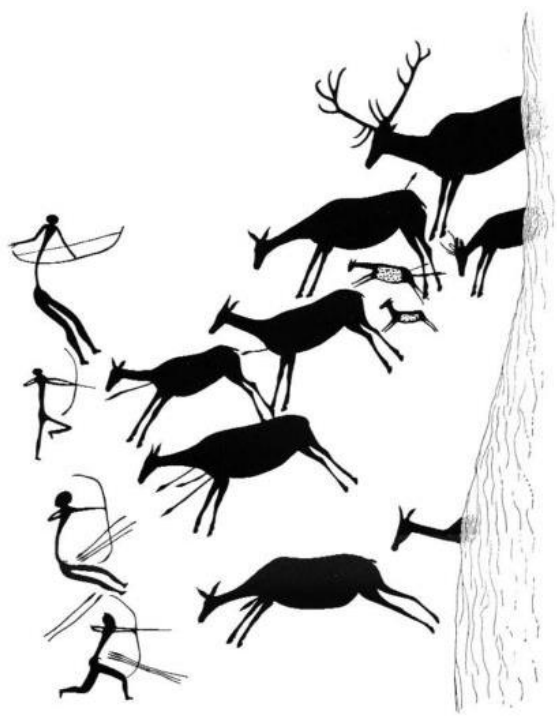

Figure 4.5 Idealised hunting scene according to Obermaier and Wernert (1919) 


\subsubsection{SCRIPTING}

Finally, the design and functionalities were developed in Unity. The features dataset and the virtual content was added to the Unity project as well as two scripts are written in C\# were associated with three buttons to control the virtual content, switching on or switching off when the user presses the buttons. An image with the text "LOADING..." is displayed while the AR app is initialising.

\subsection{USABILITY EVALUATION}

Mobile apps as a tool for dissemination and learning are experiencing extraordinary growth. Martinez et al. [119] evaluate mobile apps for heritage and conclude that most apps need to improve the user experience (UX) design; similarly, the historical content, as well as archaeological context, must be more precise. Other studies point to the lack of on-site evaluation by real users who do not know in advance the implementation or operation of the app $[120,121]$. In addition, only a small part of the visitors of archaeological sites or museums are specialists in the scientific contents presented [121]. The usability evaluation presented herein is focused on knowing if the AR app developed can help visitors (without previous rock art knowledge) to better understand the painted rock art scenes. In addition, the evaluation will allow us to know (as developers) whether the design and functionality are adequate. A group of 11 volunteers tested the AR app at Cova dels Cavalls shelter, $63.6 \%$ male and $36.4 \%$ female; the majority were over $41(63.7 \%)$ or between 31 and 40 (27.3\%) and almost all participants had university degrees (90.9\%). The survey was divided into two parts: first) a pre-questionnaire with questions related to the participants' information; and second) a questionnaire to evaluate the AR app, that included 15 questions. The answers were rated using a five-point Likert scale, ranging from strongly disagree (1) to strongly agree (5).

The pre-questionnaire was realised in order to gather participants' background information. In this evaluation, only issues related to rock art knowledge as well as the use of mobile devices was analysed. Regarding rock art knowledge, all participants claimed to be interested in rock art (100\%) as well as to know this art (90.9\%), but only $18.2 \%$ were experts in this field. These results indicate that it is important to invest in apps development related to this field. According to the mobile operating system, 90.9\% were using Android phones and $45.5 \%$ were using both phone and tablet. Therefore, apps developed must be compatible with this operating system. Regarding the questions related to $A R, 63.6 \%$ of the participants know the meaning of $A R$, and only $36.4 \%$ had previously used an AR app.

In the last decade, the use of mobile phones has increased greatly and thanks to the number of apps that are developed daily, a mobile phone can have all kinds of uses. Thus the mobile phone has been incorporated into our daily life and has become an indispensable element. This fact is reflected in the questions related to the usage of the mobile where $90.9 \%$ answered that they are using mobile apps daily. The percentage of apps used by the participants is shown in Figure 4.6; the most used apps are related to social media (17.3\%), messaging (17.3\%) and photography (15.4\%). 


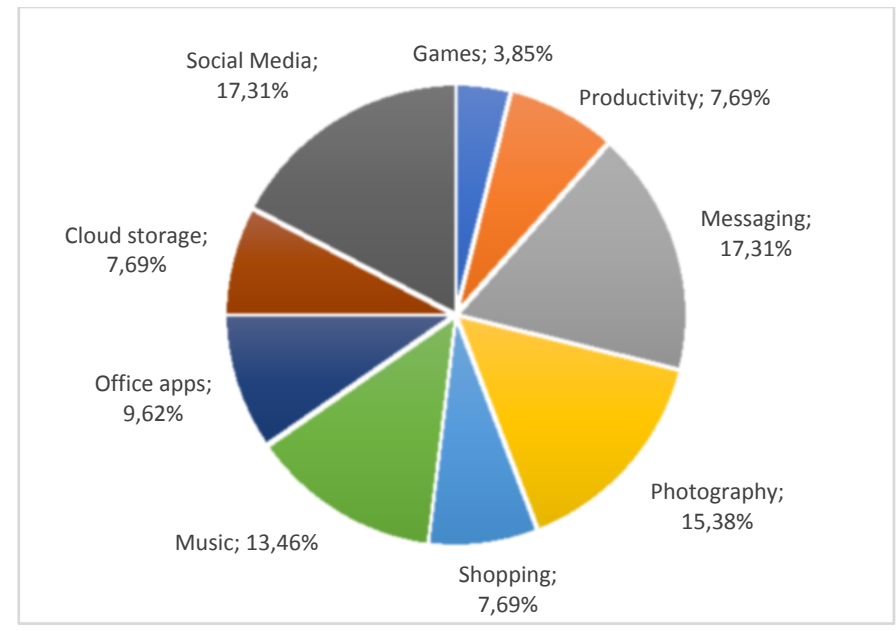

Figure 4.6 Percentage of apps used by participants

The last part of the survey measured participants' perceptions of AR usability as well as interest and motivation to visit rock art sites after using this app. Table 4-1 presents the 11 questions related to the usage of the AR app in the Cova dels Cavalls; Figure 4.7 shows the mean results. The mean answer value to questions Q1-Q4 was higher than 4.5 , indicating a high approval degree, thus for most respondents, AR improves visualization, understanding and recognition of rock art paintings. In addition, examining Table 4-2, the highest percentage of strongly agree answers (value 5) was for questions Q2 (82\%) and Q4 (91\%), indicating that this app improved a lot the painting identification.

The questions Q5-Q7 are related to the virtual content. The main problem in AR apps based on natural feature tracking is the need to recognise enough points in the scene to calculate the position and orientation of the virtual content correctly. In rock art scenes, it is more difficult to find highlighted features, thus the virtual content positioning can be less accurate or last long (around $3 \mathrm{~s}$ ). In this case, participants are neutral to these issues.

Regarding questions Q9 and Q10, the participants indicated a good agreement with these statements (mean higher than 3.5); AR added new information to the guided tours and was easy to use. Finally, most of the participants strongly agreed that $A R$ is very useful for rock art dissemination and they agreed with the AR app (Q8 and Q11 with a mean value of 4.5). As a whole, the responses indicated a great acceptance of $A R$ as a tool to improve the visit to a rock art site.

\begin{tabular}{|l|l|l|l|}
\hline Q1 & AR improves panel understanding & Q7 & Virtual content is correctly placed \\
\hline Q2 & Rock art paintings are more easily recognised & Q8 & AR app is very useful \\
\hline Q3 & AR improves rock art visit & Q9 & AR app adds new information \\
\hline Q4 & AR improves paintings visualisation & Q10 & AR app is easy to use \\
\hline Q5 & Virtual content takes a long time to appear & Q11 & I like the AR app \\
\hline Q6 & Virtual content remains fixed, flicker-free & & \\
\hline
\end{tabular}

Table 4-1 AR questionnaire. 


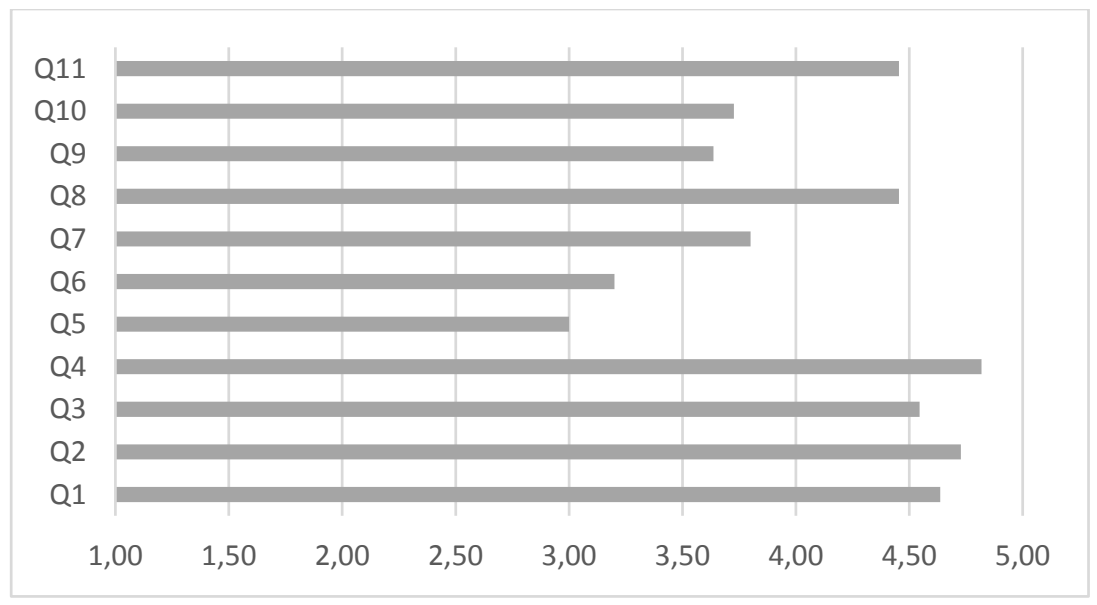

Figure 4.7 Overview of answers related to AR.

\begin{tabular}{|c|c|c|c|c|c|}
\hline & $\mathbf{1}$ & $\mathbf{2}$ & $\mathbf{3}$ & $\mathbf{4}$ & $\mathbf{5}$ \\
\hline $\mathbf{Q 1}$ & $0 \%$ & $0 \%$ & $9 \%$ & $18 \%$ & $\mathbf{7 3 \%}$ \\
\hline Q2 & $0 \%$ & $0 \%$ & $9 \%$ & $9 \%$ & $\mathbf{8 2 \%}$ \\
\hline Q3 & $0 \%$ & $0 \%$ & $9 \%$ & $27 \%$ & $\mathbf{6 4 \%}$ \\
\hline Q4 & $0 \%$ & $0 \%$ & $9 \%$ & $0 \%$ & $\mathbf{9 1 \%}$ \\
\hline Q5 & $10 \%$ & $10 \%$ & $60 \%$ & $10 \%$ & $10 \%$ \\
\hline Q6 & $10 \%$ & $0 \%$ & $60 \%$ & $20 \%$ & $10 \%$ \\
\hline Q7 & $0 \%$ & $0 \%$ & $40 \%$ & $40 \%$ & $20 \%$ \\
\hline Q8 & $0 \%$ & $0 \%$ & $9 \%$ & $36 \%$ & $55 \%$ \\
\hline Q9 & $0 \%$ & $9 \%$ & $36 \%$ & $36 \%$ & $18 \%$ \\
\hline Q10 & $0 \%$ & $9 \%$ & $36 \%$ & $27 \%$ & $27 \%$ \\
\hline Q11 & $0 \%$ & $0 \%$ & $18 \%$ & $18 \%$ & $\mathbf{6 4 \%}$ \\
\hline
\end{tabular}

Table 4-2 Percentage of responses obtained.

The four last questions (Figure 4.8) assessed how this app influenced the participants' behaviour towards cultural heritage history and its conservation. These questions were based on [122], which aimed at raising the awareness of a students' group to the importance of cultural heritage preservation and documentation through building 3D virtual models. As Figure 4.8 illustrates, most participants agree with these statements. The app increased the interest in the site and its history, therefore, in addition to improving the visualisation of the paintings, this app helped to disseminate the cultural heritage and most of the participants found this means of dissemination interesting (Q15 with a mean value of 4.3). 


\begin{tabular}{|l|l|}
\hline Q15 & $\begin{array}{l}\text { I find interesting the rock art dissemination } \\
\text { through AR apps }\end{array}$ \\
\hline Q14 & $\begin{array}{l}\text { This app made me aware of the importance of the } \\
\text { rock art conservation }\end{array}$ \\
\hline $\mathbf{Q 1 3}$ & $\begin{array}{l}\text { This app increases my interest in the history of the } \\
\text { site }\end{array}$ \\
\hline $\mathbf{Q 1 2}$ & This app motivated me to visit the site \\
\hline
\end{tabular}

Figure 4.8 Answers related to questions about the cultural heritage site.

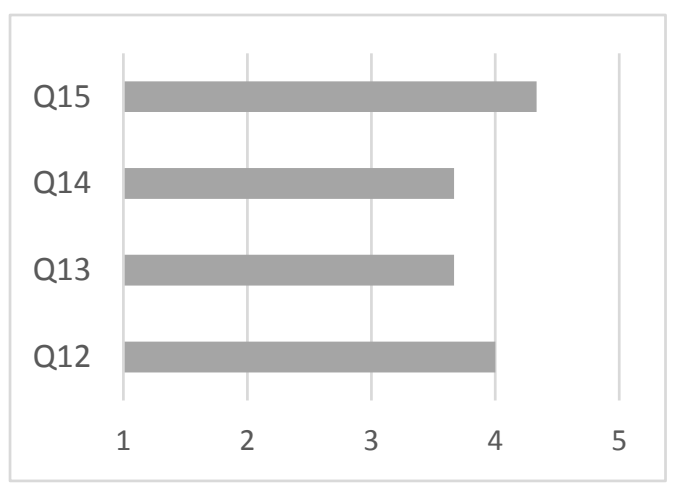

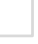

\subsection{DISCUSSION}

First of all, not everyone is aware of the existence of Levantine rock art and the number of rock art shelters that can be visited in Spain. Investing in the development of new dissemination apps can help to attract more visitors, as pointed out by $[10,98]$. In addition, it can enrich whatever traditional guided tour, making it more intuitive and enjoyable. In this regard, the Cultural Park of Valltorta-Gasulla was created, aimed at protecting, disseminating and studying Levantine art [123]. The findings of this case study showed that all participants were interested in rock art as a valuable heritage asset from our past societies. These results were expected owing to the fact that the survey was conducted to a group of visitors of the Valltorta Museum devoted to rock art in the Valltorta-Gassulla area. On the other hand, most participants were not specialist in rock art, thus they were spending their spare time visiting the natural and archaeological environment. These findings suggest a clear interest of the participants in learning about our history, and more in particular, about prehistoric rock art sites. However, in order to know the social interest in this part of our legacy, this questionnaire should be asked to a larger group of people, especially to those who are not visiting the museum. The fact of running the AR app off-site at home or primary/secondary school might attract their attention to visit more (and more often) rock art sites.

On the other hand, smartphones have become de facto a new dissemination tool. Smartphones are nowadays powerful computers equipped with a large number of sensors and that enabling the installation of all kinds of apps; therefore these devices have now become the new portable information and communication technology [124]. The usage of smartphone apps is increasing and, in some cases, is replacing laptops and desktops [125]. In this study, the usage of smartphones was evaluated and almost all participants claimed to be using smartphones apps every day, mainly for communication and social media (Figure 4.6). These findings support previous research by [125].

Regarding AR technology, future predictions suggest an exponential increase in the number of AR users [126]. This growth can already be seen in the number of AR apps available in the market. Despite of this, only $36 \%$ of respondents in this study had previously used an AR app although more than half claim to know this technology. These results show that today, the end- 
user does not use AR technology. [127] suggest that this could be due to the fact that this technology has not reached the level of maturity yet.

Overall, the results point to the overriding importance of smartphone as a means of communication and information, and the potential of AR apps, and because of this, justify the relevance of implementing mobile AR apps in order to disseminate cultural heritage. However, AR apps have not been sufficiently evaluated to know the level of acceptance and understanding from a users' point of view [127]. Hence this study is focused on the evaluation of our developed AR app. Despite some participants were unaware of this technology, nearly all of them agreed with the great usefulness of this app to visit rock art sites.

The main goal of this app was to improve the current guided tour, making easier the recognition of faint archaeological paintings, since this task is very complicated due to the state of conservation. In this regard, practically all of the respondents claimed the AR app improved the rock art visit as well as the panel understanding, specifically $91 \%$ of respondents said they strongly agreed that the AR improves paintings visualisation and the understanding of the scene. Overall, the results showed great acceptance of this AR app, mostly because in addition to adding new information interactively, it helps to understand better the rock art motifs, making it very useful in guided tours. As other researchers pointed out $[127,128]$, the perceived usefulness is a fundamental factor to determine the intention to using AR apps, thus it seems that AR apps constitute an essential tool for disseminating rock art.

Despite the advances in current markerless tracking techniques [60] and a large number of AR libraries to develop easily AR apps $[39,41]$, we have detected some problems in the AR app that can affect the user experience. These problems are related to the virtual content, which sometimes flickers or is not aligned correctly with the real paintings, causing misunderstanding. This is due to the pose estimation process, the main challenge in markerless tracking techniques $[60,117]$. ARToolkit calculates the pose estimation from a planar object, but other approaches exist to calculate the pose estimation in an unknown environment, as presented in $[59,129]$ which could improve the tracking results. In this regard, the respondents were neutral to the statement virtual content remains fixed, flicker-free, hence this is not a great problem from a user standpoint, although from the producer standpoint, it should be improved, testing other AR libraries or implementing other tracking methods. Another problem that might affect the user experience is the time that virtual content takes to appear (time response), since users have to wait around $3 \mathrm{~s}$ until the virtual content appears on the smartphone screen. This is a technical problem due to the library used for AR tracking. The ARToolKit features dataset is large enough (3182 features), thus the time to process all these features to calculate the pose estimation is long. This technical problem related to time response was evaluated in [130] where Vuforia's tracking was much faster than ARToolKit, but Vuforia was not able to recognize all the paintings in rock art scenes, so Vuforia was discarded.

Some research analysed AR as a tool to improve the motivation for learning, specifically devoted to students $[99,131]$. The survey conducted in this study showed a common agreement that the AR app increased the motivation and the interest in the history of the archaeological site. These findings support previous research by [98] who pointed that AR enhanced cultural and historical value as well as attracted different groups of visitors. In addition, according to [122], digital technologies, such as the generation of 3D models, increased the awareness of university students about the importance of preserving cultural heritage. Similar results were obtained in this study, in which most participants agreed that the AR app made them more 
aware of the paintings degradation and the importance of rock art conservation. This was possible because the AR app allows the visitor to visualise the current state and the original state of the paintings. Thus, the visitor was aware of the painting deterioration suffered over time.

\subsection{CONCLUSION}

This chapter has presented an AR app developed to ease understanding and visualisation of faint rock art painted scenes on-site through smartphones, using feature-based tracking. The AR app has been implemented in Unity with the ARToolKit library. A usability evaluation has been carried out through a questionnaire to a group of visitors in order to validate the app, as well as the method to identify the performance and user's satisfaction with the developed AR app.

Overall, the respondents showed strong interest in this AR app, highlighting mainly the use of visualising paintings recreation, which helped the inexperienced visitors to understand the rock art paintings much better. Furthermore, respondents reported that these kinds of apps are particularly suitable for young's visits to the rock art site because they are attracted by these technologies, which are highly intuitive and enjoyable. In conclusion, after assessing the outcome of the survey, it can be stated that AR is an ideal means of dissemination that adapts perfectly to the rock art field, improving the visualisation and understanding of paintings. Therefore, it can be claimed that AR apps development in this field is more than justified. 


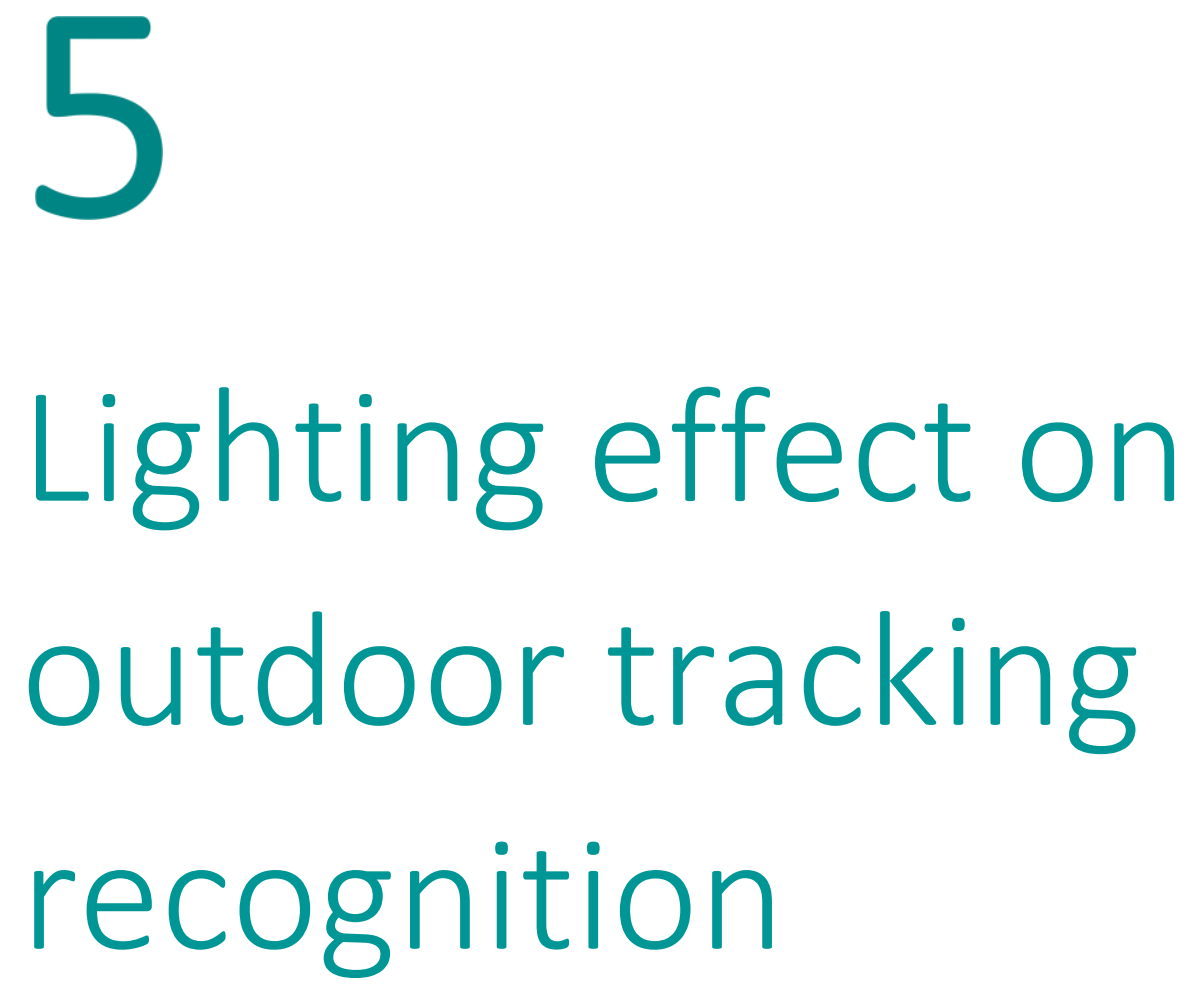

This chapter is based on the publication entitled "Augmented reality markerless multiimage outdoor tracking system for the historical buildings on parliament hill". AR applications have experienced extraordinary growth recently, evolving into a well-established method for the dissemination and communication of content related to cultural heritage-including education. AR applications have been used in museums and gallery exhibitions and virtual reconstructions of historic interiors. However, the circumstances of an outdoor environment can be problematic.

This chapter presents a methodology to develop immersive AR applications based on the recognition of outdoor buildings. To demonstrate this methodology, a case study focused on the Parliament Buildings National Historic Site in Ottawa, Canada has been conducted. The site is currently undergoing a multi-year rehabilitation program that will make access to parts of this national monument inaccessible to the public. AR experiences, including simulated photo merging of historic and present content, are proposed as one tool that can enrich the Parliament Hill visit during the rehabilitation. Outdoor AR experiences are limited by factors, such as variable lighting (and shadows) conditions, caused by changes in the environment (objects height and orientation, obstructions, occlusions), the weather, and the time of day. This chapter proposes a workflow to solve some of these issues from a multi-image tracking approach. 


\subsection{INTRODUCTION}

This chapter presents a smart tourism application based on AR for real-time visualization of the exterior of the Parliament Hill buildings, one of the most important cultural sites of Ottawa. AR technology is currently being applied in a number of disciplines and has demonstrated the capacity to deliver a palpable sense of immersion in the user. Typically, AR tracking is based on markers or known images but in some cases, such as outdoor tracking, these solutions cannot be used. Outdoor environments change constantly due to factors such as weather conditions, sunlight, or human activity. This often makes it difficult to obtain a unique image for tracking or using a marker that can last over time.

This study is focused on the development and use of a set of mobile AR solutions in outdoor scenarios at the Parliament Buildings National Historic Site of Canada (Figure 5.1a-c). The site is comprised of four buildings-Centre Block, West Block, East Block, the Library of Parliamentand the grounds. This site-known colloquially as "Parliament Hill" -is a major attraction for tourists who visit Ottawa and a popular gathering place for local residents.

As seen in Figure 5.1d, the four buildings on Parliament Hill flank a central green space. At the southern end sits the Centennial Flame monument, a well-known landmark and meeting point. This area is open and accessible to the public. Since the buildings sit on a promontory, the view beyond Centre Block is an open sky. While dramatic as an architectural setting, dynamic changes in foreground figuration and background illumination can be problematic for $A R$ tracking. This study explores solutions for outdoor tracking in this type of environment, evaluating the multi-image tracking approach from current tracking solutions, and more specifically, the image recognition approach of Vuforia Library.

This chapter demonstrates the possibility of developing functional AR apps for the recognition of the building facades directly affected by factors such as occlusions and large variations in lighting using a multi-image tracking approach. By previously evaluating the changes in light and shadows that affect the buildings, it is possible to prepare appropriate images for the recognition of the buildings for any time of the day and in different seasons.

This chapter is organized as follows. Section 5.2 presents existing works regarding tracking, AR and the dissemination of cultural heritage. Section 5.3 describes the proposed markerless tracking system and gives details about tracking challenges to evaluate the system. Section 5.4 discusses the results obtained in the evaluations performed. Section 5.5 draws conclusions and suggests future work. 


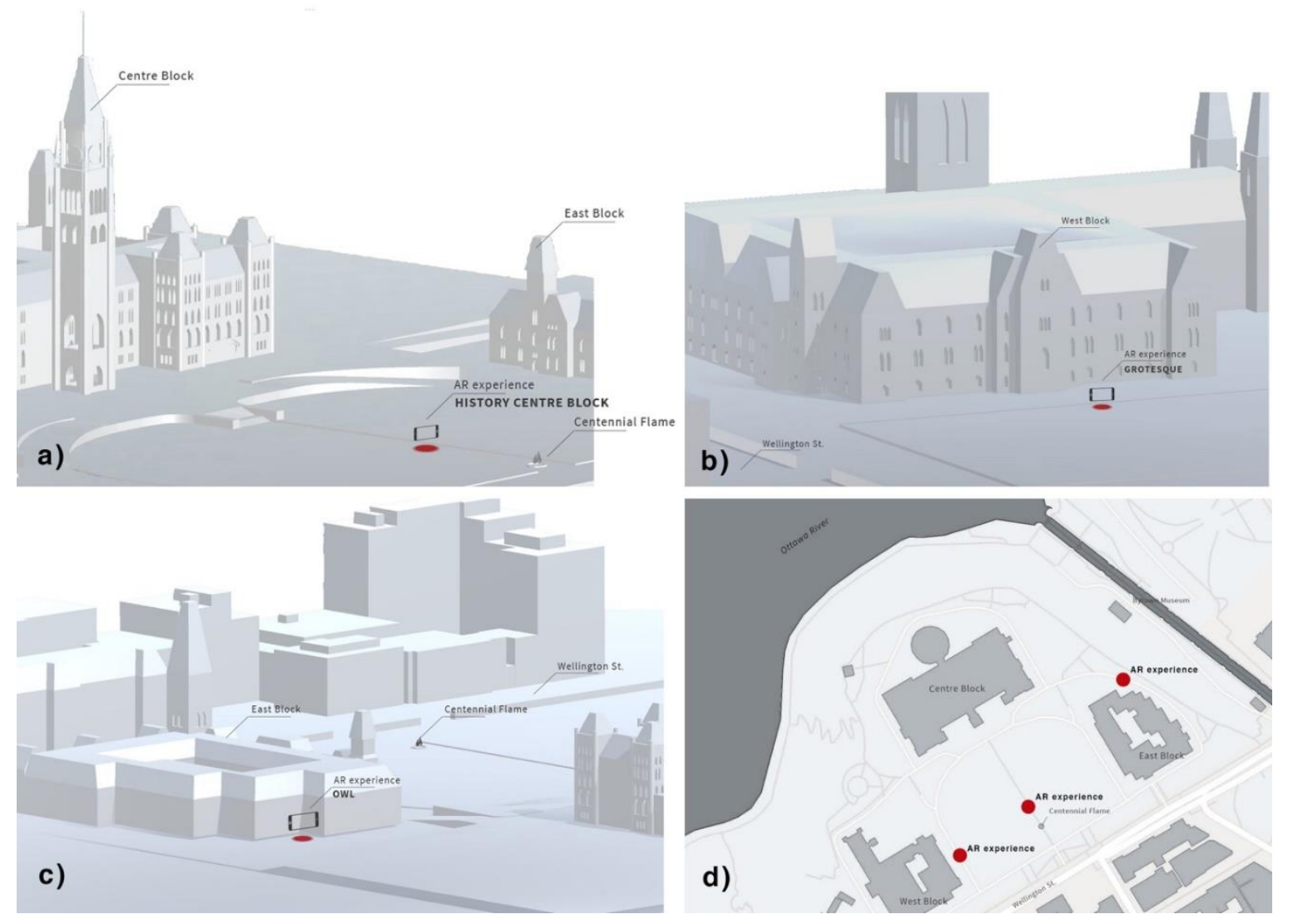

Figure 5.1 Parliament Hill (Ottawa): a) History Centre Block AR experience located at the Centre Block, b) grotesque AR experience located at the West Block, c) OWL AR experience located at the East Block, and d) geographic location of the buildings and $A R$ experiences location

\subsection{RELATED WORK}

Many studies have been conducted in the cultural heritage field with AR technology. This section describes current state-of-the-art solutions for outdoor tracking for cultural heritage, as well as the 3D data optimization required to develop an AR app.

\subsubsection{AR EXPERIENCES IN CULTURAL HERITAGE}

Azuma [38] defines AR as a system that layers interactive virtual objects on real environments in real-time, so that users perceive the virtual objects to be part of the real world. To achieve a proper immersive experience, the system must obtain a high level of accuracy for the position and orientation of the user's device so that the real and virtual objects are perfectly aligned.

The use of immersive tools to enhance access to cultural heritage is well established [107]. In recent years, AR systems have been integrated into museums, gallery exhibitions, and guided tours to improve the visitor experience. Gimeno et al. [132] present a novel, mobile augmented guide for the Casa Batlló Museum (Barcelona, Spain). Kolivand et al. [133] describe ReVitAge, an $A R$ system that shows realistic reconstructed heritage buildings in real environments. Amakawa 
et al. [134] developed The New Philadelphia AR Tour, a mobile application that allows the visitor to walk through historical building reconstruction using AR. Kim et al. [135] present an AR tour application that allows visitors to interact with the tour exhibitions and improve communication. Barrile et al. [97] present an AR application that integrates information on the ground and underground to identify buried structures on-site.

\subsubsection{TRACKING OUTDOOR}

Several tracking approaches have been studied in the last decade and can be divided into two groups: marker-based tracking and markerless tracking. The first is based on the recognition of fiducial markers $[136,137]$ and the latter is based on the recognition of natural features and points that are visible in the real environment [138].

Tracking methods have been applied in many cases and recognition algorithms are continuously improving. In the case of outdoor AR applications, there are some restrictions that hinder the tracking process such as occlusions, large variations in lighting, the impossibility of modifying the environment, as well as an ever-changing environment due to unpredictable weather conditions, pollution, or physical changes to the environment. These challenges have led many studies to focus on solving these problems.

One of the first studies of outdoor AR applications was Azuma et al. [139] who combined different sensors to obtain the position and orientation of a device. Cirulis et al. [140] developed a solution to merge a real city with virtual buildings in outdoor environments. In this case, the authors used GPS to obtain the user's location, a gyroscope for head orientation, and a digital compass for sight direction detection. These solutions suffer from poor registration because the device sensors do not have the accuracy required for AR tracking. In particular, GPS accuracy decreases in urban environments due to signal reflections.

To improve tracking accuracy, other researchers have focused on hybrid solutions. Reitmayr et al. [141] present a robust hybrid tracking system for outdoor AR in urban environments. Their system combines edge-based tracking extended to a textured 3D model with inertial and magnetometer sensors. You et al. [142] combined vision-based tracking with inertial and compass sensors to compensate for the weaknesses of each approach.

Wither et al. [143] propose a new approach called "indirect AR", which achieves perfect alignment between real and virtual worlds in outdoor scenarios. They replace the live camera view used in AR with a previously captured panoramic image where the virtual content is placed. The main problem is that some elements of the scene, such as weather, lighting, and vehicles, may not be represented correctly and the user may not feel fully immersed. The results of this study indicate that, in most conditions, users preferred indirect AR over traditional AR. Okura et al. [144], looking to improve the sense of realism, propose a system that takes into account realworld illumination, selecting the proper image from a set of pre-captured images under different weather conditions and times of the day. Gimeno et al. [132] applied this method in a museum where the small and crowded spaces made it impossible to use the feature recognition approach. While effective, this approach requires a live camera view that allows the user to take a photo with the augmented object.

The vision-based approach is another markerless solution that relies on computer vision and provides very accurate tracking, although it can be unstable as it depends on natural-feature 
detection. This method is explained in several papers $[58,59,61,145]$ and is based on keypoint extraction and feature descriptors to calculate the pose estimation. This approach has been applied for the augmentation of the urban environment [146] or in object detection in uncontrolled outdoor environments [147].

\subsubsection{D DATA OPTIMIZATION}

The capabilities of the majority of mobile devices force developers to optimize media content as much as possible. This results in the manipulation of content, whether they are images, videos, animations, or 3D models. The production of optimized, automated 3D content is an important challenge that many researchers have studied in-depth. These challenges include mesh optimization or remeshing, control of the Level-Of-Detail (LOD), and compatibility between format files.

In regards to mesh optimization, the goal is to reduce the size of the mesh while maintaining the required LOD in each use case. When simplifying and improving the quality of the meshes, the geometry and the topology of the mesh have to be taken into account and many algorithms have been developed for this purpose [148-153]. However, it is important to note that the success of the method will depend on the shape of the element one is dealing with. Therefore, the mesh optimization process must be appropriate for each specific case.

Controlling the LOD - the visualization of unnecessary details or invisible faces in the scene of the application-can help save memory. Thus, anything that is not visible to the user is not shown. For attaining these outcomes, Guidi et al. [154] control the LOD by employing multiresolution modelling sources. Some authors try to control the LOD by simplifying the models in real-time. For an in-depth review of real-time rendering, see Akenine-Möller et al. [155].

Finally, as Remondino and El-Hakim [156] have pointed out, over the years, many different 3D graphics file formats have been developed. While format standardization would make the exchange of 3D data easier, the most commonly used formats are available in the majority of software.

\subsection{MATERIALS AND METHODS}

\subsubsection{MOBILE DEVICE}

The mobile device employed for the multi-image target testing is detailed in Table 5-1.

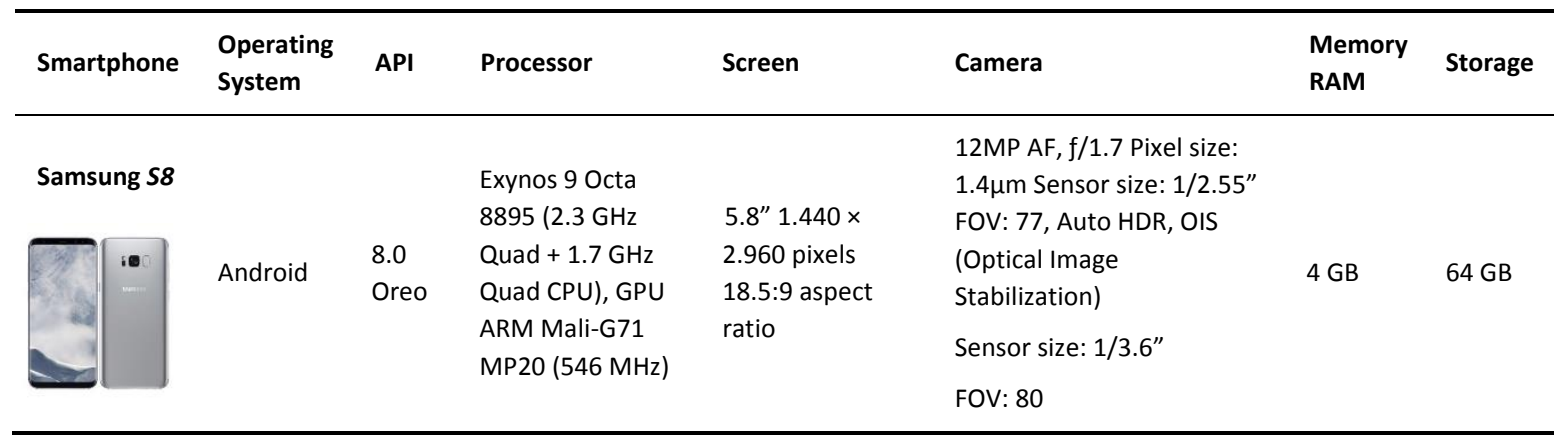

Table 5-1. Mobile device specifications. 


\subsubsection{OUTDOOR TRACKING}

Tracking is an important issue in a real-time AR context and requires a high level of precision and low latency. Camera precision is required so that the augmented content is properly aligned with the real-time view in the camera. Low latency assures that the precision is maintained even if there is a slight movement of the camera. Proper tracking provides seamless integration of "the real" and "the virtual". This paper proposes a feature-based approach using natural feature points identified from images taken in real-time through the camera of a mobile device. Virtual content is displayed only when the device detects these feature points. This type of tracking poses challenges in outdoor environments.

When it comes to developing an outdoor AR experience, numerous problems can arise that will cause poor tracking, virtual content flicker, or even tracking loss. Accordingly, it is desirable to test this type of tracking in AR apps to find out what the implicating factors are and to determine the best possible solutions.

A common way to accomplish successful AR is by detecting planar (fiducial) markers placed on the object and/or in the landscape. This is problematic in the context of historic buildings where markers are considered intrusive in most cases. Consequently, in cases involving historic buildings, it is more suitable to rely on permanent features present in the real world and use image-based tracking. This approach is less intrusive and the user can perceive the augmented elements and interact with them normally with minimum effort. However, some additional requirements must be taken into account in order to use an outdoor image tracking solution in an AR application.

The accurate position of the content depends on the detection and tracking of features that are found in the image target. The camera pose is calculated from natural features that are extracted from the image target and then compared at run time with features in the live camera image. Markerless methods exploit the natural features existing in the real scene such as the corners and edges. Therefore, to create a successful AR experience that is accurately detected, images that are rich in detail, with good contrast, and no repetitive patterns should be used. Fortunately, the Parliament Hill buildings are very detailed and provide image targets that will produce accurate tracking.

The user must be placed approximately at the same point as to where the image target was taken in order to calculate the camera pose, and consequently to activate the augmented experiences. On Parliament Hill, the image targets have been taken from accessible vantage points for visitors that coincide with the pose required for image target detection (Figure 5.1Fd), using one standard location for each experience where possible.

Furthermore, there is no control over the potential changes in the environment, such as occlusions derived from added elements of the rehabilitation or on-site events. As such, it is necessary to plan in detail the capture of target images and to avoid elements that can cause tracking malfunctions.

In addition, changes in lighting conditions can cause drastic changes in the appearance of certain objects. For example, the orientation of the facades of the buildings and the changes in the ambient light of Parliament Hill cause changes in the shadows that are cast on the buildings. Therefore, the appearance of the building facades varies depending on the time of day, the time of year, or weather conditions. All of these variations can cause a launch failure of the 
augmented content. In order to address this issue, a shadow area study was carried out (cf. Section 5.3.3).

Considering the requirements for successful AR tracking discussed above and taking a close look at the shadow studies, a vision-based approach was established and developed using the Vuforia AR library. This library is easier to use than others, such as ARCore, and it includes the multi-image approach and a free developer license. In addition, since shadows drastically affect image recognition, a multitarget approach was required. Various images of the target were implemented into one scene in order to increase detection accuracy.

\subsubsection{MULTITARGET OUTDOOR TESTING ON PARLIAMENT HILL}

The study was conducted during the summer months. It was necessary to predict the possible changes in the position of the sun since the changes in the lighting and shadows on the facades can cause a malfunction of the tracking system. Therefore, a light and shadow study on West Block, Centre Block and East Block 3D models has been carried out to show the position of the sun throughout the year (Figures 5.2-5.4, respectively):

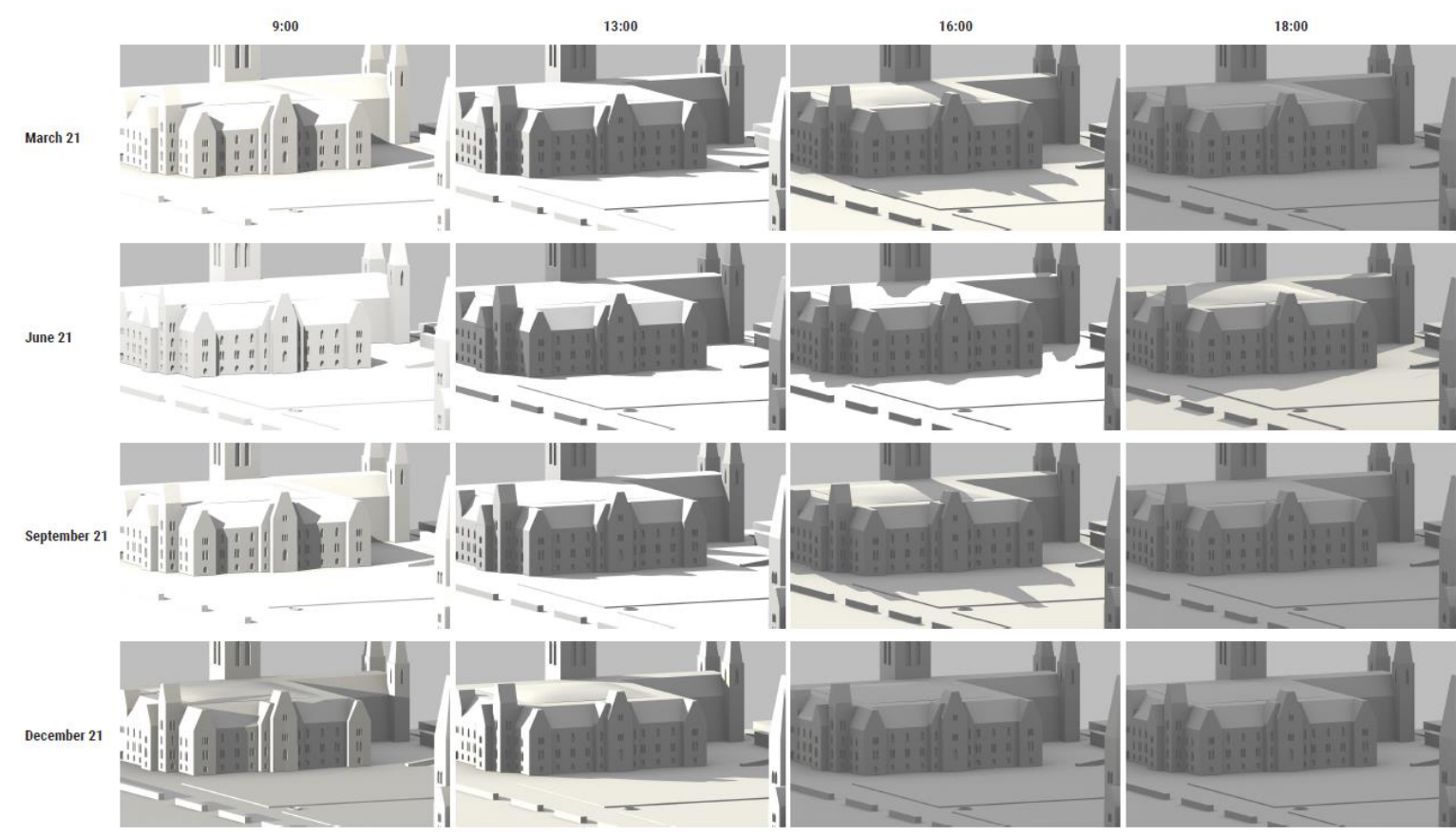

Figure 5.2 West Block Shadow Study at different times of day. 


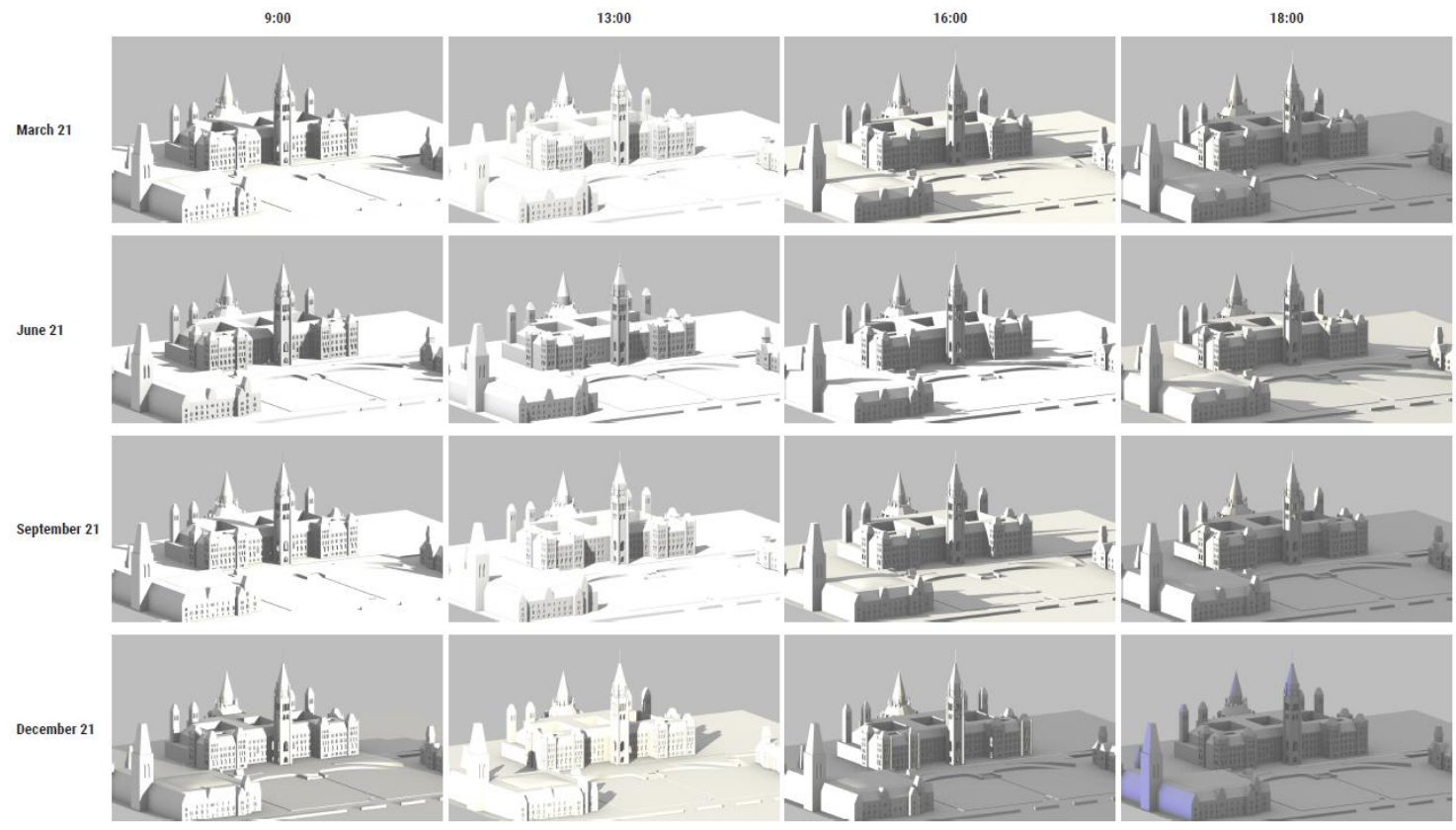

Figure 5.3 Centre Block Shadow Study at different times of the day.

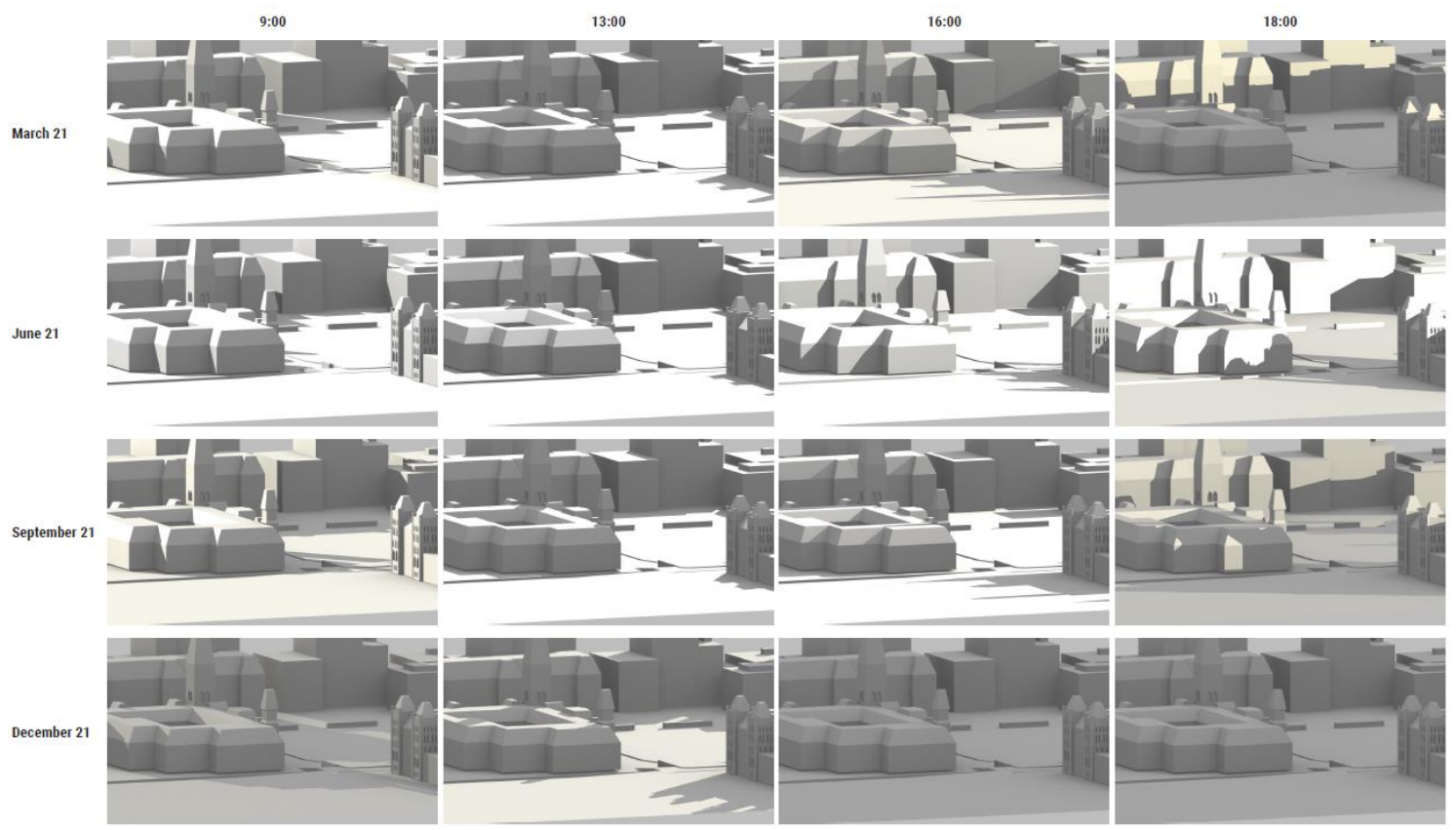

Figure 5.4 East Block Shadow Study at different times of the day.

Taking into account the orientation of the site and the sunlight mapping simulation, a set of images for the recognition of each building was taken (image targets). The shadows especially affect the West Block and Centre Block facades, as seen in Figures 5.5 and 5.6; thus, in these cases, three and four image targets have been used, respectively. As seen in the shadow study of the East Block, the sunlight does not affect this façade, thus, one image target has been used (Figure 5.7). 


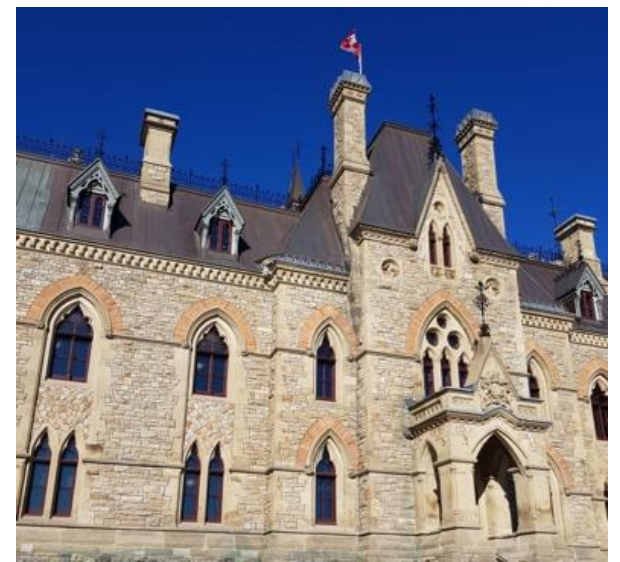

a

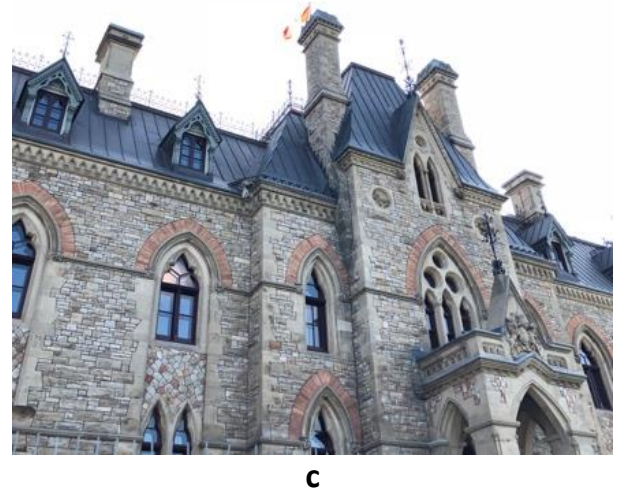

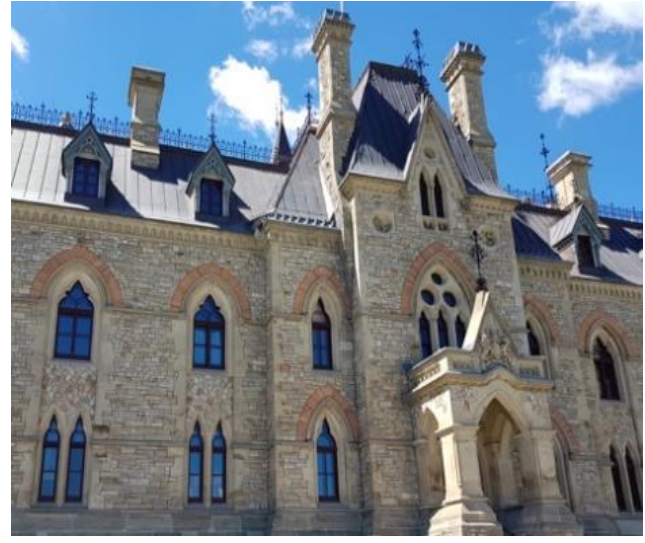

b

Figure 5.5 Image targets of West Block taken approximately 14 m away: a) Sunny $8 A M, b)$ Sunny 1 PM, and c) Sunny 6 PM.

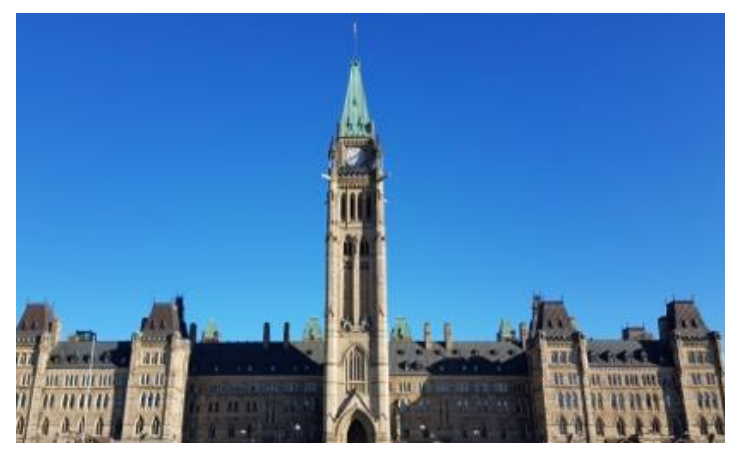

a

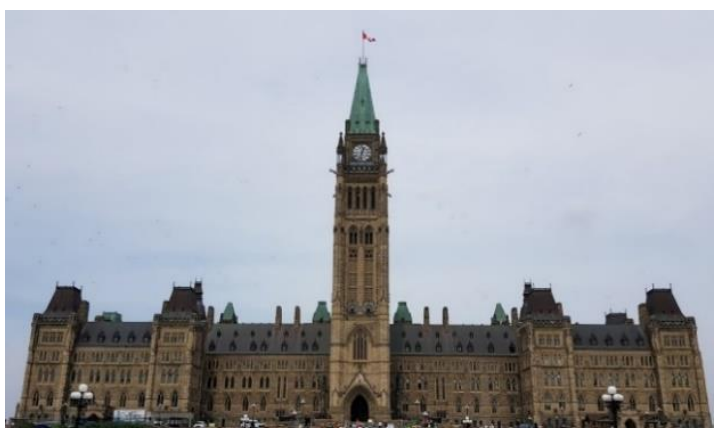

C

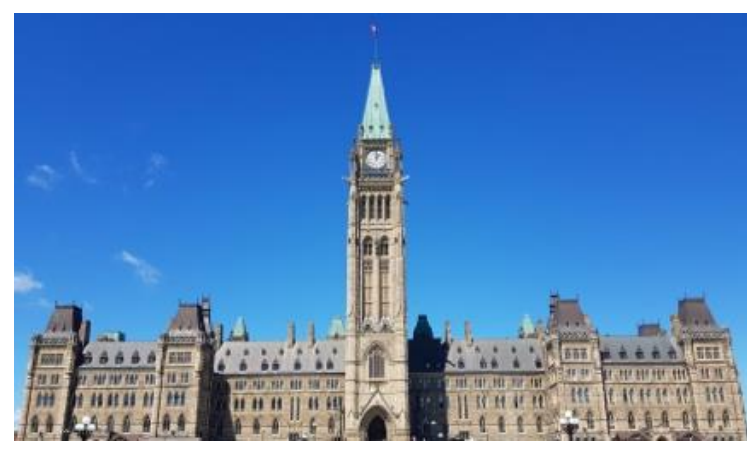

b

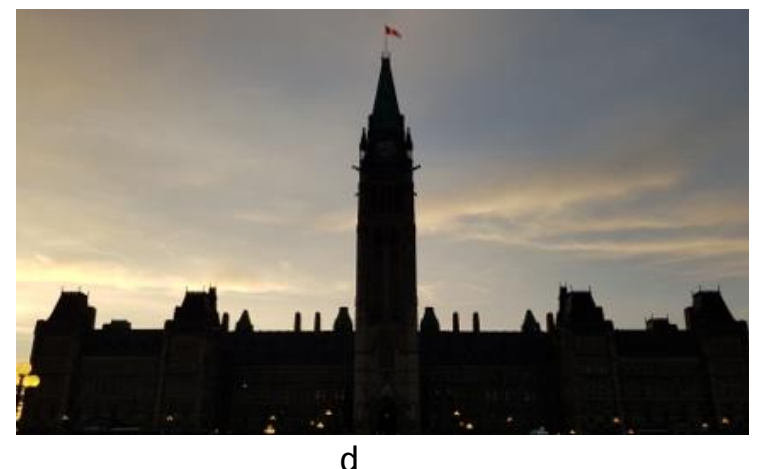

Figure 5.6 Image targets of Centre Block taken approximately 100 m away: a) Sunny 8 AM, b) Sunny 1 PM, c) Cloudy 6 PM, and d) Cloudy 9 PM. 


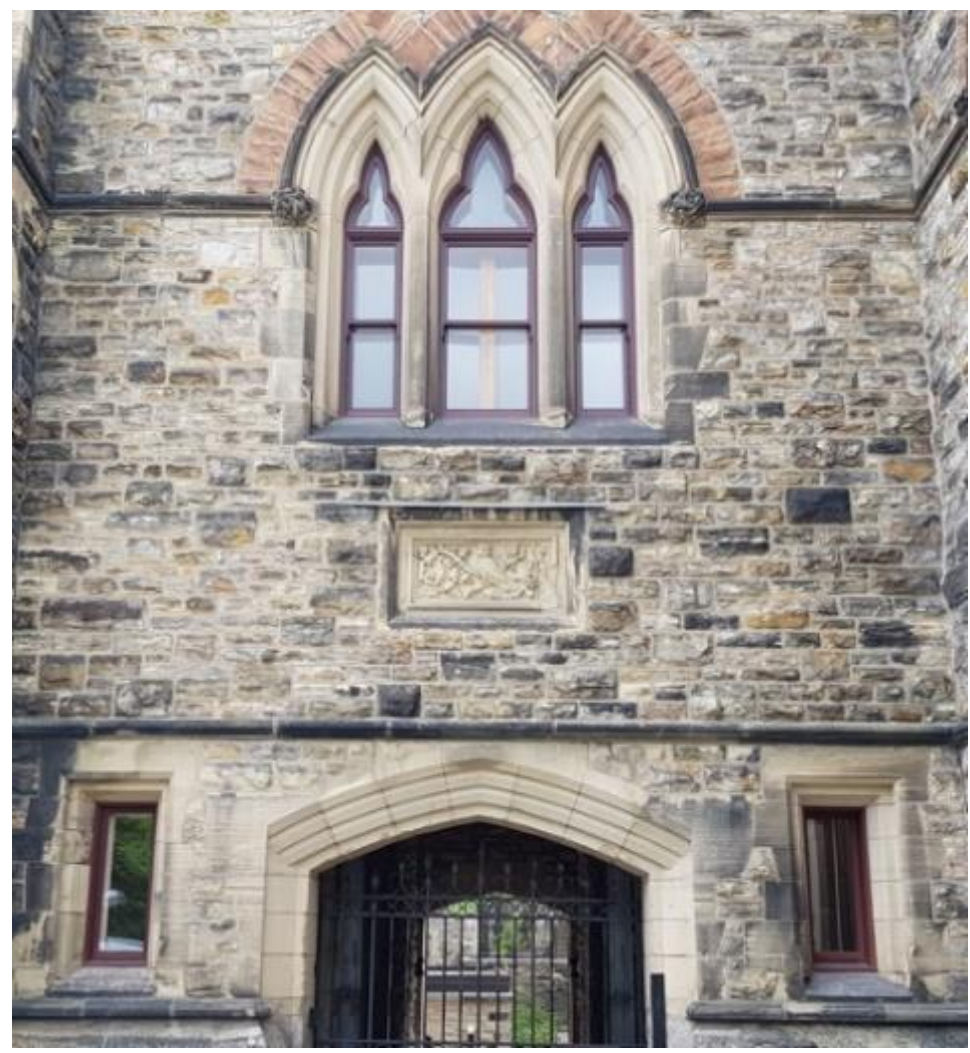

Figure 5.7 Image target of East Block taken approximately 10 m away.

Finally, to verify the correct recognition of the buildings, several tests were carried out at different times of the day and with different environmental conditions. To that end, a script to determine which image target was recognized at any time was developed. This information is summarized in Table 5.2 .

1. West Block: From 18:00 on, the sun is behind the building. Therefore, there are no shadows but from 7:00 to 18:00 the orientation of the sun causes significant change to the image of the building (Figure 5.2). All tests performed on a sunny day detected the targets correctly. On cloudy days there are no shadows on this building; for this reason, the sunny 18:00 target works well in all the test cases on cloudy days and during sunset (Table 5.2).

2. Centre Block: As in the case of West Block, during the day the sun changes the building images so four image targets were used (Table 5.2). From 18:00 on, the sun is behind the building, therefore, there are no shadows and the building image is the same as on a cloudy day (Figure 5.3).

3. East Block: The orientation of the facade of this building is not affected by the sun at any time of the day (Figure 5.4). Therefore, only one target was required and in all cases tested, recognition and tracking worked well (Table 5.2). 


\begin{tabular}{|c|c|c|c|c|c|c|c|}
\hline & \multicolumn{3}{|c|}{ SUNNY } & \multicolumn{3}{|c|}{ CLOUDY } & SUNSET \\
\hline \multicolumn{8}{|c|}{ WEST BLOCK } \\
\hline TARGET SUNNY 8 AM & $31-07-188: 34$ & & & & & & \\
\hline TARGET SUNNY 1 PM & & $\begin{array}{c}16-08-18 \\
13: 20\end{array}$ & & & & & \\
\hline TARGET SUNNY 6 PM & & & $\begin{array}{c}16-08-18 \\
18: 26\end{array}$ & $\begin{array}{c}02-08-18 \\
8: 45\end{array}$ & $\begin{array}{c}03-08-18 \\
12: 30\end{array}$ & $\begin{array}{c}30-07-18 \\
18: 15\end{array}$ & $\begin{array}{c}09-08-18 \\
20: 30\end{array}$ \\
\hline \multicolumn{8}{|c|}{ CENTRE BLOCK } \\
\hline TARGET SUNNY 8 AM & $31-07-1808: 23$ & & & & & & \\
\hline TARGET SUNNY 1 PM & & $\begin{array}{c}16-08-18 \\
13: 20\end{array}$ & & & & & \\
\hline TARGET CLOUDY 6 PM & & & $\begin{array}{c}16-08-18 \\
18: 18\end{array}$ & $\begin{array}{c}02-08-18 \\
08: 05\end{array}$ & $\begin{array}{c}03-08-18 \\
12: 30\end{array}$ & $\begin{array}{c}30-07-18 \\
18: 15\end{array}$ & $\begin{array}{c}09-08-18 \\
20: 20\end{array}$ \\
\hline TARGET CLOUDY 9 PM & & & $\begin{array}{c}16-08-18 \\
18: 18\end{array}$ & & $\begin{array}{c}03-08-18 \\
12: 30\end{array}$ & & $\begin{array}{c}09-08-18 \\
20: 47\end{array}$ \\
\hline \multicolumn{8}{|c|}{ EAST BLOCK } \\
\hline TARGET CLOUDY 3PM & $31-07-18$ 08:20 & $\begin{array}{c}16-08-18 \\
13: 35\end{array}$ & $\begin{array}{c}16-08-18 \\
18: 34\end{array}$ & $\begin{array}{c}02-08-18 \\
08: 25\end{array}$ & $\begin{array}{c}03-08-18 \\
12: 49\end{array}$ & $\begin{array}{c}30-07-18 \\
18: 20\end{array}$ & $\begin{array}{c}09-08-18 \\
20: 39\end{array}$ \\
\hline
\end{tabular}

Table 5-2 Summary of the tests carried out at different times of the day on sunny and cloudy days at Parliament Hill buildings.

\subsubsection{REALISM}

It is essential to maintain a sense of realism in an AR app in order to provide a seamless experience. This is accomplished by ensuring the user feels that the digital objects belong to the real world, thus 3D content should be as visually consistent with the real world as possible. However, how realistic an object appears must be balanced with file size. For example, in the case of photogrammetric 3D modelling, the fidelity of the final 3D model can be very high, but the size of the generated file may be too large for mobile apps $[88,157,158]$. Current practice makes use of remeshing techniques and the addition of normal maps to reduce the size of the mesh while maintaining the realism of the final 3D model. By incorporating realistic 3D models and add interactivity to the AR experience, the user can feel more immersed in the app.

\section{Remeshing architectural features.}

It is possible to create extremely high-quality 3D models using photogrammetry. However, the generated 3D models contain a very large number of polygonal faces, resulting in meshes that are too heavy and complex for loading and displaying in mobile devices. Therefore, the recreation and optimization of the same polygonal surface with more optimal geometry by retopologizing the mesh is necessary for AR app development. Instant Meshes, an open-source, quad-based auto-retopology software has been used herein to simplify complex meshes faster and easier than other workflow methodologies [157]. 


\section{Texturing grotesques.}

The goal in retexturing meshes is to make a low-resolution mesh as visually similar as possible to a high-resolution mesh using a set of processes that transfer details from one model to another (the process is known as baking). Baking a mesh will retain detailed information from a high-resolution mesh that is otherwise lost in a low-resolution version [159].

Normal maps can project the geometry of a high-resolution mesh onto a low-resolution mesh. As such, the combination of two texture layers, one being a coloured texture and the second being a normal map, can be utilized to add detail at different angles. In this case, the texture of the photogrammetric 3D model and the normal map were used to produce a mesh that resembles a highly photorealistic photogrammetric 3D model, even though it is a lowresolution mesh.

\section{Interactivity.}

Typically, AR applications rely on passive experiences in which the user points the camera of a mobile device to the scene and virtual objects are displayed. However, a more active experience can be developed through greater interaction with the app and device. As such, for this study, different actions have been developed to display and modify the virtual content using Unity, a powerful cross-platform game engine with the ability to manipulate 3D content using C\# scripting. This software, compared to others, is the easiest to use [41] and Vuforia Library provides a plugin for it.

The intent of the AR experiences at the Centre Block is to show visitors the history of the building. The first Centre Block that was built in the late 1800s was destroyed by a fire in 1916 . While the structure that was built to replace it has a similar building footprint and symmetrical facade, the second Centre Block is taller and has a more predominant central element-the Peace Tower. The Peace Tower is the terminus of a long central axis of the Parliamentary grounds.

To show the architectural differences between the original Centre Block (Figure 5.8b) and the Centre Block standing on Parliament Hill today (Figure 5.8a), a set of archival images was used to create an animation of the construction process over the last century. When the application recognizes the current Centre Block building, it presents the first archival image, after which the user can view the rest of the images by swiping the touch screen (Figure 5.8). Additionally, pressing a button can activate or deactivate the animation. 
Another important feature of the application is the possibility for the user to take a photo with the historical content in the background, similar to a modern-day 'selfie'. To accomplish this, a button has been added that takes a screenshot and stores it in the device's gallery using the Unity Native Gallery plugin. The virtual content that arose is always displayed in front of the real world, that is, virtual images appear in front of everything, covering the people intended to be part of the photo being taken. To solve the occlusion problem, the virtual images were placed above the visitors, which was possible due to the position of the building as seen in Figure 8 . In addition, the background frame was changed to transparent, thus avoiding covering part of the subject's body. Once the AR experience is launched at the Centre Block (Figure 1a), it allows the virtual content to appear above the subject in the photo.

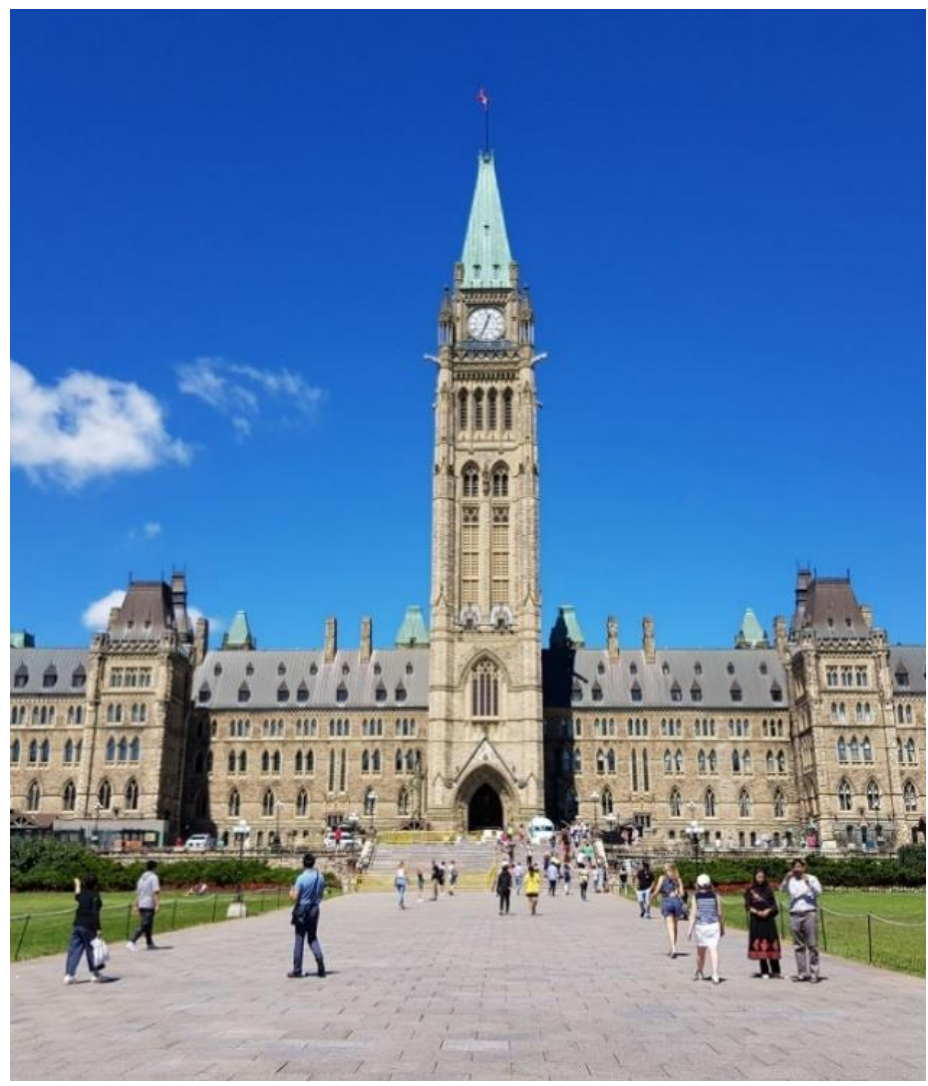

a 


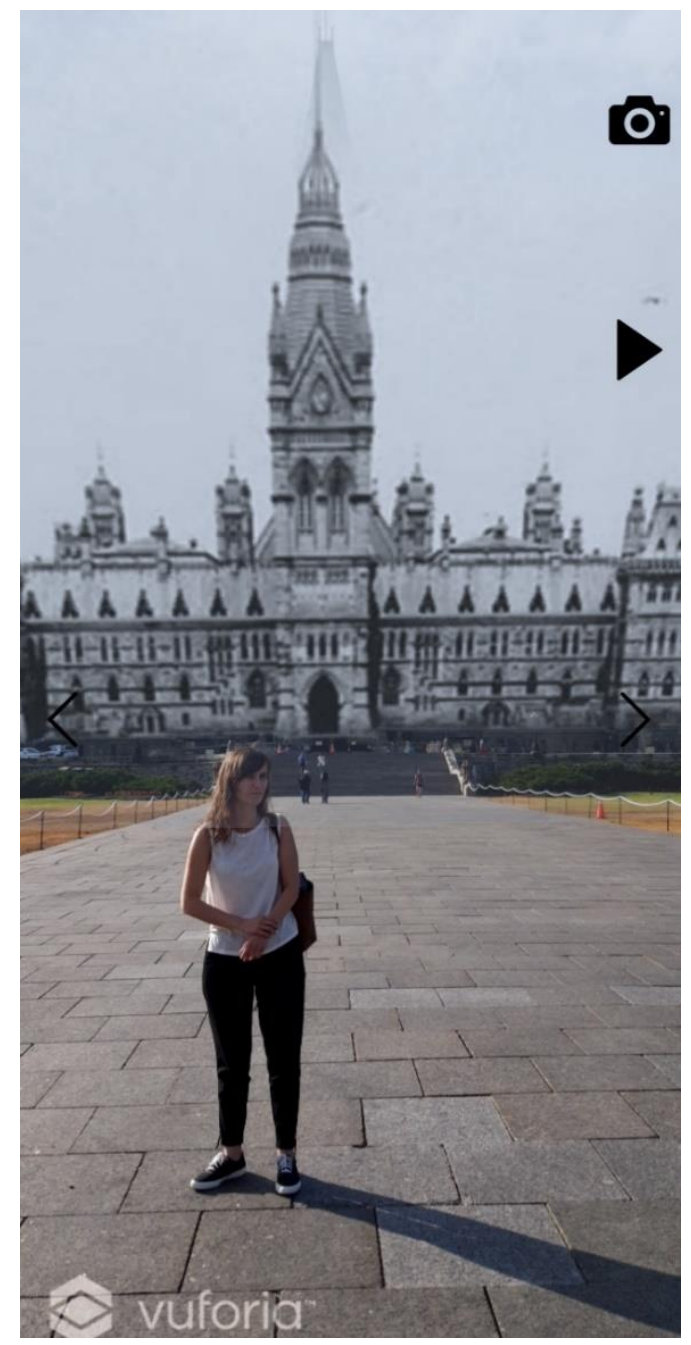

b

Figure 5.8 Centre Block: a) Tourist photography (2018) and b) simulated photography merging historic and present (2018) content as a deliverable of the History Centre Block AR app. This app was developed with the Vuforia AR Library.

On the West Block, there are two grotesques placed on the East facade of the building situated on either side of the entrance to the East Wing. As an attempt to better showcase appreciation for these grotesques, an AR experience was developed that presents two interactive hotspots (Figure 5.9) which, upon being tapped, open up a new display with an animation of the 3D grotesque selected. In addition, the user can zoom in and zoom out to see the detail of each 3D model. 


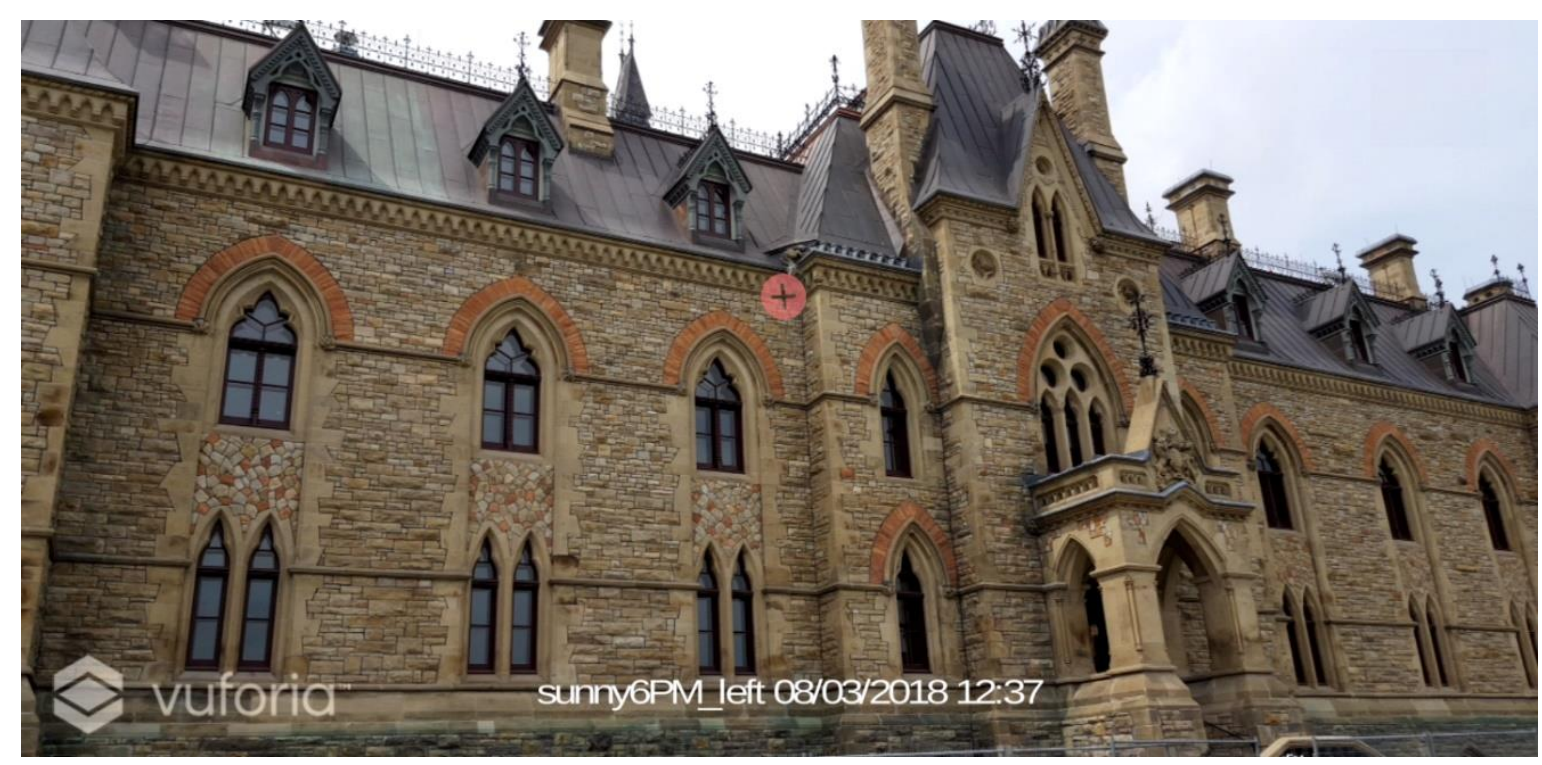

Figure 5.9 Screenshot taken with the Grotesque AR experience in which the hotspot appears.

\subsection{DISCUSSION}

The image recognition presented herein works well due to the flat nature of the buildings' facades. However, the AR app must be launched from a specific location in order to maintain the same geometry between images captured by the user and the image used as a markerless target. Since image recognition is based on a set of geometric features from the stored image, the image must be the same. This remains problematic. The orientation of the sun creates very harsh shadows that change depending on the time of day, producing different images of the building. For this reason, tracking in the afternoon does not work with an image target taken in the morning. However, by adding different image targets at different times of the day, this problem was solved. From 18:00 on, the sun is behind the Hill and there are no shadows on the façades, just like on a cloudy day. If the facade is not affected by the sun, as in the case of East Block, the application works with one image target regardless of the time of the day.

This application was developed during the summer. For other seasons, it would be necessary to add additional images.

Another thing to consider is the realism of the virtual content. According to Bruno et al. and Comes et al. [88,158], visual realism depends on two components: first, the capacity of the virtual object to appear real in contrast to the geometry and texture of the model and, second, the fidelity of the lighting. In the case presented herein, the images superimposed on the Centre Block have been previously processed, eliminating the background and have been placed and scaled to obtain a good alignment with the real building so that the user perceives the image to be as real as possible. The problem with the Vuforia library is that it does not produce shadows when the virtual content is added. This affected the quality of the grotesque experience in particular. The issue could be addressed by using other libraries that compensate for shadowssuch as ARCore.

The main goal of an AR application is to display virtual and real objects together accurately with minimal registration error so that the user feels that the virtual objects are part of the real scene. The problem that arises is that virtual objects are always displayed in front of the real 
objects causing a lack of realism. This problem arises when the user wants to take a selfie with the augmented content. When the user partially blocks the view of the virtual content, it does not work properly as it should be hidden away to make it appear behind the user. To avoid the occlusion issue in this case study, a transparent background frame has been added to the image (virtual content) so that it does not cover users who want to take selfies. In addition, due to the building position, the augmented image is typically above the user, thus avoiding the occlusion problem. This method works flawlessly for users of average height, so a more appropriate solution would be to use a real-time method to calculate the occlusion. Currently, occlusion issues are a major challenge in AR and several studies are focused on solving this problem. Behzadan et al. [160] introduce a depth-based occlusion handling method to detect and correct occlusion cases between virtual and real objects in real-time and in an outdoor, unprepared environment. Yuan et al. [161] propose an effective occlusion handling method based on 3D reconstruction. Other research studies follow a contour-based approach to resolve the occlusion problem in AR $[162,163]$. The problem with these solutions is that they require significant processing power. This may be less of a problem in the future.

One of the advantages of an AR app is the ability to display large amounts of information related to an object and to access that information interactively. This can be used to enhance the tourist experience [164] or to augment learning experiences in the context of structured education [165].

\subsection{CONCLUSIONS}

In this chapter, outdoor AR tracking has been studied using a markerless multi-image approach in a real environment. The markerless multi-image approach is characterized by using a set of images taken at different times of the day and taken from the same position. The results demonstrate that this approach is effective in an outdoor environment with dramatic changes in lighting, thus this methodology could be applied in most cases if a thorough study of the lighting is conducted beforehand.

The advantages of this markerless multi-image approach over others, such as model-based tracking, are faster processing time and the availability of free libraries (i.e., as provided by Vuforia and ARCore) that include image tracking. Multi-image tracking is a new way to achieve a functional AR application in outdoor environments, being fast and easy to apply. Despite the increased number of AR applications that are being developed and applied to smart tourism, especially in the field of cultural heritage, these applications are generally focused on museum exhibitions due to the difficulty to achieve adequate results in outdoor environments, as has been reported in this paper.

In future work, additional imagery will be added to enrich the markerless image dataset (i.e., pictures with snow). This multi-image approach will be compared with model-based tracking to identify the best AR solution for outdoor environments. 


\section{6}

\section{Overall Discussion}

This thesis has delved into AR through mobile devices. The main frameworks have been analysed showing their strengths and drawbacks. The methodology to implement an outdoor application has been studied analysing its main disadvantages and how to solve them. And, finally, the technology has been evaluated through the opinion of the users who have also valued its usability. Even so, there are still many points to be analysed along the way.

This study has focused on 2D tracking, from the premise that in the places where this technology has been applied, the objects recognition was on practically flat walls which can be considered as a 2D plane. The results obtained from 2D tracking have been successful, but currently, there are frameworks that have 3D tracking, mainly useful for the recognition of complex 3D objects. It would be interesting to apply 3D tracking to the rock art paintings recognition covered by this study in order to compare the results and to establish which approach is more accurate and whether it improves the recognition and tracking of the paintings in any way. Furthermore, using 3D tracking it would not be necessary to split the area into small 2D planes but a larger area could be used. In addition, it would be necessary to analyse the paintings recognition on more irregular walls where the approach to a $2 \mathrm{D}$ plane is not possible, to evaluate if with 3D tracking it works. The use of this approach is less extended because nowadays there are few frameworks that include it and it is usually a paid service. The research [166] includes a comparison of frameworks for Mobile AR development where they are decomposed by the type of 2D and 3D tracking.

Besides flatness, the main problem with outdoor tracking is natural lighting. As the recognition object is in an environment with changing illumination, the recognition image does not coincide in some cases with the image of the real object, since during the different hours of the day the lighting changes can cause very strong shadows and colour differences on the object. In Section 5.3.2 the different outdoor tracking methods have been shown, and finally in this 
study a vision-based approach based on the recognition of multiple images has been adopted, which has given very good results.

The drawback of this methodology is the need to add as many images as there are drastic variations in lighting, which can increase the weight of an application that contains several recognition scenarios. However, for an application such as the one developed in Section 5.3.3 this approach works well. Another option provided by libraries such as Vuforia is object recognition, where the 3D model of the object is used instead of 2D images. In this way, the problems of illumination and camera perspective could be avoided although it has a higher computational cost [167]. Whenever developing an outdoor AR application, this issue must be taken into account by choosing an approach that allows the application to work at any time of the day, regardless of the lighting.

During the research carried out in the Canadian Parliament Hill, specifically during the development of the Centre Block application, the problem of occlusion was discovered. This problem arises when real objects are in front of virtual objects in the scene. If the occlusion is not taken into account, the virtual object is always positioned in front, even though the virtual object should actually be occluded by the real object in the scene. This leads to the user getting the wrong idea of reality and detracts from realism [164].

This problem was recurring in the Centre Block app due to the scenario configuration. The recognition object (the building itself) was located far away from the user, in an area where people frequently pass by in front of it, which often caused the virtual image to be displayed in front of people. When this happened, the realism of the app was lost and there was no longer a sense of immersion. As has been studied throughout this research, an AR app has to be immersive, the user has to have the feeling that the augmented objects are part of reality, if this does not happen the app will not be considered as a succesful development.

In short, occlusion refers to hiding virtual objects behind real elements of the scene. This is currently the biggest challenge that remains to be solved in AR. A robust solution to this problem will lead to optimal and highly immersive applications. Mixed Reality (MR) emerged to meet this challenge. In this approach, real and virtual world objects merge and interact in real-time. Proper handling of the occlusion between real and virtual objects is the most important property for the MR system to work correctly [168]. This technology is the solution to the limitations of AR but due to high cost and computational needs, it has not been a widely adopted method. The launch of new MR devices, such as Microsoft's HoloLens, will help the technology to expand [169]. Some studies such as $[169,170]$ evaluate MR in the medical field. Medicine is one of the fields where $M R$ is being used the most, although there are also some researches applied to cultural heritage; [107] makes a compilation of some of them.

Mainly, to resolve the occlusion problem, a 3D reconstruction of the scene is required. The better the 3D reconstruction is, the more accurate the occlusion result will be. There are two approaches for handling occlusion problem: model-based and depth-based [163].

The model-based method requires a pre-built mesh of the scene. This is an accurate method but only valid for static scenes, with this method objects that are not part of the prebuilt model, such as people or moving objects, will not be occluded. Thus, achieving an occlusion in real-time, for the whole objects of the scene, a real-time map is required. This is achieved with the depth-based approach. 
Real-time occlusion handling requires a depth map, this is the depth-based approach. This method uses smartphone sensors or stereo cameras to obtain the 3D depth map [171]. The main drawbacks are the high computational cost which is unmanageable for many of today's smartphones and inaccurate depth information. Currently, several studies are focused on improving this method [171-173].

Smartphone technology is astonishing and the advances are huge. In 2018 some high-end models began to incorporate TOF (Time of Flight) sensors, i.e. a system for determining depth information based on infrared light. This technique calculates the distance from the time elapsed between the emission and reception of infrared light. With these IR sensors, the real-time depth map is a reality. At the moment this technology is available in several high-end smartphones, such as Samsung Galaxy S20 Ultra, Real X2 Pro, Honor View20 or LG G8s. It is an indication of how technology is evolving and the possibilities that are yet to come.

On the other hand, Apple is including in its new models the LIDAR, a scanner based on infrared light, very similar to the TOF but more accurate, capable of obtaining a point cloud in a few seconds. In addition, for iPhones with this Lidar Scanner, ARKIT 4 includes a Depth API which, combined with the generated 3D mesh, provides a real-time depth map [174].

Besides the sensors integration in the new smartphones, in June 2020 Google announced the ARCore Depth API. The API uses a depth-from-motion algorithm to build depth maps only with a single RGB camera [175]. This solution was included in the ARCore library precisely to improve the occlusion problem and allow the creation of more realistic experiences on all kinds of mobiles. The API works on devices without TOF although the depth map obtained is more accurate if the device is equipped with a sensor.

Therefore, it seems that the occlusion problem already has a solution, although it would be interesting in future works, including the occlusion treatment with the use of these libraries in order to evaluate the existing solutions as well as to assess how much the realism of the applications is improved.

The work here has focused solely on the development and analysis of AR applications for smartphones, since the majority of the population now has these devices. But there are mixed reality smartglasses (based on MR) that are in technological expansion, such as Microsoft HoloLens, whose great advantage is that it allows you to explore the surroundings hands-free. These devices make the AR experience much comfortable and natural. Without the need to hold the smartphone, these wearable headsets offer the possibility to visualise virtual information from the user's point of view, while still being able to manipulate objects [170].

HoloLens is equipped with four cameras and a depth sensor to simultaneously map the environment and track the device's movements, which can be used to create a 3D mesh [176]. The major drawback is their high price but they are indispensable for some jobs such as guidance or remote assistance [177]. That is the case studied in [178] where the use of Hololens in the industry as remote assistance in maintenance tasks was evaluated, one of the results found that HoloLens remote assistance was clearer than traditional methods. In the medical field, these devices have huge potential not only in remote guidance, but also in education, simulation or even telemedicine. One example is the [170] study evaluating HoloLens in pathology applications whereby residents can be guided through remote instructions with all kinds of virtual information such as 3D images, diagrams and so on. 
Several companies are currently developing their own AR glasses, such as Qualcumm [179], Sony [180] or Apple. This suggests that the market is interested in this type of device and is betting on AR technology. Over time, the technology will improve and become cheaper, making it available to many. Although in cultural heritage applications, such as those developed in this research, being hands-free is not a necessity, it seems that AR glasses are more comfortable and easier to use. In future work, it would be interesting to know if the end-user prefers these devices instead of their own phone, and to evaluate the advantages of using these devices over the smartphone ones.

As detailed above, the development of AR despite being more than two decades old, depends on the technological moment. As technology progresses, AR improves and becomes more important in our society, from providing additional information for tourism to being used for everyday tasks.

This thesis provides a starting point to know the current state of this technology applied in the cultural field, but it also serves as a sample to know at what point it is, what advances have been made and what remains to be done. Clearly, it is a technology that is gradually being consolidated and in the field studied here, it will be and already is very important. Dissemination through this technology will continue to grow and more and more examples of use cases will be seen.

As outlined in this chapter, there is still some room for improvement in current $A R$ applications but the coming future is very promising. New technologies are advancing quickly and this favours $A R$ in more immersive and natural experiences. Existing solutions will have to be further improved, but AR is already a great tool for dissemination in all fields, especially in rock art, and will become even more so in the future. 


\section{7 \\ Conclusions}

This thesis arose from the hypothesis that challenging rock art and cultural heritage dissemination can be greatly aided by $A R$ techniques. The use of this new visualization technology, which is still in development and evolution, allows showing information in situ on any surface. The main goal of this study was to improve rock art dissemination by making use of new technologies.

The conclusion after the thesis development is actually AR is a great means to this end. It helps, enriches, complements any object, set or site with all kinds of information. It is an intuitive and easy to use technology that, in a comfortable way, provides a great amount of information, and if a good mobile application is designed with good contents, it can greatly favour the understanding of rock art and the dissemination of cultural heritage as a whole. In order to reach this conclusion, the thesis has been divided into several important issues which required indepth study and which are summarised below.

The first goal was to study AR as a visualisation technique and its use and development on mobile devices. The technology is quite advanced and the current smartphones are very powerful which helps enormously in the development of applications of this type. There are many AR libraries and researches but the application of these techniques on rock art is largely conditioned by the place where the paintings are located.

The image recognition technique studied in this thesis is conditioned by $2 \mathrm{D}$ images but the real environment cannot be considered as a flat surface. In many cases, the rock art paintings are located on rock walls that can be assumed as laying on a 2D plane if they are subdivided into small areas, but there will be cases where it is not possible. In those cases, it will be necessary to search for a library that allows 3D tracking and study its correct functioning and performance.

Another issue is the irregular lighting. There will be places where the solar lighting changes drastically throughout the day, or places in the darkness where the rock motifs are not seen properly. 
As explained throughout this document, the recognition and tracking require easily recognizable features in the image captured by the smartphone's camera. This problem can be solved from a multi-image approach, as studied in Chapter 5 . When developing an AR application outdoors, it will have to be borne in mind how the recognition scenario will change throughout the day and over time. Knowing all the possible scenarios, it will be able to establish the images required for the application.

It is therefore essential to evaluate the site where the AR is requested, based on the requirements set out in Chapter 3 , and to assess which programming libraries are best suited. If the place of study does not comply with the minimum requirements of lighting, distance to the object and minimum features detected, it will not be possible to apply the evaluated technique.

Regarding the analysis of the AR libraries, the conclusions were that not all the libraries are valid for rock art due to the above (difficulty in detecting features). The problem is that the commercial libraries are designed for simple applications such as the detection of book photographs. In the case of rock art, it will depend on the place and its conditions. At the moment of study and development of this thesis, the most used libraries were Vuforia and Artoolkit, with this last one being the only open-source tool. While Vuforia was one of the libraries with more trajectory and more references of reported cases, this library did not work in a real case due to the fact that the features detected were not enough. It is therefore very important to study the different libraries and choose the most appropriate one according to the prerequisites.

The good thing is that as the technology advances, new libraries are developed and the existing ones are improved as well as new functionalities are added, which ensures that in the future, the applications developed here can be improved with the new libraries. An example of this is the two Software Development Kits (SDK) presented in 2017 by Apple and Google for building AR applications for mobile devices: ARKit and ARCore. These two frameworks described in [181] include very interesting new capabilities based mainly on adding realism to the developed applications such as light estimation, shadows generation, environmental understanding or flat surface detection. Both frameworks are easy to use which facilitates the growth of new applications.

The second objective was to know the user's interest in this technology. Although a priori this technology seems very suitable as a tool for disseminating rock art, it is essential to know the opinion of the user to whom it is addressed. The response from users who tried the rock art app was very positive. They found the application very useful as it allows them to perfectly locate the paintings and understand what they represent, which without this help is very difficult, in some cases impossible, due to the degradation of the paintings.

In addition to rock art application, a small number of cultural heritage AR applications were developed and tested by different groups of people. Summarizing the survey result, initially, AR applications are quite impressive and people react very well, but then, if the application does not have other functionalities, people may react to losing interest. Therefore, it is important to add interactivity to these applications, such as quiz games, animations, interest information, or interactions with social network and not just augmented objects. Applications should show renewed information over time, providing new data to users each time they use them.

During the surveys it was realized that for most users AR was an unknown technology and therefore the first time they used it, being a bit complicated to understand despite its ease of 
use. This is a bit contradictory, because even though AR was introduced more than a decade ago and is constantly growing, it is still unknown to a large number of people.

In conclusion, there is still a need to invest in developing more AR applications that reach the end-user and become part of his/her daily life. In addition, these applications must meet the requirements of usability, be well designed and be attractive to the user. So that they are a good resource and more and more users seek this type of application. The design of the application is as important as the correct running of the technology. Following these premises, in the future AR applications may dominate the fields of cultural heritage dissemination.

After all, the goal of an AR application is to be immersive, to provide a sense of reality and to run smoothly. These objectives have been met in this research but with new MR techniques, this can be improved. Therefore, in order to complete the analysis of outdoor tracking and seeing the need to handle occlusion correctly, future work should focus on studying the 3D tracking and depth mask libraries in order to develop an MR application. This will provide insight into the differences between 2D and 3D tracking and possible improvements in the quality of more realistic and immersive experiences. However, it is necessary to check if current mid-range smartphones have enough computational requirements to obtain a fast and accurate result in the recognition and tracking of 3D objects.

Therefore, it would be necessary for future works to make a comparison between 2D and 3D tracking and a detailed study of occlusion handling. Moreover, given that both iOS and Android currently provide their own libraries for AR, it would be interesting to determine whether it is possible to use these libraries to create the applications developed here and to analyse their functionalities. 


\section{References}

[1] C.D. Kounavis, A.E. Kasimati, E.D. Zamani, Enhancing the tourism experience through mobile augmented reality: Challenges and prospects, International Journal of Engineering Business Management. 4 (2012) 1-6. https://doi.org/10.5772/51644.

[2] J. Carmigniani, B. Furht, M. Anisetti, P. Ceravolo, E. Damiani, M. Ivkovic, Augmented reality technologies, systems and applications, Multimedia Tools and Applications. 51 (2011) 341-377. https://doi.org/10.1007/s11042-010-0660-6.

[3] T.H. Höllerer, S.K. Feiner, Chapter Nine Mobile Augmented Reality, in: Telegeoinformatics: Location-Based Computing and Services, 2004: pp. 1-39.

[4] D. Chatzopoulos, C. Bermejo, Z. Huang, P.A.N. Hui, Mobile Augmented Reality Survey : From Where We Are to Where We Go, IEEE Access. 5 (2017) 6917-6950. https://doi.org/10.1109/ACCESS.2017.2698164.

[5] C. Garrett, Bernie M.; Anthony, Joseph; and Jackson, Using Mobile Augmented Reality to Enhance Health Professional Practice Education, Current Issues in Emerging ELearning. 4 (2018) Article 10.

[6] E.Z. Barsom, M. Graafland, M.P. Schijven, Systematic review on the effectiveness of augmented reality applications in medical training, Surgical Endoscopy. 30 (2016) 41744183. https://doi.org/10.1007/s00464-016-4800-6.

[7] S. Bernhardt, S.A. Nicolau, L. Soler, C. Doignon, The status of augmented reality in laparoscopic surgery as of 2016, Medical Image Analysis. 37 (2017) 66-90. https://doi.org/10.1016/j.media.2017.01.007.

[8] D.D. Han, T. Jung, Dublin AR: Implementing Augmented Reality (AR) in Tourism, Information and Communication Technologies in Tourism 2014. (2013). https://doi.org/10.1007/978-3-319-03973-2.

[9] J. Challenor, M. Ma, A Review of Augmented Reality Applications for History Education and Heritage Visualisation, Multimodal Technologies and Interaction. 3 (2019) 39.

[10] J.M. Gutierrez, M.A. Molinero, O. Soto-Martín, C.R. Medina, Augmented Reality Technology Spreads Information about Historical Graffiti in Temple of Debod, Procedia $\begin{array}{lllll}\text { Computer } & \text { Science. } & 75 & \text { (2015) }\end{array}$ https://doi.org/http://dx.doi.org/10.1016/j.procs.2015.12.262.

[11] R. Pierdicca, E. Frontoni, P. Zingaretti, E.S. Malinverni, F. Colosi, R. Orazi, Making Visible the Invisible. Augmented Reality Visualization for 3D Reconstructions of Archaeological Sites, Augmented and Virtual Reality: Second International Conference, AVR 2015. 9254 (2015) 25-37. https://doi.org/10.1007/978-3-319-22888-4.

[12] G. Younes, R. Kahil, M. Jallad, D. Asmar, I. Elhajj, G. Turkiyyah, H. Al-harithy, Virtual and augmented reality for rich interaction with cultural heritage sites : A case study from the Roman Theater at Byblos, Digital Applications in Archaeology and Cultural Heritage. 5 (2017) 1-9. https://doi.org/10.1016/j.daach.2017.03.002. 
[13] UNESCO, Rock Art of the Mediterranean Basin on the Iberian Peninsula, (2020). http://whc.unesco.org/en/list/874 (accessed June 15, 2020).

[14] Ines Domingo Sanz, LRA (Levantine Rock Art), Quaterly E-Journal of Atelier in Cooperation with Uispp-Cisnep. International Scientific Commission on the Intellectual and Spiritual Expressions of Non-Literate Peoples. (2016).

[15] V. Villaverde Bonilla, R. Martínez, P.M. Guillem Calatayud, E. López-Montalvo, I. Domingo Sanz, What do we mean by Levantine rock art?, The Levantine Question: PostPalaeolithic Rock Art in the Iberian Peninsula. (2012) 81-106.

[16] ICOMOS, ICOMOS International Cultural Tourism Charter: Principles And Guidelines For Managing Tourism At Places Of Cultural And Heritage Significance, 2002.

[17] V. Vlahakis, N. loannidis, J. Karigiannis, M. Tsotros, M. Gounaris, D. Stricker, T. Gleue, P. Daehne, L. Almeida, Archeoguide: An augmented reality guide for archaeolog sites, IEEE Computer Graphics and Applications. 22 (2002) 52-60. https://doi.org/10.1109/MCG.2002.1028726.

[18] T. Miyashita, P. Meier, T. Tachikawa, S. Orlic, T. Eble, V. Scholz, A. Gapel, O. Gerl, S. Arnaudov, S. Lieberknecht, An augmented reality museum guide, Proceedings - 7th IEEE International Symposium on Mixed and Augmented Reality 2008, ISMAR 2008. (2008) 103-106. https://doi.org/10.1109/ISMAR.2008.4637334.

[19] I.R. Draganov, O.L. Boumbarov, Investigating Oculus Rift Virtual Reality Display Applicability to Medical Assistive System for Motor Disabled Patients, The 8th IEEE International Conference on Intelligent Data Acquisition and Advanced Computing Systems: Technology and Applications. (2015) 751-754.

[20] S. Valtolina, S. Franzoni, P. Mazzoleni, E. Bertino, Dissemination of Cultural Heritage Content through Virtual Reality and Multimedia Techniques: A Case Study, 11th International Multimedia Modelling Conference. (2005) 214-221. https://doi.org/10.1109/MMMC.2005.36.

[21] A. Fineschi, A. Pozzebon, A 3d virtual tour of the santa maria della scala museum complex in siena, italy, based on the use of oculus rift hmd, 2015 International Conference on 3D Imaging (IC3D). (2015) 1-5. https://doi.org/10.1109/IC3D.2015.7391825.

[22] S.L. Kim, H.J. Suk, J.H. Kang, J.M. Jung, T.H. Laine, J. Westlin, Using Unity 3D to facilitate mobile augmented reality game development, Internet of Things (WF-IOT), 2014 IEEE World Forum On. (2014) 21-26. https://doi.org/10.1109/WF-loT.2014.6803110.

[23] ARToolKit, Open Source Augmented Reality SDK I ARToolKit.org, (2017). http://artoolkit.org/ (accessed December 10, 2017).

[24] BeyondAR, Home / BeyondAR, (2016). http://beyondar.com/ (accessed May 26, 2016).

[25] DroidAR, DroidAR by bitstars, (2017). https://bitstars.github.io/droidar/ (accessed December 10, 2017).

[26] Mixare, mixare I Free Open Source Augmented Reality Engine, (2016). http://www.mixare.org/ (accessed May 26, 2016).

[27] Vuforia, Home I Vuforia, (2016). http://www.vuforia.com/ (accessed May 26, 2016).

[28] Oculus-Rift, Oculus Rift, (2016). https://www.oculus.com/en-us/rift/ (accessed May 26, 2016).

[29] P.S. Paul, S. Goon, A. Bhattacharya, History and comparative study of modern game 
engines, International Journal of Advanced Computed and Mathematical Sciences. 3 (2012) 245-249.

[30] Unity - Manual: Unity Manual, Unity - Manual: Unity Manual, (2016). http://docs.unity3d.com/Manual/UnityManual.html (accessed February 24, 2016).

[31] Unreal-Engine, Unreal Engine Technology I Home, (2016). https://www.unrealengine.com/blog (accessed May 26, 2016).

[32] CryEngine, CryEngine, (2016). https://www.cryengine.com/features (accessed May 26, 2016).

[33] G. Pavlidis, A. Koutsoudis, F. Arnaoutoglou, V. Tsioukas, C. Chamzas, Methods for 3D digitization of Cultural Heritage, Journal of Cultural Heritage. 8 (2007) 93-98. https://doi.org/http://dx.doi.org/10.1016/j.culher.2006.10.007.

[34] Y. Furukawa, J. Ponce, Accurate, Dense, and Robust Multiview Stereopsis, Pattern Analysis and Machine Intelligence, IEEE Transactions On. 32 (2010) 1362-1376. https://doi.org/10.1109/TPAMI.2009.161.

[35] N. Micheletti, J.H. Chandler, S.N. Lane, Structure from Motion ( SfM ) Photogrammetry, Geomorphological Techniques. 2 (2015) 1-12.

[36] J.L. Lerma García, M. Santana Quintero, E. Heine, B. Van Genechten, Theory and practice on terrestrial laser scanning. Training material bases on practical applications, Editorial Universitat Politècnica de València, Valencia, 2008.

[37] S. Siltanen, Diminished reality for augmented reality interior design, Visual Computer. 33 (2015) 1-16. https://doi.org/10.1007/s00371-015-1174-z.

[38] R. Azuma, A survey of augmented reality, Presence: Teleoperators and Virtual Environments. 6 (1997) 355-385. https://doi.org/10.1.1.30.4999.

[39] D. Amin, S. Govilkar, Comparative Study of Augmented Reality Sdk'S, International Journal on Computational Sciences \& Applications. 5 (2015) 11-26. https://doi.org/10.1227/01.NEU.0000297044.82035.57.

[40] R. Azuma, Y. Baillot, S. Feiner, S. Julier, R. Behringer, B. Macintyre, Recent Advances in Augmented Reality, leee Computer Graphics And Applications. (2001) 34-47. https://doi.org/10.4061/2011/908468.

[41] S. Blanco-Pons, B. Carrión-Ruiz, J.L. Lerma, Review of augmented reality and virtual reality techniques in rock art, in: Proceedings of the 8th International Congress on Archaeology, Computer Graphics, Cultural Heritage and Innovation 'ARQUEOLÓGICA 2.0,' 2016: pp. 176-183. https://doi.org/http://dx.doi.org/10.4995/arqueologica8.2016.3561.

[42] N. Brancati, G. Caggianese, M. Frucci, L. Gallo, P. Neroni, Experiencing touchless interaction with augmented content on wearable head-mounted displays in cultural heritage applications, Personal and Ubiquitous Computing. 21 (2017) 203-217. https://doi.org/10.1007/s00779-016-0987-8.

[43] B. Ridel, P. Reuter, J. Laviole, N. Mellado, N. Couture, X. Granier, The Revealing Flashlight: Interactive Spatial Augmented Reality for Detail Exploration of Cultural Heritage Artifacts, Journal on Computing and Cultural Heritage. 7 (2014) 6:1-6:18. https://doi.org/10.1145/2611376.

[44] Z.B. Haladová, R. Szemzö, T. Kovačovský, J. Žižka, Utilizing Multispectral Scanning and Augmented Reality for Enhancement and Visualization of the Wooden Sculpture 
Restoration Process, Procedia Computer Science. 67 (2015) 340-347. https://doi.org/10.1016/j.procs.2015.09.278.

[45] C.Y. Chen, B.R. Chang, P. Sen Huang, Multimedia augmented reality information system for museum guidance, Personal and Ubiquitous Computing. 18 (2014) 315-322. https://doi.org/10.1007/s00779-013-0647-1.

[46] I. Domingo, B. Carrión, S. Blanco, J.L. Lerma, Evaluating conventional and advanced visible image enhancement solutions to produce digital tracings at el Carche rock art shelter, Digital Applications in Archaeology and Cultural Heritage. 2 (2015) 79-88. https://doi.org/http://dx.doi.org/10.1016/j.daach.2015.01.001.

[47] B. Carrión-Ruiz, S. Blanco-Pons, J.L. Lerma, Digital image analysis of the visible region through simulation of rock art paintings, in: Proceedings of the 8th International Congress on Archaeology, Computer Graphics, Cultural Heritage and Innovation 'ARQUEOLÓGICA 2.0,' 2016: pp. 169-175. https://doi.org/http://dx.doi.org/10.4995/arqueologica8.2016.3560.

[48] D. Khan, S. Ullah, I. Rabbi, Factors affecting the design and tracking of ARToolKit markers, Computer Standards and Interfaces. 41 (2015) 56-66. https://doi.org/10.1016/j.csi.2015.02.006.

[49] A.B. Dos Santos, J.B. Dourado, A. Bezerra, ARToolkit and Qualcomm Vuforia: An Analytical Collation, Proceedings - 18th Symposium on Virtual and Augmented Reality, SVR 2016. (2016) 229-233. https://doi.org/10.1109/SVR.2016.46.

[50] I. Rabbi, S. Ullah, M. Javed, K. Zen, Analysis of ARToolKit Fiducial Markers Attributes for Robust Tracking, 1st International Conference of Recent Trends in Information and Communication Technologies Analysis (IRICT). (2014) 281-290.

[51] ARToolkit, ARToolkit, (2017). https://archive.artoolkit.org/ (accessed October 2, 2017).

[52] Vuforia, Vuforia, (2017). https://www.vuforia.com/ (accessed October 2, 2017).

[53] J. Fischer, M. Eichler, D. Bartz, W. Straßer, A hybrid tracking method for surgical augmented reality, Computers and Graphics (Pergamon). 31 (2007) 39-52. https://doi.org/10.1016/j.cag.2006.09.007.

[54] G. Sörös, H. Seichter, P. Rautek, E. Gröller, Augmented visualization with natural feature tracking, Proceedings of the 10th International Conference on Mobile and Ubiquitous Multimedia. (2011) 4-12. https://doi.org/10.1145/2107596.2107597.

[55] C. González, D. Vallejo, J. Albusac, J. Castro, Realidad Aumentada. Un enfoque práctico con ARToolKit y Blender, (2011) 2-120.

[56] Vuforia, Vuforia-VuMark, (2017). https://library.vuforia.com/articles/Training/VuMark (accessed April 4, 2017).

[57] G. Wang, B. Wang, F. Zhong, X. Qin, B. Chen, Global optimal searching for textureless 3D object tracking, Visual Computer. 31 (2015) 979-988. https://doi.org/10.1007/s00371015-1098-7.

[58] R. Radkowski, J. Oliver, Natural feature tracking augmented reality for on-site assembly assistance systems, in: R. Shumaker (Ed.), Virtual, Augmented and Mixed Reality. Systems and Applications. VAMR 2013. Lecture Notes in Computer Science, Springer, Berlin, Heidelberg, 2013: pp. 281-290. https://doi.org/10.1007/978-3-642-39420-1-30.

[59] H. Uchiyama, E. Marchand, Object Detection and Pose Tracking for Augmented Reality: Recent Approaches, 18th Korea-Japan Joint Workshop on Frontiers of Computer Vision (FCV). (2012) 1-8. 
[60] E. Marchand, H. Uchiyama, F. Spindler, E. Marchand, H. Uchiyama, F. Spindler, Pose estimation for augmented reality : a hands-on survey, IEEE Transactions on Visualization and Computer $\quad$ Graphics. $22 \quad$ 2633-2651. https://doi.org/10.1109/TVCG.2015.2513408.

[61] P. Moreels, P. Perona, Evaluation of Feature Detectors and Descriptors based on 3D Objects, International Journal of Computer Vision. 73 (2007) 263-284. https://doi.org/10.1007/s11263-006-9967-1.

[62] D.G. Lowe, Distinctive image features from scale invariant keypoints, International Journal of Computer Vision. $60 \quad$ (2004) 91-11020042. https://doi.org/http://dx.doi.org/10.1023/B:VISI.0000029664.99615.94.

[63] S. Wu, A. Oerlemans, E.M. Bakker, M.S. Lew, A comprehensive evaluation of local detectors and descriptors, Signal Processing: Image Communication. 59 (2017) 150-167. https://doi.org/10.1016/J.IMAGE.2017.06.010.

[64] P. Alahi A., Ortiz R., Vandergheynst, FREAK: Fast Retina Keypoint, Computer Vision and $\begin{array}{llll}\text { Pattern } \quad \text { Recognition } & \text { (CVPR). }\end{array}$ https://doi.org/10.1109/CVPR.2012.6247715.

[65] Unity, Unity, (n.d.). https://unity3d.com/es (accessed October 12, 2017).

[66] U. Engine, Unreal Engine, (2017). https://www.unrealengine.com/ (accessed October 10, 2017).

[67] CRYENGINE, CRYENGINE I The complete solution for next generation game development by Crytek, (n.d.). https://www.cryengine.com/ (accessed June 7, 2017).

[68] M. Fiala, ARTag, a fiducial marker system using digital techniques, Proceedings of the IEEE Computer Society Conference on Computer Vision and Pattern Recognition. 2 (2005) 590-596. https://doi.org/10.1109/CVPR.2005.74.

[69] ArUco, ArUco: a minimal library for Augmented Reality applications based on OpenCV I Aplicaciones de la Visión Artificial, https://www.uco.es/investiga/grupos/ava/node/26 (accessed April 19, 2018).

[70] Vuforia, Image Targets, (2017). https://library.vuforia.com/articles/Training/ImageTarget-Guide (accessed April 11, 2017).

[71] ARToolkit, About, (2017). https://artoolkit.org/about-artoolkit (accessed April 11, 2017).

[72] ARToolkit, Documentation, (2017). https://artoolkit.org/documentation/ (accessed April 12, 2017).

[73] Camera-Calibration, Camera Calibration App for Android [ARToolkit], (n.d.). https://archive.artoolkit.org/documentation/doku.php?id=4_Android:android_camera_ calibration (accessed October 16, 2017).

[74] R. Martínez, V. Villaverde, La Cova dels Cavalls en el barranc de la Valltorta, Generalitat Valenciana, 2002.

[75] S. Liu, S. Ge, H. Yu, Research on Robustness Recognition Algorithms in Augmented Reality, 3rd International Conference on Information Science and Control Engineering (ICISCE). (2016) 547-552. https://doi.org/10.1109/ICISCE.2016.123.

[76] J. Seo, J. Shim, J.H. Choi, J. Park, T.D. Han, Enhancing marker-based AR technology, in: International Conference on Virtual and Mixed Reality. Virtual and Mixed Reality - New Trends, Springer, Berlin, Heidelberg, 2011: pp. 97-104. https://doi.org/10.1007/978-3642-22021-0_12. 
[77] J.L. Lerma, S. Navarro, M. Cabrelles, A. Elena, N. Haddad, T. Akasheh, Integration of Laser Scanning and Imagery for Photorealistic 3D Architectural Documentation, Laser Scanning, Theory and Applications. (2011). https://doi.org/10.5772/14534.

[78] D. Pritchard, J. Sperner, S. Hoepner, R. Tenschert, Terrestrial laser scanning for heritage conservation: the Cologne Cathedral documentation project, ISPRS Annals of Photogrammetry, Remote Sensing and Spatial Information Sciences. IV-2/W2 (2017) 213-220. https://doi.org/10.5194/isprs-annals-IV-2-W2-213-2017.

[79] L. Gomes, O. Regina Pereira Bellon, L. Silva, 3D reconstruction methods for digital preservation of cultural heritage: A survey, Pattern Recognition Letters. 50 (2014) 3-14. https://doi.org/10.1016/j.patrec.2014.03.023.

[80] K. Themistocleous, Model reconstruction for $\mathbf{3 d}$ vizualization of cultural heritage sites using open data from social media: The case study of Soli, Cyprus, Journal of Archaeological Science: Reports. 14 (2016) 774-781. https://doi.org/10.1016/j.jasrep.2016.08.045.

[81] A. Koutsoudis, B. Vidmar, G. Ioannakis, F. Arnaoutoglou, G. Pavlidis, C. Chamzas, Multiimage 3D reconstruction data evaluation, Journal of Cultural Heritage. 15 (2014) 73-79. https://doi.org/10.1016/j.culher.2012.12.003.

[82] M. Mortara, C.E. Catalano, F. Bellotti, G. Fiucci, M. Houry-Panchetti, P. Petridis, Learning cultural heritage by serious games, Journal of Cultural Heritage. 15 (2014) 318-325. https://doi.org/10.1016/j.culher.2013.04.004.

[83] L. De Marchi, A. Ceruti, A. Marzani, A. Liverani, Augmented reality to support on-field post-impact maintenance operations on thin structures, Journal of Sensors. 2013 (2013). https://doi.org/10.1155/2013/619570.

[84] C. Portales, P. Alonso-Monasterio, M. Jose Vinals, 3D Virtual Reconstruction and Visualisation of the Archaeological Site Castellet De Bernabe (Lliria, Spain), Virtual Archaeology Review. 8 (2017) 75-82. https://doi.org/10.4995/var.2017.5890.

[85] H. Rua, P. Alvito, Living the past: 3D models, virtual reality and game engines as tools for supporting archaeology and the reconstruction of cultural heritage - the case-study of the Roman villa of Casal de Freiria, Journal of Archaeological Science. 38 (2011) 32963308. https://doi.org/10.1016/j.jas.2011.07.015.

[86] A. Koutsoudis, F. Arnaoutoglou, C. Chamzas, On 3D reconstruction of the old city of Xanthi. A minimum budget approach to virtual touring based on photogrammetry, Journal of Cultural Heritage. 8 (2007) 26-31. https://doi.org/10.1016/j.culher.2006.08.003.

[87] A. Bustillo, L. Martínez, M. Alaguero, L.S. Iglesias, The Church of the Charterhouse of Miraflores in Burgos : Virtual Reconstruction of Artistic Imagery, Proceedings of the 38th Annual Conference on Computer Applications and Quantitative Methods in Archaeology. (2013).

[88] F. Bruno, S. Bruno, G. De Sensi, M.L. Luchi, S. Mancuso, M. Muzzupappa, From 3D reconstruction to virtual reality: A complete methodology for digital archaeological exhibition, Journal of Cultural Heritage. 11 (2010) 42-49. https://doi.org/10.1016/j.culher.2009.02.006.

[89] C. Castagnetti, M. Giannini, R. Rivola, Image-based virtual tours and 3d modeling of past and current ages for the enhancement of archaeological parks: The visualversilia 3d project, International Archives of the Photogrammetry, Remote Sensing and Spatial Information Sciences - ISPRS Archives. 42 (2017) 639-645. https://doi.org/10.5194/isprs- 
Archives-XLII-5-W1-639-2017.

[90] A. Gaucci, S. Garagnani, A.M. Manferdini, Reconstructing the lost reality archaeological analysis and Transmedial Technologies for a perspective of Virtual Reality in the Etruscan city of Kainua, in: 2015 Digital Heritage, 2015: pp. 227-234. https://doi.org/10.1109/DigitalHeritage.2015.7419502.

[91] T. Coenen, L. Mostmans, K. Naessens, MuseUs: Case Study of a Pervasive Cultural Heritage Serious Game, Journal on Computing and Cultural Heritage. 6 (2013) 1-19. https://doi.org/10.1145/2460376.2460379.

[92] F. Gabellone, A. Lanorte, N. Masini, R. Lasaponara, From remote sensing to a serious game: Digital reconstruction of an abandoned medieval village in Southern Italy, Journal of Cultural Heritage. $23 \quad$ (2017) 63-70. https://doi.org/10.1016/j.culher.2016.01.012.

[93] A. Bustillo, M. Alaguero, I. Miguel, J.M. Saiz, L.S. Iglesias, A flexible platform for the creation of 3D semi-immersive environments to teach Cultural Heritage, Digital Applications in Archaeology and Cultural Heritage. 2 (2015) 248-259. https://doi.org/10.1016/j.daach.2015.11.002.

[94] K.E. Chang, C.T. Chang, H.T. Hou, Y.T. Sung, H.L. Chao, C.M. Lee, Development and behavioral pattern analysis of a mobile guide system with augmented reality for painting appreciation instruction in an art museum, Computers and Education. 71 (2014) 185-197. https://doi.org/10.1016/j.compedu.2013.09.022.

[95] G. Caggianese, P. Neroni, L. Gallo, Natural Interaction and Wearable Augmented Reality for the Enjoyment of the Cultural Heritage in Outdoor Conditions, De Paolis L., Mongelli A. (Eds) Augmented and Virtual Reality. AVR 2014. Lecture Notes in Computer Science. 8853 (2014) 267-282. https://doi.org/10.1007/978-3-319-13969-2.

[96] E. Dall'Asta, N. Bruno, G. Bigliardi, A. Zerbi, R. Roncella, Photogrammetric techniques for promotion of archaeological heritage: The archaeological museum of parma (Italy), International Archives of the Photogrammetry, Remote Sensing and Spatial Information Sciences - ISPRS Archives. 41 (2016) 243-250. https://doi.org/10.5194/isprsarchives-XLIB5-243-2016.

[97] V. Barrile, A. Fotia, G. Bilotta, D. De Carlo, Integration of geomatics methodologies and creation of a cultural heritage app using augmented reality, Virtual Archaeology Review. 10 (2019) 40-51. https://doi.org/10.4995/var.2019.10361.

[98] M.C. tom Dieck, T.H. Jung, Value of augmented reality at cultural heritage sites: A stakeholder approach, Journal of Destination Marketing \& Management. 6 (2017) 110117. https://doi.org/10.1016/j.jdmm.2017.03.002.

[99] Á. Di Serio, M.B. Ibáñez, C.D. Kloos, Impact of an augmented reality system on students' motivation for a visual art course, Computers and Education. 68 (2013) 585-596. https://doi.org/10.1016/j.compedu.2012.03.002.

[100] E. López-Montalvo, V. Villaverde, C. Roldán, S. Murcia, E. Badal, An approximation to the study of black pigments in Cova Remigia (Castellón, Spain). Technical and cultural assessments of the use of carbon-based black pigments in Spanish Levantine Rock Art, Journal of Archaeological Science. $52 \quad$ (2014) 535-545. https://doi.org/http://dx.doi.org/10.1016/j.jas.2014.09.017.

[101] I. Domingo, V. Villaverde, E. López-Montalvo, J.L. Lerma, M. Cabrelles, Latest developments in rock art recording: Towards an integral documentation of Levantine rock art sites combining 2D and 3D recording techniques, Journal of Archaeological 
Science. 40 (2013) 1879-1889. https://doi.org/10.1016/j.jas.2012.11.024.

[102] V.M. López-Menchero Bendicho, Á. Marchante Ortega, M.L. Vincent, Á.J. Cárdenas Martín-Buitrago, J. Onrubia Pintado, Uso combinado de la fotografía digital nocturna y de la fotogrametría en los procesos de documentación de petroglifos: el caso de Alcázar de San Juan (Ciudad Real, España), Virtual Archaeology Review. 8 (2017) 64-74. https://doi.org/10.4995/var.2017.6820.

[103] A. Iturbe, R. Cachero, D. Cañal, A. Martos, Digitalización de cuevas con arte paleolítico parietal de Bizkaia. Análisis científico y divulgación mediante nuevas técnicas de visualización, Virtual Archaeology Review. 9 (2018) 57-65.

[104] M. Bea, J. Angás, Geometric documentation and virtual restoration of the rock art removed in Aragón (Spain), Journal of Archaeological Science: Reports. 11 (2017) 159168. https://doi.org/10.1016/j.jasrep.2016.11.025.

[105] J.M. Pérez, e-ARt REALIDAD AUMENTADA Y ARTE RUPESTRE, in: XXXIV Reunión de Asociaciones y Entidades Para La Defensa Del Patrimonio Cultural y Su Entorno., 2015: pp. 1-4.

[106] O. Choudary, V. Charvillat, R. Grigoras, P. Gurdjos, MARCH : Mobile Augmented Reality for Cultural Heritage, in: The 17th ACM International Conference on Multimedia, 2009: pp. 1023-1024.

[107] M.K. Bekele, R. Pierdicca, E. Frontoni, E.S. Malinverni, J. Gain, A Survey of Augmented, Virtual, and Mixed Reality for Cultural Heritage, Journal on Computing and Cultural Heritage. 11 (2018) 1-36. https://doi.org/10.1145/3145534.

[108] L. Barazzetti, F. Remondino, M. Scaioni, Extraction of accurate tie points for automated pose estimation of close-range blocks, The International Archives of Photogrammetry and Remote Sensing. 37 (2010) 151-156.

[109] S. Siltanen, Theory and applications of marker-based augmented reality, 2012.

[110] E. Razuvalova, A. Nizamutdinov, Virtual Reconstruction of Cultural and Historical Monuments of the Middle Volga, Procedia Computer Science. 75 (2015) 129-136. https://doi.org/10.1016/j.procs.2015.12.229.

[111] A. Merlo, E.V. Filippo, F. Carlos, The Mayan mascarón from Chilonché ( Petén , Guatemala ): New technologies for cultural heritage dissemination, International Conference on Cultural Heritage and New Technologies. (2012) 1-16.

[112] A.G.R. Marto, A.A. de Sousa, A. Gonçalves, DinofelisAR Demo Augmented Reality Based on Natural Features, $12^{\text {a }}$ Conferência Ibérica de Sistemas e Tecnologias de Informação, Lisboa. 64 (2017) 852-861. https://doi.org/doi.org/10.1016/j.procs.2015.08.638.

[113] S. Garrido-Jurado, R. Muñoz-Salinas, F.J. Madrid-Cuevas, M.J. Marín-Jiménez, Automatic generation and detection of highly reliable fiducial markers under occlusion, Pattern Recognition. 47 (2014) 2280-2292. https://doi.org/10.1016/j.patcog.2014.01.005.

[114] Vuforia, Vuforia Developer Portal, (2017). https://developer.vuforia.com/ (accessed December 15, 2017).

[115] Wikitude, Wikitude Augmented Reality- The World's Leading Cross-Platform AR SDK, (2017). https://www.wikitude.com/ (accessed December 15, 2017).

[116] AR-media ${ }^{\mathrm{TM}}$, AR-media ${ }^{\mathrm{TM}}$ - Home, (2017). http://www.armedia.it/ (accessed December 15, 2017).

[117] R. Radkowski, J. Oliver, Natural feature tracking augmented reality for on-site assembly 
assistance systems, Lecture Notes in Computer Science (Including Subseries Lecture Notes in Artificial Intelligence and Lecture Notes in Bioinformatics). 8022 LNCS (2013) 281-290. https://doi.org/10.1007/978-3-642-39420-1-30.

[118] ARToolKit, Training ARToolKit Natural Feature Tracking (NFT) to Recognize and Track an Image

[ARToolkit],

(n.d.). https://archive.artoolkit.org/documentation/doku.php?id=3_Marker_Training:marker_ nft_training (accessed November 2, 2017).

[119] T. Martínez Gil, V. López Benito, A. Mikel, J. Santacana Mestre, ¿Entretener o aprender? La evaluación de las tecnologías móviles en la Didáctica del Patrimonio, ENSAYOS, Revista de La Facultad de Educación de Albacete. 33 (2018) 39-52.

[120] M. Asensio Brouard, J. Santacana Mestre, E. Pol Méndez, APPLE Project (APP Learning Evaluation): primeros resultados de un estudio hecho en la ciudadela ibérica de Calafell, Revista de Didácticas Específicas. 17 (2017) 8-38.

[121] M. Asensio, Y. Castro, E. Asenjo, E. Pol, J.A. Rodríguez, P. Paredes, A. Cabrera, I. Rodríguez, C. Villar, Cómo aprender disfrutando de la Cocina Valenciana: un modelo de evaluación para el diseño de dispositivos de Realidad Aumentada, in: A. Cabrera, I.M. Rodríguez, C. Villar (Eds.), La Cocina Valenciana Del Museo Nacional de Artes Decorativas. Una Relectura a Través de La Tecnología de Realidad Aumentada, 2013: p. 153-187.

[122] P. Redweik, A.P. Cládio, M.B. Carmo, J.M. Naranjo, J.M. Sanjosé, Digital Preservation of Cultural and Scientific Heritage: Involving University Students to Raise Awareness of Its Importance, Virtual Archaeology Review. $8 \quad$ (2017) 22-34. https://doi.org/10.4995/var.2017.4629.

[123] R. Martínez Valle, El Parque cultural de Valltorta-Gasulla (Castellón), Trabajos de Prehistoria. 57 (2000) 65-76. https://doi.org/10.3989/tp.2000.v57.i2.248.

[124] A. Oulasvirta, T. Rattenbury, L. Ma, E. Raita, Habits make smartphone use more pervasive, Personal and Ubiquitous Computing. 16 (2012) 105-114. https://doi.org/10.1007/s00779-011-0412-2.

[125] D. Wang, Z. Xiang, D.R. Fesenmaier, Smartphone Use in Everyday Life and Travel, Journal of Travel Research. 55 (2016) 52-63. https://doi.org/10.1177/0047287514535847.

[126] M. Billinghurst, A. Clark, G. Lee, A Survey of Augmented Reality, Foundations and Trends $^{\circledR}$ in Human-Computer Interaction. 8 (2015) 73-272. https://doi.org/10.1561/1100000049.

[127] T. Olsson, M. Salo, Online user survey on current mobile augmented reality applications, 2011 10th IEEE International Symposium on Mixed and Augmented Reality. (2011) 75-84. https://doi.org/10.1109/ISMAR.2011.6092372.

[128] A.-C. Haugstvedt, J. Krogstie, Mobile augmented reality for cultural heritage: A technology acceptance study, 2012 IEEE International Symposium on Mixed and Augmented Reality (ISMAR). 247-255. https://doi.org/10.1109/ISMAR.2012.6402563.

[129] R. Egodagamage, M. Tuceryan, Distributed Monocular SLAM for Indoor Map Building, Journal of Sensors. 2017 (2017). https://doi.org/10.1155/2017/6842173.

[130] S. Blanco-Pons, B. Carrión-Ruiz, J.L. Lerma, Augmented reality application assessment for disseminating rock art, Multimedia Tools and Applications. (2018). https://doi.org/10.1007/s11042-018-6609-x.

[131] A. Martin-Gonzalez, A. Chi-Poot, V. Uc-Cetina, Usability evaluation of an augmented 
reality system for teaching Euclidean vectors, Innovations in Education and Teaching International. 53 (2016) 627-636. https://doi.org/10.1080/14703297.2015.1108856.

[132] J.J. Gimeno, C. Portalés, I. Coma, M. Fernández, B. Martínez, Combining traditional and indirect augmented reality for indoor crowded environments. A case study on the Casa Batlló museum, Computers and Graphics (Pergamon). 69 (2017) 92-103. https://doi.org/10.1016/j.cag.2017.09.001.

[133] H. Kolivand, A. El Rhalibi, M. Shahrizal Sunar, T. Saba, ReVitAge: Realistic virtual heritage taking shadows and sky illumination into account, Journal of Cultural Heritage. (2018) 1-10. https://doi.org/10.1016/j.culher.2018.01.020.

[134] J. Amakawa, J. Westin, New Philadelphia: using augmented reality to interpret slavery and reconstruction era historical sites, International Journal of Heritage Studies. 24 (2018) 315-331. https://doi.org/10.1080/13527258.2017.1378909.

[135] J.B. Kim, C. Park, Development of mobile AR tour application for the national palace museum of Korea, Lecture Notes in Computer Science (Including Subseries Lecture Notes in Artificial Intelligence and Lecture Notes in Bioinformatics). 6773 LNCS (2011) 55-60. https://doi.org/10.1007/978-3-642-22021-0_7.

[136] K. Pentenrieder, P. Meier, G. Klinker, Analysis of Tracking Accuracy for Single-Camera Square-Marker-Based Tracking, Proc. Dritter Workshop Virtuelle Und Erweiterte Realität Der GI-Fachgruppe VR/AR. (2006) 15. https://doi.org/10.1.1.13.3084.

[137] H. Kato, M. Billinghurst, Marker tracking and HMD calibration for a video-based augmented reality conferencing system, Proceedings 2nd IEEE and ACM International Workshop on Augmented Reality (IWAR'99). (n.d.) 85-94. https://doi.org/10.1109/IWAR.1999.803809.

[138] J. Herling, W. Broll, Markerless Tracking for Augmented Reality, in: B. Furht (Ed.), Handbook of Augmented Reality, Springer New York, New York, NY, 2011: pp. 255-272. https://doi.org/10.1007/978-1-4614-0064-6_11.

[139] R. Azuma, B. Hoff, H. Neely, R. Sarfaty, A motion-stabilized outdoor augmented reality system, Proceedings IEEE Virtual Reality (Cat. No. 99CB36316). 99 (1999) 252-259. https://doi.org/10.1109/VR.1999.756959.

[140] A. Cirulis, K.B. Brigmanis, 3D outdoor augmented reality for architecture and urban planning, Procedia Computer Science. $25 \quad$ (2013) 71-79. https://doi.org/10.1016/j.procs.2013.11.009.

[141] G. Reitmayr, T. Drummond, Going out: robust model-based tracking for outdoor augmented reality, $2006 \mathrm{IEEE} / \mathrm{ACM}$ International Symposium on Mixed and Augmented Reality. (2006) 109-118. https://doi.org/10.1109/ISMAR.2006.297801.

[142] S. You, U. Neumann, R. Azuma, Orientation tracking for outdoor augmented reality registration, IEEE Computer Graphics and Applications. 19 (1999) 36-42. https://doi.org/10.1109/38.799738.

[143] J. Wither, Y.T. Tsai, R. Azuma, Indirect augmented reality, Computers and Graphics (Pergamon). 35 (2011) 810-822. https://doi.org/10.1016/j.cag.2011.04.010.

[144] F. Okura, T. Akaguma, T. Sato, N. Yokoya, Indirect augmented reality considering realworld illumination change, ISMAR 2014 - IEEE International Symposium on Mixed and Augmented Reality - Science and Technology 2014, Proceedings. (2014) 287-288. https://doi.org/10.1109/ISMAR.2014.6948453.

[145] G. Sörös, H. Seichter, P. Rautek, E. Gröller, Augmented visualization with natural feature 
tracking, Proceedings of the 10th International Conference on Mobile and Ubiquitous Multimedia. (2011) 4-12. https://doi.org/10.1145/2107596.2107597.

[146] L. Carozza, D. Tingdahl, F. Bosché, L. van Gool, Markerless vision-based augmented reality for urban planning, Computer-Aided Civil and Infrastructure Engineering. 29 (2014) 2-17. https://doi.org/10.1111/j.1467-8667.2012.00798.x.

[147] J. Rao, Y. Qiao, F. Ren, J. Wang, Q. Du, A Mobile Outdoor Augmented Reality Method Combining Deep Learning Object Detection and Spatial Relationships for Geovisualization, Sensors. 17 (2017) 1951. https://doi.org/10.3390/s17091951.

[148] H. Hoppe, T. Derose, J. Mcdonald, W. Stuetzle, T. Duchamp, Mesh Optimization, in: ACM (Ed.), Proceedings of the 20th Annual Conference on Computer Graphics and Interactive Techniques, 1993: pp. 19-26. https://doi.org/10.1145/166117.166119.

[149] J. Rossignac, P. Borrel, Multi-resolution 3D approximations for rendering complex scenes, Modeling in Computer Graphics. (1993) 455-465. https://doi.org/10.1007/9783-642-78114-8_29.

[150] M.H. Gross, A. Member, O.G. Staadt, R. Gatti, Efficient Triangular Surface Appr Using Wavelets and Quadtree Dat, IEEE Transactions on Visualization and Computer Graphics. 2 (1996) 130-143. https://doi.org/10.1109/2945.506225.

[151] M. Botsch, M. Pauly, C. Rossl, S. Bischoff, L. Kobbelt, Geometric modeling based on triangle meshes (SG), in: ACM SIGGRAPH 2006 Courses, 2006. https://doi.org/10.1145/1185657.1185839.

[152] N. Pietroni, M. Tarini, P. Cignoni, Almost isometric mesh parameterization through abstract domains, IEEE Transactions on Visualization and Computer Graphics. 0 (2009) 1-15. https://doi.org/10.1109/TVCG.2009.96.

[153] D. Khan, D.-M. Yan, F. Ding, Y. Zhuang, X. Zhang, Surface remeshing with robust userguided segmentation, Computational Visual Media. 4 (2018) 113-122. https://doi.org/10.1007/s41095-018-0107-y.

[154] G. Guidi, F. Remondino, M. Russo, F. Menna, A. Rizzi, S. Ercoli, A Multi-Resolution Methodology for the 3D Modeling of Large and Complex Archeological Areas, International Journal of Architectural Computing. 7 (2009) 39-55. https://doi.org/10.1260/147807709788549439.

[155] T. Akenine-Möller, E. Haines, N. Hoffman, Real-Time Rendering, 3rd ed., 2008. https://doi.org/10.1201/b10644-23.

[156] F. Remondino, S. El-Hakim, Image-Based 3D Modelling : a Review, The Photogrammetric Record. 21 (2006) 269-291. https://doi.org/10.1111/j.1477-9730.2006.00383.x.

[157] L. Zhui, J. Hyyppa, R. Cheni, Z. Liu, An approach of 3D model simplification for mobile phone based navigation application, Image Rochester NY. (2009) 2-5.

[158] R. Comes, C. Neamțu, Z. Buna, I. Badiu, P. Pupeză, Methodology To Create 3D Models for Augmented Reality Applications Using Scanned Point Clouds, Mediterranean Archaeology and Archaeometry. 14 (2014) 35-44.

[159] Unity, The Photogrammetry Workflow, 2018.

[160] A.H. Behzadan, V.R. Kamat, Scalable algorithm for resolving incorrect occlusion in dynamic augmented reality engineering environments, Computer-Aided Civil and Infrastructure Engineering. 25 (2010) 3-19. https://doi.org/10.1111/j.14678667.2009.00601.x. 
[161] Y. Tian, Y. Long, D. Xia, H. Yao, J. Zhang, Handling occlusions in augmented reality based on 3D reconstruction method, Neurocomputing. 156 (2015) 96-104. https://doi.org/10.1016/j.neucom.2014.12.081.

[162] M.-O. Berger, Resolving occlusion in augmented reality: a contour based approach without 3D reconstruction, Proceedings of IEEE Computer Society Conference on Computer Vision and Pattern Recognition. (1997) 91-96. https://doi.org/10.1109/CVPR.1997.609304.

[163] Y. Tian, T. Guan, C. Wang, Real-time occlusion handling in augmented reality based on an object tracking approach, Sensors. 10 (2010) 2885-2900. https://doi.org/10.3390/s100402885.

[164] L.W. Shang, M.H. Zakaria, I. Ahmad, Mobile phone augmented reality postcard, Journal of Telecommunication, Electronic and Computer Engineering. 8 (2016) 135-139.

[165] S. Sunil, S.S.K. Nair, An Educational Augmented Reality App to Facilitate Learning Experience, 2017 International Conference on Computer and Applications, ICCA 2017. (2017) 279-282. https://doi.org/10.1109/COMAPP.2017.8079771.

[166] G.-D. Voinea, F. Girbacia, C.C. Postelnicu, A. Marto, Exploring Cultural Heritage Using Augmented Reality Through Google's Project Tango and ARCore, in: M. Dugulean\ua, M. Carrozzino, M. Gams, I. Tanea (Eds.), VR Technologies in Cultural Heritage, Springer International Publishing, Cham, 2019: pp. 93-106.

[167] B. Carrión-Ruiz, S. Blanco-Pons, M. Duong, J. Chartrand, M. Li, K. Prochnau, S. Fai, J.L. Lerma, Augmented Experience To Disseminate Cultural Heritage: House of Commons Windows, Parliament Hill National Historic Site (Canada), ISPRS - International Archives of the Photogrammetry, Remote Sensing and Spatial Information Sciences. XLII-2/W9 (2019) 243-247. https://doi.org/10.5194/isprs-archives-xlii-2-w9-243-2019.

[168] D.R. Walton, A. Steed, Accurate real-time occlusion for mixed reality, Proceedings of the ACM Symposium on Virtual Reality Software and Technology, VRST. Part F1319 (2017). https://doi.org/10.1145/3139131.3139153.

[169] L. Chen, T.W. Day, W. Tang, N.W. John, Recent developments and future challenges in medical mixed reality, Proceedings of the 2017 IEEE International Symposium on Mixed and Augmented Reality, ISMAR 2017. (2017) 123-135. https://doi.org/10.1109/ISMAR.2017.29.

[170] M.G. Hanna, I. Ahmed, J. Nine, S. Prajapati, L. Pantanowitz, Augmented reality technology using microsoft hololens in anatomic pathology, Archives of Pathology and Laboratory Medicine. 142 (2018) 638-644. https://doi.org/10.5858/arpa.2017-0189-OA.

[171] J. Jorge, R.K. Dos Anjos, R. Silva, Dynamic occlusion handling for real-time AR applications, Proceedings - VRCAI 2019: 17th ACM SIGGRAPH International Conference on Virtual-Reality Continuum and Its Applications in Industry. (2019). https://doi.org/10.1145/3359997.3365700.

[172] J. Valentin, A. Kowdle, J.T. Barron, N. Wadhwa, M. Dzitsiuk, M. Schoenberg, V. Verma, A. Csaszar, E. Turner, I. Dryanovski, J. Afonso, J. Pascoal, K. Tsotsos, M. Leung, M. Schmidt, O. Guleryuz, S. Khamis, V. Tankovitch, S. Fanello, S. Izadi, C. Rhemann, Depth from motion for smartphone Ar, SIGGRAPH Asia 2018 Technical Papers, SIGGRAPH Asia 2018. 37 (2018). https://doi.org/10.1145/3272127.3275041.

[173] R. Du, E. Turner, M. Dzitsiuk, L. Prasso, I. Duarte, J. Dourgarian, J. Afonso, J. Pascoal, J. Gladstone, N. Cruces, S. Izadi, A. Kowdle, K. Tsotsos, D. Kim, DepthLab: Real-time 3D interaction with depth maps for mobile augmented reality, UIST 2020 - Proceedings of 
the 33rd Annual ACM Symposium on User Interface Software and Technology. (2020) 829-843. https://doi.org/10.1145/3379337.3415881.

[174] ARKit - Apple Developer, (n.d.). https://developer.apple.com/arkit/ (accessed June 26, 2018).

[175] Depth API overview for Android I ARCore I Google Developers, (n.d.). https://developers.google.com/ar/develop/java/depth/overview (accessed February 23, 2021).

[176] M.W. Patrick Hübner, Steven Landgraf, \& S. Wursthorn, Evaluation of the Microsoft HoloLens for the Mapping of Indoor Building Environments, Dreiländertagung Der DGPF, Der OVG Und Der SGPF. (2019) 44-53.

[177] Apps, Services, and Solutions for HoloLens 2 I Microsoft HoloLens, (n.d.). https://www.microsoft.com/en-us/hololens/apps (accessed February 28, 2021).

[178] W. Vorraber, J. Gasser, H. Webb, D. Neubacher, P. Url, Assessing augmented reality in production: Remote-assisted maintenance with HoloLens, Procedia CIRP. 88 (2020) 139-144. https://doi.org/10.1016/j.procir.2020.05.025.

[179] Qualcomm Advances AR Industry with the Qualcomm Snapdragon XR1 AR Smart Viewer Reference Design I Qualcomm, (n.d.). https://www.qualcomm.com/news/releases/2021/02/23/qualcomm-advances-arindustry-qualcomm-snapdragon-xr1-ar-smart-viewer (accessed March 4, 2021).

[180] Support - SmartEyeglass SED-E1 - Sony Developer World, (n.d.). https://developer.sony.com/develop/smarteyeglass-sed-e1/ (accessed March 4, 2021).

[181] P. Nowacki, M. Woda, Capabilities of ARCore and ARKit Platforms for AR/VR Applications, Advances in Intelligent Systems and Computing. 987 (2020) 358-370. https://doi.org/10.1007/978-3-030-19501-4_36. 
